\title{
THE EFFECT OF EMPLOYER HEALTH INSURANCE OFFERING ON THE GROWTH AND SURVIVAL OF SMALL BUSINESS PRIOR TO THE AFFORDABLE CARE ACT
}

\author{
by
}

\author{
C. J. Krizan \\ U.S. Census Bureau
}

\author{
Adela Luque \\ U.S. Census Bureau
}

Alice Zawacki

U.S. Census Bureau

\section{CES 14-22 April, 2014}

The research program of the Center for Economic Studies (CES) produces a wide range of economic analyses to improve the statistical programs of the U.S. Census Bureau. Many of these analyses take the form of CES research papers. The papers have not undergone the review accorded Census Bureau publications and no endorsement should be inferred. Any opinions and conclusions expressed herein are those of the author(s) and do not necessarily represent the views of the U.S. Census Bureau. All results have been reviewed to ensure that no confidential information is disclosed. Republication in whole or part must be cleared with the authors.

To obtain information about the series, see www.census.gov/ces or contact Fariha Kamal, Editor, Discussion Papers, U.S. Census Bureau, Center for Economic Studies 2K132B, 4600 Silver Hill Road, Washington, DC 20233, CES.Papers.List@census.gov. 


\begin{abstract}
:
We first review information on the relationship between small employers' decisions to offer health insurance prior to 2010 and i) financial factors (including premium variability and tax advantages), ii) labor markets with a focus on employee characteristics and the demand for employer's health insurance, iii) insurance markets and products, discussing access and insurance options with lower premium costs, and iv) the health insurance regulatory environment with an examination of state-level reform and health insurance mandates. We then discuss employer reactions to rising health care costs, followed by a review of factors other than rising health care costs that often affect the growth and survival of a small business.

We first review information on the relationship between small employers' decisions to offer health insurance prior to 2010 and i) financial factors (including premium variability and tax advantages), ii) labor markets with a focus on employee characteristics and the demand for employer's health insurance, iii) insurance markets and products, discussing access and insurance options with lower premium costs, and iv) the health insurance regulatory environment with an examination of state-level reform and health insurance mandates. We then discuss employer reactions to rising health care costs, followed by a review of factors other than rising health care costs that often affect the growth and survival of a small business.

In the remaining sections, we describe our longitudinal analysis of how health insurance offering (HIO) affected the expansion and survival of small businesses. Using 2001-05 linked data from the Longitudinal Business Database (LBD) and the Insurance Component of the Medical Expenditure Panel Survey (MEPS-IC), we look at how HIO affected four measures of business performance (growth in employment, growth in payroll, growth in average wage, and survival) - after controlling for business characteristics and relevant state-level variables. We employ instrumental variable twostage least squares estimation to address the endogeneity that permeates the question at hand.

We find that young businesses (both large and small) that offer health insurance grow at not significantly different rates as those that do not, possibly due to selection effects. Older businesses offering health insurance - both small and large - seem to have higher employment and payroll growth. Survival is strongly and positively correlated with HIO for older establishments at both large and small firms. However, these results should be interpreted with extreme caution due the concerns we raise about the available testing methodology for our context.
\end{abstract}

\footnotetext{
* Any opinions and conclusions expressed herein are those of the authors and do not necessarily represent the views of the US. Census Bureau, or the Upjohn Institute. All results have been reviewed to ensure that no confidential information is disclosed. This research is supported by a grant from the Upjohn Institute. The authors thank reviewers at the Urban Institute and Center for Economic Studies for their comments and suggestions.
} 


\section{Table of Contents}

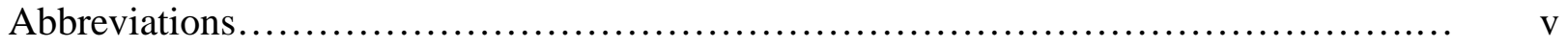

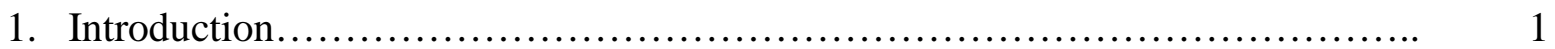

2. Health insurance offers.................................................. 8

2.1 Financial factors.............................................. 11

2.1.1 Price sensitivity and premium variability.......... 11

2.1.2 Regulations on premiums....................... 16

2.1.3 Risk-related costs and participation rates........... 17

2.1.4 Administrative costs........................... 19

2.1.5 Tax advantages............................... 22

2.2 Labor market................................................... 23

2.2.1 Employee characteristics and demand for own employer's health insurance....................... 23

2.2.2 Recruitment and retention....................... 26

2.3 Insurance markets and products................................. 27

2.3.1 Access.......................................... 27

2.3.2 Insurance options with lower premium costs........ 29

2.4 Health insurance regulatory environment........................ 30

2.4.1 Legislation, insurance offers, and business size...... 30

2.4.2 State reform.................................. 32

2.4.3 Health insurance mandates...................... 35

2.5 Concluding remarks....................................... 37

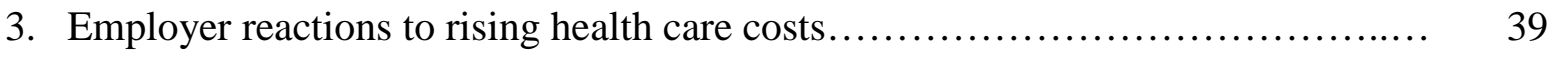

3.1 Discontinuing health insurance benefits......................... 39

3.2 Reducing benefits........................................... 41

3.3 Increasing employee contributions towards premiums................ 42

3.4 Labor market responses....................................... 45

3.5 Concluding remarks........................................ 49

4. Growth and Survival of Small Businesses.................................. 51

4.1 Business environment....................................... 51

4.2 Small business origination and health insurance................... 56

4.3 Job growth and survival of young and small businesses.............. 59

4.4 Concluding remarks............................................ 61

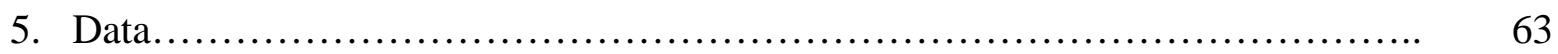

5.1 The Longitudinal Business Database .......................... 63

5.2 The Medical Expenditure Panel Survey - Insurance Component ...... 66

5.3 Analytical Dataset .......................................... 67

5.4 Concluding Remarks ....................................... 68 


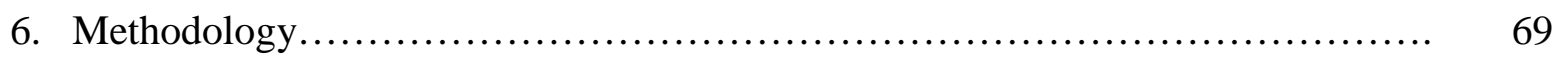

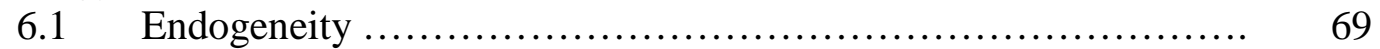

$6.2 \quad$ Modeling ................................................... 75

$6.3 \quad$ Selectivity and Final Algorithm ............................... $\quad 78$

$6.4 \quad$ Empirical Implementation ..................................... 79

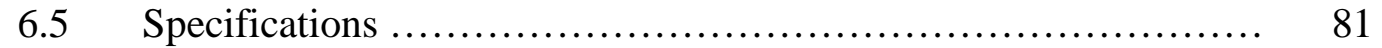

6.6 Measurement Improvement Considerations...................... 83

$6.7 \quad$ Concluding Remarks ....................................... 84

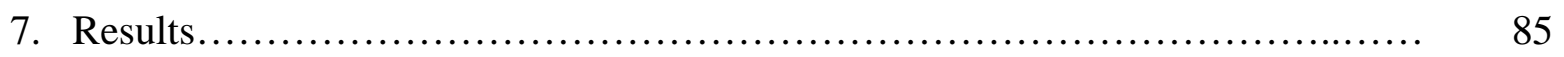

$7.1 \quad$ Size Effects ............................................... 85

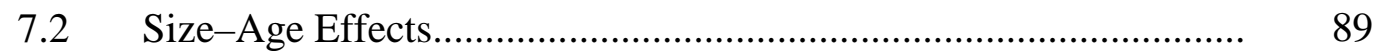

7.4 Sensitivity Analysis........................................................... 92

$7.5 \quad$ Instrument Tests....................................................................... 92

7.6 Concluding Remarks........................................................................ 95

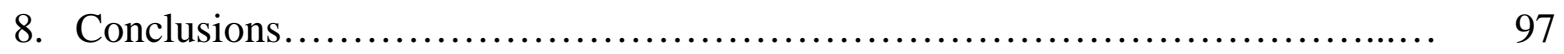

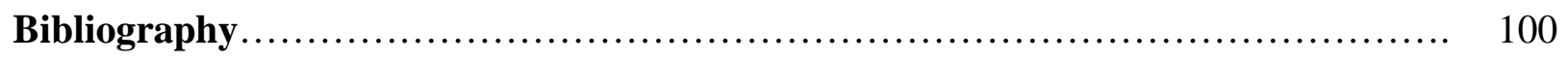

\section{Tables}

Table 2.1. Percent of private sector establishments and employees with health

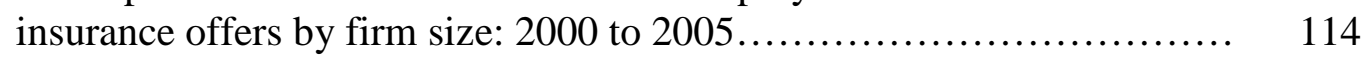

Table 2.2 Change in percent of private-sector establishments that offer health insurance by firm size and selected establishment characteristics: 2000 to $2005 . . . .$.

Table 2.3 Factors related to decision to offer health insurance......................... 117

Table 2.4 National totals for cost of hospitalization and physician service health plans offered by employers in the U.S. private sector.

Table 2.5 Change in percent of private-sector establishments that offer health insurance by firm size and selected workforce characteristics: 2000 to 2005.

Table 2.6 Annual percent change in national totals for cost of hospitalization and physician service health plans offered by employers in the U.S. private sector by industry category

Table 2.7 Characteristics of state small group health insurance markets.

Table 5.1 LBD Data Illustration. 
Table 5.2 Sample LBD Statistics.......................................................

Table 5.3 Average Total Single Premium per Enrolled Employee at Private-sector

Establishments that Offer Health Insurance by Firm Size

Table 6.1 Mean of Dependent Variable and Establishment Characteristics by Size.......

Table 7.1 IV \& OLS Results on the Effect of Health Insurance Offering on Employment, Payroll and Average Wage Levels by Firm Size

Table 7.2 IV \& OLS Results on the Effect of Health Insurance Offering on Employment, Payroll and Average Wage Growth and Establishment Survival by Firm Size.

Table 7.3 IV Results on the Effect of Health Insurance Offering on

Employment, Payroll and Average Wage Levels by Firm Size and Age..........

Table 7.4 IV Results on the Effect of Health Insurance Offering on Employment, Payroll and Average Wage Growth and Establishment Survival by Firm Size and Age

Table 7.5 Alternative IV Specifications 133

Table 7.6 IV Tests

\section{Figures}

Figure 2.1 Difference in percent of establishments from firms with less than 10 employees and 1,000 or more employees offering health insurance: 2000 ..

Figure 2.2 Difference in percent of establishments from firms with less than 10 employees and 1,000 or more employees offering health insurance: 2005 .

Figure 2.3 Change in average total single premium (in dollars) per enrolled employee at private sector establishments that offer health insurance by firm size: 2000 and 2005.

Figure 2.4 Percent increase in premiums for single coverage from 2000 to 2005: Private sector establishments belong to firms with less than 10 employees.

Figure 2.5. Percent change in premiums for family coverage from 2000 to 2005: Private sector establishments belong to firms with less than 10 employees. 
Figure 2.6 State Health Insurance Index from the Council for Affordable Health Insurance. .........................................................

Figure 2.7 Mandated benefits by state and percent contribution towards premium costs:

2005.

Figure 3.1 Average total employee contribution (in dollars) per enrolled employee at private-sector establishments that offer health insurance by firm size:

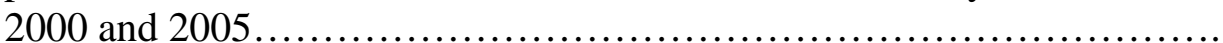

Figure 3.2 Percent of total premiums contributed by enrolled employees at privatesector establishments that offer health insurance by firm size.................

Figure 3.3 Percent of total premiums contributed for single coverage by employees enrolled at private-sector establishments that offer health insurance by firm size and percent low-wage employees.............................

Figure 3.4 Percent of private-sector establishments that offer health insurance that offer at least one plan that required no employee contribution by firm size........

Figure 4.1 Unemployment Rate Comparison: Detroit MI vs. Bethesda-Rockville MD..... 


\section{Abbreviations}

ACA

AHRQ

COBRA

ERISA

ESI

GAO

HIO

KRI

MEPS-IC

LBD
Patient Protection and Affordable Care Act

Agency for Healthcare Research and Quality

Consolidated Omnibus Budget Reconciliation Act

Employee Retirement Income Security Act

Employer-sponsored health insurance

Government Accountability Office

Health Insurance Offer

Kauffman-RAND Institute for Entrepreneurship Public Policy

Medical Expenditure Panel Survey-Insurance Component

Longitudinal Business Database 


\section{Introduction}

The purpose of this monograph is to present some evidence on how offering health insurance and rising health care costs impacted the growth and survival of small businesses prior to passage of the 2010 Patient Protection and Affordable Care Act (ACA). ${ }^{1}$ While there have been numerous studies addressing the themes traditionally associated with employer health insurance offerings and small businesses ${ }^{2}$ (as discussed below), there has not been a longitudinal multivariate analysis addressing how offering health insurance may impact a small business' growth and survival.

Health care expenditures have been increasing over time in the United States. They were over 17.6 percent of the country's gross domestic product in 2009. In 2000 they represented 13.2 percent. $^{3}$ Nominal per capita national health expenditures increased 40 percent, from $\$ 4,789$ in 2000 to $\$ 6490$ in $2009^{4}$. Expenditures on health care and the rise in costs could hamper the growth and survival of small businesses.

Since almost all firms start out small (Haltiwanger et al. 2009), small firms are important to general economic growth, while their share of total employment is smaller than for larger firms. Firms with less than 20 workers employ about 20 percent of all workers in the non-farm private economy versus about 48 percent employed by large firms (500+ workers) or almost 1 in 4 workers employed by very large firms $(10,000+)$ -

\footnotetext{
${ }^{1}$ It is beyond the scope of this monograph to analyze how 2010 ACA will impact health insurance offering behavior of small businesses. This work will serve as a baseline against which to compare the effects of ACA reforms pertaining to small businesses.

${ }^{2}$ Such as determinants of a firm's decision to offer health insurance, the factors that make small firms less likely to offer it and employer reaction to rising health care costs.

${ }^{3}$ U.S. total expenditures on health as a percent of gross domestic product exceeds that of other countries in the Organisation for Economic Co-operation and Development (OECD). Switzerland has the next highest percent but trails behind the U.S. by 2.8 percent in 2000 and 3.7 percent in 2005 (OECD, 2007). Without standard errors, we are unable to comment on the significance of these differences.

${ }^{4}$ https://www.cms.gov/NationalHealthExpendData/.../highlights.pdf The authors' deflated the data using BLS’ online CPI calculator.
} 
based on data from the 1975-2005 Longitudinal Business Database (Haltiwanger et al. 2009). Although the statistics point out that most of this economic activity is concentrated in large employers, small businesses create (and destroy) a disproportionately large number of jobs (Davis, Haltiwanger and Schuh (1996)) and characterize new businesses, thus their growth and survival are important in the U.S. economy.

In order to grow and survive, small businesses must compete with larger businesses for employees. In order to attract and retain workers, businesses of all sizes often offer health insurance to be competitive in the labor market. However, small businesses may be at a disadvantage in hiring workers who value employer-sponsored health insurance (ESI) since premium costs are higher for smaller employers than for larger businesses. This disadvantage in the labor market resulting from greater health care costs may have profound effects on the performance of new and small businesses and has important implications for overall economic growth.

Chapter 2 presents evidence showing higher premium costs and lower health insurance offer rates for small employers than for large employers. In addition, small employers are more likely to employ low-wage workers (Brown and Medoff, 1989), which can place them at a further disadvantage for offsetting high premium costs with higher wages. ${ }^{5,6}$ Trends associated with fewer carriers in the small group insurance market can also have negative implications for small business access and affordability to

\footnotetext{
${ }^{5}$ Empirical studies and various reports on small businesses use a multitude of definitions. For example, small may be defined as less than 10, less than 25, less than 50 (GAO, 2009), less than 100, or less than 500 employees (Small Business Administration). When first citing findings from these various sources, the specific size definition used by the authors or organization generally is provided.

${ }^{6}$ Brown and Medoff (1989) use various data sources with different size measures.
} 
insurance. Finally, health insurance regulations may also affect offers of insurance to employees, as well as the small business's decision to grow and expand. All of these factors can make it difficult for a small employer to offer a competitive compensation package to attract quality workers.

The state in which small business is located also affects their ability to offer health insurance because of a number of factors. States can have varying health care costs, impose their own regulations on health insurance offerings, experience different small group health insurance markets in terms of the number of insurers and market shares, and are characterized by different percents of small and young businesses. We will discuss these differences and how small business performance may be hampered as a result of state-level characteristics throughout this monograph. The discussions provide descriptive statistics for economic characteristics at the state level, including differences in health insurance offers, premiums and the insurance regulatory environment.

Chapter 2 of this monograph highlights these state-level variations by focusing on 4 states in the discussions, one from each region of the country. Arizona in the west and New York in the northeast are discussed because on a number of economic dimensions relevant to small businesses and health insurance offers, statistics generally show more favorable conditions in these two states. In contrast, North Dakota in the Midwest and Tennessee in the south tend to show less favorable conditions. ${ }^{7}$ For example, statistics on

\footnotetext{
${ }^{7}$ The authors admit that the selection of these states has been done in a very rudimentary fashion. That is, states are picked based on how many times the state is an outlier on a number of different dimensions including differences in offer rates, premium increases, tax incentives for small businesses for offering health insurance, and characteristics of the states' health insurance markets. In addition, statistics on the state's percent of employers that are young and small, as well as changes in the percent of the smallest establishments are taken into consideration. Finally, since estimates are often based on MEPS-IC data and some states do not have data collected for them in 2000, these are excluded from consideration. However, many other economic considerations are omitted (e.g., business tax rates). The primary purpose of picking
} 
the percent of a state's establishments belonging to the smallest firms ${ }^{8,9}$ show rather marked differences. While the percent dropped from 2000 to 2005 by 0.2 percent in the country overall, North Dakota saw a 4.6 percentage point drop and New York saw a 0.6 percent increase. A number of factors in the business environment may contribute to these differences, such as changes in state tax codes creating more or less favorable conditions for a small business.

In addition to geographic variation, differences by industry may also be relevant to our analysis of the growth and survival of small businesses and industry controls are included in the models. Higher health care and insurance costs may make it difficult for small businesses to compete with larger employers for quality, skilled workers who may be integral to business performance in some industries. Higher wages and salary are generally associated with higher skill levels and can consequently influence worker demand for health insurance. That is, employees contributing to insurance premium costs on a pretax basis may value health insurance more because of their greater income and associated marginal tax rate. If small businesses face higher costs for offering health insurance and find it difficult to offer this benefit, they may find it difficult to offer a compensation package that competes with those offered by larger employers for the higher skilled workers. Ultimately, this disadvantage may hinder the growth and survival of small businesses and this monograph discusses relevant differences by industry.

a few states is to aid in the discussion of how states can differ as numerous statistics are presented throughout the monograph.

${ }^{8}$ Establishments refer to the physical location where business activity takes place. A firm may control one or more establishments.

${ }^{9}$ Throughout this monograph, references to the smallest firms will refer to firms with less than 10 employees. When discussing the largest firms, this will refer to those with 1,000 or more employees. 
While the decision to offer health insurance may be influenced by a multitude of financial, labor, and insurance-related issues, how employers cope with rising health care costs can place them at a further disadvantage in attracting and retaining skilled workers. In chapter 3 we present findings showing small employers may eliminate insurance offers and/or reduce the generosity of offerings. Aside from making changes to benefits, businesses may make changes in their employment practices, such as increasing their reliance on part-time workers or hiring workers with lower expected health care costs. While these strategies may help the small employer control escalating compensation costs associated with offering health insurance, their ultimate effect on the quality, morale, and productivity of the workforce and business performance are unknown.

The focus of this monograph is on the effects of offering health insurance on the growth and survival of small businesses, however, other economic factors may be simultaneously influencing organizations and are discussed in chapter 4 . These include the general condition of the business environment, as well as trends in industries and workforces. For example, we study the growth and survival of small businesses from 2000 to 2005, which includes the recession of 2001. Evidence suggests that business growth during economic downturns is less likely than during good times. In addition, the private sector of the U.S. economy has seen a transition away from manufacturing and unionization in recent decades, which may contribute to fewer insurance offerings by employers of all sizes. Finally, the economy has also been characterized in recent decades by an aging workforce, which can also contribute to a sicker risk pool and higher health insurance costs for an employer. This may be especially true for small employers 
who have been found to have an older workforce (Headd, 2000; Nichols et al., 1997), ${ }^{10}$ making it more challenging financially to offer competitive compensation packages. The evidence presented in this chapter show that difficult economic times and trends in industries and workforces might place small businesses at an even greater disadvantage when competing with large businesses for skilled labor.

The evidence presented in these early chapters suggest that many different workforce, employer, and market factors may influence the growth and survival of small businesses and are important to consider in our empirical analysis. In Chapter 5 we describe the data sources used in our analysis, and in Chapter 6 we begin the discussion of our methodology for examining the effects of offering health insurance on the growth and survival of small businesses. No known studies address these issues and public access to relevant data measures can limit applied microanalysis of them.

In our study we link two confidential datasets, the Medical Expenditure Panel Survey-Insurance Component (MEPS-IC) and the Longitudinal Business Database (LBD). The former provides data on whether an employer offers health insurance, which we use as a proxy for health care costs. Measures on workforce and employer characteristics are also available. The LBD provides information on employer payroll and size over time and permits analysis of longitudinal changes in small business performance and survival using these measures. Linkage of these data provides a rich and unique source of information to study these issues so important in the U.S. economy. While many studies have documented the low rate of health insurance offers among

\footnotetext{
${ }^{10}$ Headd (2000) defines a small business as firms with less than 500 employees, and some might argue that this many employees does not truly reflect a small business. However, this is the definition used by the Small Business Administration. Nichols et al. (1997) use different data sources that define small businesses using different size categories including less than 100 employees.
} 
small firms and have examined the potential factors determining this low rate, no multivariate studies have examined the relationship between the growth and survival of small businesses and health care costs.

The mixed findings of our instrument tests indicate that caution should be exercised when interpreting our results. With that caveat, we find that businesses offering health insurance offer larger total compensation packages than do similar businesses that do not offer coverage to their workers. These businesses also grow faster and survive longer. We also present results controlling for age as well as size. In these regressions, young businesses (both large and small) that offer health insurance grow at the same rate as those that do not, possibly due to selection effects. However, offering health insurance was correlated with higher employment and payroll growth at both large and small businesses. Finally, survival was strongly, positively correlated with Health Insurance Offering for older establishments at both large and small firms and for small young firms. In sum, these results suggest that young small businesses offering health insurance seem to be more likely to survive, and once they have been in business for a while, offering health insurance seems to increase their chances of success (as measured by employment and payroll growth). 


\section{Health Insurance Offers}

This chapter provides a brief summary of the reasons and factors influencing why a small business may or may not offer health insurance. ${ }^{11}$ We categorize these into financial and labor market factors, insurance products and markets, and the health insurance regulatory environment. High premiums and costs factor prominently in reasons why employers do not offer insurance, while employee recruitment and retention dominate the discussion of why some employers offer the benefit.

Premiums, risk-related costs, administrative expenses, and lack of familiarity with tax advantages represent financial reasons why small businesses may be reluctant to offer Employee Sponsored Insurance (ESI). Labor-related factors are important to our analysis of the growth or employment of small businesses and the decision to offer ESI.

Therefore, the influences of employee demand, as well as recruitment and retention, are presented. We discuss various aspects of insurance products and markets, including access and the introduction of lower premium cost options, which may affect small businesses more than larger employers. Finally, we review various regulations and mandates passed in recent decades that may potentially influence the small businesses' decision to offer ESI as well as their decision to grow.

In our empirical analyses, we use the employer's offer of health insurance to workers as a proxy for health care costs. While this is not a perfect match, we believe it

\footnotetext{
${ }^{11}$ Issues related to small businesses offering health insurance are examined in the following but not exhaustive list of references: Abraham et al., 2009; Neese 2009; Pierron and Fronstin 2008; Blumberg 2007; Gates et al. 2007; Kapur et al. 2006; Matthews et al. 2006; Kaiser Family Foundation/Health Research Educational Trust 2005, 2000; Bunce and Wieske 2005; Actuarial Research Corporation 2003; Carpenter 2003; Fronstin et al., 2003; Glied et al., 2003; Monheit and Schone 2003; Buchmueller and DiNardo 2002; Lee 2002; Garrett et al. 2001; Congressional Budget Office 2000; General Accounting Office 2000; Fronstin and Helman, 2000; Monheit and Vistnes, 1999; Nichols et al., 1997; Morrisey et al. 1994).
} 
is a reasonable measure of changes in employers' ability to pay. Between 2000 and 2005, the percentage of small firms offering health insurance declined. There was a more substantial decline in the share of small-firm employees who worked in establishments that offered health insurance. Over the same period health insurance offers by large firms was largely unchanged. Table 2.1 supports these points, while Table 2.2 gives evidence that the pattern largely held across industries. While the percent of establishments offering insurance and belonging to the smallest firm size significantly decreased from 39.6 percent in 2000 to 35.7 percent in $2005,{ }^{12}$ the percent of employees in establishments that offer health insurance in the smallest firms significantly dropped from 53.2 percent to 43.7 percent during this same time period. ${ }^{13}$

Virtually all businesses start out small, which leads us to look at offers by young firms also. Table 2.2 shows the percent of establishments offering health insurance by firm size and firm age. In the smallest establishments of any firm age a significant decrease in the percent of establishments offering health insurance is seen. Small establishments belonging to firms with 10 to 24 employees and less than 5 years old saw

\footnotetext{
${ }^{12}$ MEPS-IC estimates of offers by establishments from firms with less than 50 employees show a similar declining pattern from 2000 to 2004 from 47.2 percent to 41.9 percent, but then increase in 2005 to 43.4 percent. The overall decrease from 2000 to 2005 is significant.

${ }^{13}$ All estimates based on the MEPS-IC presented in this monograph use data from private sector establishments. While collected in the MEPS-IC, public sector data for state and local governments are not included in the figures, discussion, or analyses. Also, the text will often discuss publicly-available statistics from the MEPS-IC for establishments from the smallest firms (less than 10 employees) and the largest firms (1,000 or more employees). Readers will often also find similar statistics presented for small employers defined as having less than 50 employees in footnotes. This alternative definition coincides with our empirical analyses on small businesses, defined as those with less than 50 workers. Our study uses this definition in order to avoid potential disclosure on the smaller sample of businesses with less than 10 workers.
} 
a significant drop in the percent offering health insurance from 57 percent in 2000 to 38.2 percent in $2005 .^{14}$

The economic, regulatory, and demographic characteristics of the state in which a small business is located may also impact its decision to offer health insurance. Most relevant may be the state's per capita health care costs, insurance markets, and health insurance legislation passed by the state making the offer of this employee benefit more or less attractive. Our empirical analysis will include state fixed effects to help capture the various influences of the businesses’ environment. Figures 2.1 and 2.2 show statelevel maps using the MEPS-IC to show the difference in the percent of establishments between the smallest and largest firms offering health insurance in 2000 and 2005, respectively (Agency for Healthcare Research and Quality (AHRQ), 2000 and 2005). These maps show that New York is among the states with the smallest percentage point difference in offers, averaging about 54 percent for 2000 and 2005. This is small relative to some states, such as North Dakota and Tennessee, both with a difference in offers greater than 70 percentage points. As noted earlier, New York was selected for discussion purposes because on a number of factors related to small businesses and health insurance New York was generally more favorable than North Dakota and Tennessee. These factors may reduce the likelihood that small businesses in these two states offer health insurance.

\footnotetext{
${ }^{14}$ When defining small and large establishments using firm size of less than 50 and 50 or more employees, the establishments belonging to the youngest firms (less than 5 years of age) saw significant decreases in offers whether small or large. Small establishments belonging to firms of all other firm ages also saw significant decreases. The same pattern is seen when looking at the percent of employees in establishments that offer health insurance and from small or large firms.
} 
Many factors impact the decision of whether or not a business offers ESI.

Therefore, while addressing why a business offers insurance or not is beyond the scope of this paper, ${ }^{15}$ awareness of these factors is important. These are discussed throughout the remainder of this chapter and Table 2.3 provides a summary of select empirical studies and reports examining these issues related to health insurance offers.

\subsection{Financial factors}

\subsubsection{Price sensitivity and premium variability. The number one reason} generally given by small employers for not offering ESI is cost, premiums are too high. In addition, with fewer employees (i.e., potential enrollees), small employers generally do not have as much clout as larger employers to negotiate lower rates. Figure 2.3 shows the change from 2000 to 2005 in the average total single premium (in dollars) per enrolled employee at private-sector establishments that offer health insurance by firm size using the MEPS-IC (AHRQ 2000 and 2005). The increase in premiums during this time period for any firm size is 45 to 54 percent. ${ }^{16}$ Premium costs in both years are highest in establishments belonging to the smallest firms. ${ }^{17}$ The largest gap in premium costs is

\footnotetext{
${ }^{15}$ While our empirical analysis will predict health insurance offers to address their endogeneity in models explaining changes in business performance, our work does not attempt to explain offers per se.

${ }^{16}$ While increases in premiums from 2000 to 2005 for establishments from the smallest firms are not significantly larger than increases in premiums for those from the largest firms, plans offered by small firms may become increasingly less generous than those offered by the largest firms. For example, larger increases in deductibles, copayments, and coinsurance may have occurred during this time period for the plans offered by the establishments from the smallest firms.

${ }^{17}$ In a report prepared for the Small Business Administration (Actuarial Research Corporation, 2003), no difference is seen in premiums by firm size when using 1997 Robert Wood Johnson Foundation data that includes estimates for firms with 1 to 9 employees. In contrast, 1997 MEPS-IC data does show higher premiums for the smallest businesses. The Small Business Administration report suggests that since administrative costs are higher for the small employers, similar premiums may reflect lower actuarial values for their plans. Small firms may purchase less generous plans (e.g., with higher deductibles or fewer
} 
between establishments from firms with less than 10 employees and 10 to 24 employees, growing from a difference of \$223 in 2000 to \$327 in 2005.

As health care costs and premiums rise, employers' financial burden can also increase through their contributions towards premiums. Inflation-adjusted premiums from the MEPS-IC for single coverage for 2000 rose over 13 percent from \$2,655 to \$3,010 in 2005. ${ }^{18}$ Employer outlays for ESI also increased. From 2000 to 2005, the cost of employer contributions for single coverage and family coverage rose approximately 50 and 30 percent respectively according to national totals from the MEPS-IC (see Table 2.4).

Similar to these national trends, almost all states saw a significant increase from 2000 to 2005 in the average total single premium per enrolled employee at establishments that offer health insurance regardless of size. While the smallest establishments across the U.S. saw premium costs for single coverage rise about 45 percent from 2000 to 2005 (AHRQ 2000 and 2005), some states saw larger increases (see Figure 2.4). For example, premiums for single coverage for the smallest employers rose over 96 percent in North Dakota. As noted earlier, North Dakota fared worse than many states on a number of factors related to small business and health insurance offerings. The larger increase in premium costs in this state may be related to these other factors such as the number of insurance carriers and the market share for the largest carrier (see discussion below). ${ }^{19}$

covered services). In addition, state regulations may prevent insurers from raising premiums significantly in order to cover actual costs that include medical and administrative expenses. State regulations may also limit the extent of premium variation. Finally, comparing premium costs between offering firms, large and small, does not provide information on the costs faced by non-offering firms. These costs can be higher.

${ }^{18}$ Other surveys also show large increases in premium costs (Holve et al. 2002; Gencarelli, 2005).

${ }^{19}$ Note also that North Dakota has a lower median age than the nation as a whole - although it does have $2 \%$ more people 65 years of age or older 
Based on MEPS-IC estimates, the U.S. increase in premiums for family coverage rose for the establishments from the smallest firms by about 53 percent, and Figure 2.5 shows that states with increases close to this average are exclusively located in the western half of the country while the largest premium increases are concentrated in the eastern half. Tennessee and Arizona increases in family coverage premiums deviate from the average with increases of more than 86 percent and about 32 percent, respectively. ${ }^{20}$ Workforce characteristics may help explain some of this variation. For example, greater proportions of older workers with poorer health status and greater health care costs in some states may lead to higher premium costs.

The decision to offer insurance means the small employer is committing to a large financial and administrative burden. Health insurance costs can make up a substantial percentage of the employer's cost for worker compensation packages, and this percentage can grow with rising health care costs. Average health insurance costs as a share of payroll increased from 8 to 11 percent for small firms ${ }^{21}$ from 2000 to 2005, representing a 30 percent increase (Eibner 2008). ${ }^{22,23}$ Small businesses have been found to be more sensitive to price than large businesses when deciding whether or not to offer insurance (Hadley and Reschovsky, 2002; Gruber and Lettau, 2004; Feldman et al., 1997) and have

(http://factfinder.census.gov/servlet/ACSSAFFFacts?_event=Search\&geo_id=\&_geoContext=\&_street=\& county $=\&$ _ cityTown $=\& \_$state $=04000$ US38\& zip $=\&$ lang $=$ en \& sse $=$ on \&pctxt $=$ fph\&pgsl $=010$ )

${ }^{20}$ The U.S. increase from 2000 to 2005 for establishments belonging to small firms defined as less than 50 employees is almost 46 percent, but the U.S. increase for establishments belonging to large firms (50 or more employees) is about 52 percent.

${ }^{21}$ Firms with less than 25 employees (Eibner, 2008).

${ }^{22}$ Economic burden is measured using ratio of per-capita health insurance costs relative to per capita payroll. The analysis finds that payroll remained relatively stable during this time, therefore, the increased burden measured by this ratio is attributed to increases in health care costs.

${ }^{23}$ Eibner notes, however, that a lot of variance existed. That is, 25 percent of businesses with less than 25 employees spent less than 6 percent while another 25 percent spent more than 15 percent of payroll on health insurance benefits. 
a higher elasticity of demand (Gruber and Lettau, 2004). ${ }^{24}$ Hadley and Reschovsky

(2002) also find that very small employers and those employing more low-wage workers

are more responsive to premium costs.

Economic theory posits that employees not employers bear the cost of rising

health insurance costs through reduced wages (Summers 1989; Pauly 1994). ${ }^{25,26,27}$ That

is, workers who value the insurance offering accept a wage lower than they would have

received if no health insurance had been offered. But since small firm workers tend to

earn lower wages, ${ }^{28}$ these workers are less able to offset the cost of health insurance

through reduced wages. This may contribute to small employers being less likely to offer

health insurance. Using the MEPS-IC, Table 2.5 shows that the percent of establishments

from the smallest firms with more low wage workers offering insurance is much smaller

than for establishments with fewer low-wage workers.

\footnotetext{
${ }^{24}$ Hadley and Reschovsky (2002) and Gruber and Lettau (2004) define small as less than 100 employees and Feldman et al. (1997) define small as less than 50 employees.

${ }^{25}$ The goal of our analysis is to examine the impact of health care costs on a small employer's growth and survival, and not to address compensating differentials involving wages and health insurance offers. For discussions on compensating differentials see Hwang et al. (1992), Currie and Madrian (1999), and Royalty (2008).

${ }^{26}$ However, empirical studies have not consistently shown this result (Currie and Madrian 1999) and Sommers (2005) indicates that when wages are sticky and insurance premiums increase, the employer will bear some of the burden.

${ }^{27}$ In the cross section, we expect to see more productive workers earning higher wages and being offered health insurance. While attempts are made in the models to control for worker quality and skill, the authors acknowledge it is difficult to distinguish between increases in small business performance resulting from unmeasured aspects of labor quality and direct ways in which health insurance may increase performance. Nguyen and Zawacki (2009) study the relationship between health insurance offers and labor productivity in the manufacturing sector. The authors point out that if health insurance improves worker health and that improved health increases productivity, then ceteris paribus, a positive relationship between health insurance offers and productivity would be seen. Similarly in our study, if health insurance improves worker health this may translate into improved performance by the small business. These findings generally hold using different definitions of small.

${ }^{28}$ Small businesses pay lower wages than larger firms and this may be due to the higher costs of turnover or monitoring in larger firms (Belfield and Wei 2004). Brown and Medoff (1989) study the employer sizewage effect, which is found to be both an establishment and firm size effect, and find that higher-quality workers in large firms explains about one half of the wage differential. The authors find that offering inferior working conditions, using high wages to forestall unionization, and greater product market power do little to explain the remaining difference in wages paid by large versus small employers.
} 
Undoubtedly, part of the challenge for small businesses is the unpredictable rate at which health care costs faced by small businesses rise (Robert Wood Johnson Foundation, 2008). ${ }^{29}$ Small employers, with more low-wage workers (Brown and Medoff, 1989; Oi and Idson 1999) and greater turnover (Nichols, et al. 1997) than larger employers may be particularly vulnerable to rising costs. Variability in premium costs has been shown to be negatively associated with the percentage of high-wage workers and positively related to the firm's turnover rate (Cutler, 1994; Nichols et al., 1997). ${ }^{30}$

The variability in total health insurance costs faced by industries from year-toyear from 2000 to 2005 is shown in Table 2.6 (AHRQ 2000-2005). Establishments in the agriculture, fishing, and forestry industry, a sector with a smaller number of establishments relative to other sectors but with almost 84 percent of business with less than 10 workers in 2005 (AHRQ 2005), saw the percent change in total costs vary from decreases of about 26 percent to increases of over 74 percent during different year-toyear periods. In contrast, professional services, the second largest sector with almost 1.4 million establishments in 2005 and over 60 percent of establishments with less than 10 workers, saw only increases in total costs that range from 4 percent from 2004 to 2005 to almost 22 percent from 2002 to 2003.

\footnotetext{
${ }^{29}$ In this report, small businesses ranged from 3 to 50 employees.

${ }^{30}$ The impact of expansions in the Consolidated Omnibus Budget Reconciliation Act (COBRA) of 1985 to businesses with less than 20 employees in some states on turnover is uncertain. COBRA amended the federal law Employee Retirement Income Security Act (ERISA) of 1974, which applied to firms with 20 or more employees. COBRA required temporary continuation of group health insurance to employees and their dependents when employment was terminated. As of 2009, 40 states subsequently established programs to extend COBRA coverage to firms with less than 20 workers (Kaiser State Health Facts 2009) (see Table 2.7). Employees of these very small businesses may feel less locked into their positions if they can leave the employer and continue insurance coverage. On the other hand, small businesses may be able to recruit more easily if individuals know that COBRA provisions have been set up. While some states only provide continuation of coverage for 4 months, more than 24 percent of the 40 states continue coverage for 3 years. Individuals must pay the full premium cost for COBRA coverage, and in some states an additional administrative cost. In most states, the individual pays 100-102 percent of the group premium cost, but the cost is 115 percent in Florida and 125 percent in Nevada (Kaiser State Health Facts 2009).
} 
2.1.2. Regulations on premiums. As discussed above, cost is a primary reason small businesses give for not offering health insurance to employees. Variation in premiums charged to small employers providing the same coverage can be quite large, prompting 47 states by 2003 to adopt regulations on premium variability (General Accounting Office (GAO), 2003). However, differences in premium-setting requirements and specific restrictions could still vary across state borders. For example, premiums charged to small businesses could be substantially affected by different risk factors. In addition, these regulations often stipulated how much premiums could be adjusted upon renewal but not how the total amount of premiums in the small group market could increase or how often premiums could be increased (GAO 2003).

Some state requirements include limitations on premium variation among small businesses but these apply only to insurers. In other words, these only affect employers purchasing coverage from insurers (GAO 2003). These regulations may have little impact, since small businesses in a National Federation of Independent Business poll ${ }^{31}$ report being more likely to purchase insurance from brokers or agents than insurers. Only 11 percent of small employers report buying insurance directly from insurers, while

\footnotetext{
${ }^{31}$ According to Dennis (2000), membership in the National Federation of Independent Business is made up of over one-half million owners of independent businesses throughout the country and found in all industries, about 1 in 10 employers in the U.S. is a member. 98 percent of members have firms with less than 100 workers. In contrast to the known profile of the small firm population, the National Federation of Independent Business sample is older, disproportionately located in small cities and towns, and larger on average (members' median size is 6 employees and almost 60 percent of the small business population have 4 or fewer employees). In general, results cited in this monograph from polls of National Federation of Independent Business members have 80 to 90 percent response rates.
} 
71 percent of small employers offering health insurance report in 2007 purchasing coverage through a broker or agent (Dennis 2007). ${ }^{32}$

2.1.3. Risk-related costs and participation rates. Small business' reluctance to offer health insurance can arise from different sources of risk and associated financial factors. First, the employer may feel that firm revenues and profits are too variable to take on the financial commitment to offer ESI. New businesses, usually starting out small, may be particularly uncertain about their financial future and reluctant to offer ESI. This apprehension may have increased from 2000 to 2005, particularly with the recession during 2001. MEPS-IC estimates reveal that establishments belonging to the youngest firms (less than 5 years old) experienced the greatest drop in the percent offering insurance (data not shown). The percent of establishments offering insurance dropped from 36.8 percent in 2000 to 27.7 percent in 2005 (AHRQ 2000 and 2005). The decrease in offers is also significant in all other firm age categories, but the drop is smaller. $^{33}$

Adverse health risks are also related to the small businesses' concern regarding the uncertainty of premiums. One very sick employee can raise premium costs for a small employer in one year's time. ${ }^{34}$ If only a small percentage of employees enroll in a health plan offered by a small business, insurers are more concerned that only sick

\footnotetext{
${ }^{32} 8$ percent purchased insurance through a business organization or trade group, and 5 percent from an association of providers (Dennis, 2007).

${ }^{33}$ The same patterns are found when looking at the percent of employees in establishments that offer health insurance by firm age.

${ }^{34}$ Monheit and Vistnes (1994) find, however, little evidence that workers at small firms (25 or fewer workers) and their dependents would be adverse health risks if they obtained coverage comparable to that held by large-firm employees. In addition, the insured at small (less than 50 employees) and large employers have reported similar health characteristics (GAO, 2001).
} 
employees are enrolling. Therefore, minimum participation rates are sometimes imposed to avoid the risk of adverse selection. A 2003 National Federation of Independent Business poll indicates that one-third of all small businesses faced minimum participation requirements, although businesses with less than 10 employees were less likely to face this requirement (Morrisey, 2003). To raise participation rates and avoid adverse selection, insurers may require the employer to pay 50 to 100 percent of the premium cost for employees (Gencarelli, 2005). This increases the financial burden for offering ESI and can reduce offer rates.

Insurers' concerns regarding the risk pool at a small employer leads to insurers using medical underwriting ${ }^{35}$ and raising premiums to cover the cost of this additional process for small employers. Medical underwriting leads to small employers with healthy workers being charged low premiums and small employers with less healthy workers being charged higher premiums. 42 percent of establishments with 1 to 4 employees offering insurance were subject to medical underwriting, while only 21 percent of firms with 50 or more workers underwent this process (Cantor et al., 1995).

As noted earlier, greater premium variability is found among small firms than large firms (Cutler 1994) and considered evidence that greater adverse selection issues exist in the small group market (Gruber 2000). For very small groups, each person may be required to provide a detailed medical history. This adds a cost that is not incurred by insurers for large employers whose employees are not screened as extensively (GAO, 2001). Since employee health conditions are scrutinized with medical underwriting and changes in just one or more employees can result in premium changes, small firms will

\footnotetext{
${ }^{35}$ Medical underwriting refers to insurers calculating expected medical costs based on the health status of enrollees in order to set a firm's premiums (Lee, 2002).
} 
experience more premium variability, which can discourage them from offering insurance. Finally, to help protect themselves from an unanticipated large expense, insurers may also add a surcharge of 1 to 5 percent of the small employer's premiums to increase their financial reserves (GAO, 2001).

2.1.4. Administrative costs. While workers' health status and rising health care costs can lead to higher premiums, administrative costs can also contribute towards the cost of premiums and have been shown to be a significant factor in small business’ decision to offer ESI (Abraham et al. 2009). ${ }^{36}$ The Government Accountability Office (GAO, 2001) found that these costs represent 20 to 25 percent of the premium cost for small businesses but only 10 percent for large firms. This is because fixed administrative costs such as marketing, billing, and pricing for ESI are lower when spread over a larger number of employees. The loading factor on insurance ${ }^{37}$ purchased by firms with less than 5 employees has been found to be over 40 percent higher than that on very large firms with over 10,000 employees (Congressional Research Service, 1988). As noted by Nichols et al (1997), small businesses tend to have greater turnover. The authors comment that an employer's changing workforce leads to repeatedly enrolling and disenrolling and medically underwriting subscribers and insurers may charge high administrative costs to cover the associated expenses.

The majority of small employers purchase insurance through a broker and agent. Large employers, on the other hand, often employ their own human resource specialists

\footnotetext{
36 The authors use categorical measures of establishment size, including 3 to 10 or less than employees.

${ }^{37}$ The loading factor is the administrative expense added to the premium cost to cover activities such as billing and enrollment.
} 
who perform various administrative tasks (e.g., determining eligibility, enrollment, educating employees, etc.). Brokers and agents can contribute to higher premiums for small businesses, ranging from 8 to 10 percent of the premium cost (Actuarial Research Corporation, 2003; GAO 2001). ${ }^{38}$ This cost is generally greater than the lump sum or fixed hourly fee paid by larger employers for assistance with administering health insurance benefits (GAO 2001). In addition, because of their size, small firms have difficulty containing the cost of ESI because they lack bargaining clout and cannot afford to hire specialists to negotiate with insurance companies (Carpenter 2003).

Administrative costs associated with self-insured indemnification may also prevent small businesses from pursuing this option. Large firms are more likely to selfinsure because they can afford to hire staff to administer the plans, they also have the financial resources to pay medical claims, and the large employers can negotiate with health care providers in order to set up customized arrangements for deductibles and copayments (Pierron and Fronstin 2008). MEPS-IC estimates show these patterns. About 79 percent of establishments from firms with 500 or more employees self-insured at least one plan in 2005. In contrast, only about 12 percent of establishments from small firms (whether defined as less than 50 or less than 100) self-insured at least one health plan in the same year. ${ }^{39}$ No significant increase is seen from $2000 .^{40}$

\footnotetext{
${ }^{38}$ Broker commissions can cost small businesses ( 2 to 50 workers) 2 to 8 percent more in premium costs, and are even included by insurers in the premiums for small businesses not using brokers (Conwell, 2002).

39 The 2006 Kaiser Family Foundation/Health Research and Educational Trust report and Pierron and Fronstin (2008) show similar patterns.

40 The same patterns are seen when comparing establishments from small firms defined as less than 50 employees and large firms with 50 or more employees.
} 
Self-insuring is often appealing to employers who are then only subject to federal regulations, which supersede state ESI regulations and mandates. ${ }^{41}$ Firms who selfinsure can also save on premium costs in a number of ways. They avoid paying state premium taxes, profit/risk charges, and broker commissions. These expenses can contribute from 2 to 11 percent to premium costs (Actuarial Research Corporation, 2003).

To help reduce administrative costs, small employers may purchase insurance coverage through associations or trusts. It has been stated, however, that these plans would do little to lower administrative costs (Congressional Budget Office 2000). In fact, administrative and insurer costs may actually rise if the association or trust must market itself to small businesses (Actuarial Research Corporation, 2003). This report goes on to say that economies of scale cannot be achieved for some administrative costs such as underwriting applications, renewals, booklets with plan costs, and premium collections for specific enrollments each month. In 2001, 21 states had health purchasing alliances to help small businesses purchase insurance. While these alliances have helped increase options they have not been found to reduce costs (Wicks, Hall, and Meyer 2000), increase the percent of small businesses' offering insurance (Long and Marquis 2001b) or grow or maintain enrollment. With group purchasing cooperatives accounting for a very small percentage of each state's enrollment in ESI (less than 5 percent), reduced administrative costs and premiums are considered difficult to achieve (GAO 2000).

\footnotetext{
${ }^{41}$ When employers purchase insurance coverage from insurance companies, they are subject to state and federal laws. However, ERISA exempts self-insured plans from state mandates and this motivates many employers to self-insure. ERISA prevents multi-state employers from meeting regulations from all the different states where they operate.
} 
2.1.5. Tax advantages. Compounding the concerns about cost is the small employers’ possible lack of knowledge about the tax treatment for health insurance premium costs. The 2002 Small Employer Health Benefits Survey revealed that 57 percent of small employers did not know that health insurance premiums are 100 percent tax deductible for employers (Fronstin et al., 2003). 38 percent responded that they did not know that employees do not pay tax on the share of premiums paid by the employer. If employers do not realize that offering health insurance may provide some tax advantages, they lack this incentive to offer benefits. On the other hand, if the small employer has a predominantly low wage workforce, these workers would benefit less from the tax treatment.

Some states have also set up other tax incentive programs for small employers, which businesses may be unaware of. These programs may provide transitional tax credits when small businesses insure for the first time or premium subsidies that go directly to the employee or through the employer (Kauffman-RAND Institute for Entrepreneurship Public Policy (KRI), 2007). Table 2.7 shows that in 2008, 13 states or about 25 percent of all states offered tax incentives for small employers to purchase health insurance (Kaiser State Health Facts 2008). 7 of these states authorized tax credits, while 6 states offered deductions to small employers offering health insurance. Arizona provides a tax credit as incentive to small employers to offer insurance, but North Dakota, New York, and Tennessee do not provide tax credits or deductions. 


\subsection{Labor market}

\subsubsection{Employee characteristics and demand for own employer's health}

insurance. Employee demand can be important in the employer's decision to offer ESI. If a business believes its workers may not need or want health insurance from their own employer, the benefit may not be offered. ${ }^{42}$ This is supported by evidence showing workers at firms not offering ESI have characteristics similar to workers at firms offering ESI who decline insurance coverage (Long and Marquis, 1993). These workers tend to be young, low-wage earners who work part-time.

Further research supports these findings. Small employers who do not offer insurance have workers with a low demand for health insurance, including relatively young and healthy workers and those likely to have high turnover (Monheit and Vistnes, 1994, 1999). ${ }^{43,44,45}$ In contrast, firms with workers who earn higher wages, have a higher level of educational attainment and lower rates of turnover, and with higher gross revenue are significantly more likely to offer health insurance (Holve et al. 2003). ${ }^{46}$ However, using somewhat different measures of worker demand to capture the effects of human capital and income-related factors, including tenure, age, household income, and education, Abraham et al. (2009) conclude that very little of the difference in offer rates between smaller and larger establishments can be attributed to worker demand. Part of

\footnotetext{
${ }^{42}$ Monheit and Vistnes (2008) find that individuals expressing low preferences for health insurance are less likely to enroll in offered plans.

${ }^{43}$ Levy (1998) does not look exclusively at small firms but finds that firms with all middle-age workers or with all older workers are more likely to offer insurance than firms with all young workers.

${ }^{44}$ Small businesses have also been found to be more likely to hire workers receiving public assistance (Headd 2000). If the government program provides coverage for medical expenses, this can also reduce the demand for ESI.

${ }^{45}$ Monheit and Vistnes (1994) define small firms as having less than 26 employees.

${ }^{46}$ Holve et al. (2003) look at businesses with 3 to 24 workers.
} 
the explanation for the difference in these findings on the relationship between offers of ESI and worker demand may relate to Abraham et al. (2009) using MEPS household data rather than business data. For example, the authors use individual tenure rather than turnover at the employer level and use household income rather than a measure of wages for the business’ workforce.

As mentioned earlier, economic theory states that employees carry the financial burden for health insurance costs with reduced wages. ${ }^{47}$ Employees who are low wage and changing jobs often, however, may be less inclined to trade wages for health insurance coverage than high-wage workers (Nichols et al. 1997). ${ }^{48}$ Table 2.5 shows that the percent of establishments belonging to firms of all sizes and offering insurance is smaller in low-wage establishments ${ }^{49}$ than high-wage establishments (AHRQ 2000 and 2005). ${ }^{50,51}$ Earlier data from 1987 and 1996 shows similar patterns and when offer rates were generally higher in these years, high-wage small firms had similar offer rates to large firms (Lee 2002). ${ }^{52}$ However, other studies show large firms are more likely than

\footnotetext{
${ }^{47}$ However, empirical studies have not consistently shown this result (Currie and Madrian 1999) and Sommers (2005) indicates that when wages are sticky and insurance premiums increase, the employer will bear some of the burden.

${ }^{48}$ While not focusing on employer size, some studies examining the uninsured find that lack of affordability for health insurance leads to noncoverage (Bundorf and Pauly 2006; Levy and DeLeire 2008). Low-wage workers may find the higher premiums in small businesses particularly unaffordable.

${ }^{49}$ Low-wage establishments have 50 percent or more of their workers earning a low wage and high-wage establishments have less than 50 percent of their workers earning low wages. In 2000, the MEPS-IC defined low wage as less than $\$ 9.50$ per hour and in 2005 defined low wage as less than $\$ 10$ per hour.

${ }^{50}$ Marquis and Long (2001b) find that employers of low-wage workers are much less likely to offer health insurance than other employers, although the authors do not look exclusively at small employers.

${ }^{51}$ Household data also shows that low-wage workers are less likely to be offered or eligible for ESI than high-wage workers (Garrett et al. 2001; Collins et al. 2003).

${ }^{52}$ Firms with less than 26 workers are used for these findings (Lee, 2002).
} 
small firms to offer health insurance even after controlling for wage levels or average payroll per employee (Glied et al. 2003; Garrett et al. 2001). ${ }^{53}$

Younger and older workers may have lower demand for health insurance. Young workers may not value health insurance as much as older workers and may be voluntarily uninsured because they have a better health status. Individuals over age 65 are eligible for Medicare and this can reduce the need for ESI by these older workers. Consequently, small businesses may have less employee demand for ESI, since small employers tend to have either younger or older workers (Headd, 2000; Nichols et al., 1997), whereas large firms employ more workers in prime age (i.e., 25-54).

In contrast to small firms, large firms are much more likely to offer ESI to parttime and temporary workers (although few temporary workers are offered ESI) (Econometrica, 2007; 2004 Kaiser Family Foundation/Health Research Educational Trust). Table 2.5 shows the change from 2000 to 2005 in the percent of private-sector establishments that offer health insurance by firm size and percent of full-time employees using the MEPS-IC. These data show that establishments with fewer full-time workers are less likely to offer health insurance, regardless of firm size. About 21 percent of establishments with less than 25 percent of their workers employed full-time are offered health insurance. ${ }^{54}$ Data from the MEPS-IC also shows that only about 9.5 percent of establishments belonging to the smallest firms with predominantly part-time workers offer health insurance versus over 90 percent of establishments from the largest firms (See Table 2.5). It is interesting that from 2000 to 2005, these establishments have an

\footnotetext{
${ }^{53}$ Glied et al. (2003) look at small firms with less than 100 workers, mid-sized firms, and large firms with 500 or more workers. Garrett et al. (2001) look at the smallest firms (less than 10 employees).

${ }^{54}$ The 2004 Kaiser Family Foundation/Health Research and Educational Trust survey provides similar results.
} 
increase in the percent offering health insurance. This finding also holds for firms with 25-99 and 1000 or more employees (AHRQ 2000 and 2005).

2.2.2. Recruitment and Retention. While financial reasons appear to deter small businesses from offering health insurance, the primary reasons to offer coverage appear to be employee recruitment and retention. ${ }^{55}$ The tightness of the labor market faced by employers can also influence their reactions to rising health care costs. That is, while small employers may be facing rising health insurance costs they may be reluctant to drop coverage if they are also facing a tight labor market. If labor markets are not tight and unemployment is high, employers may not see the value of offering health insurance in order to attract workers. Marquis and Long (2001a) find that small firms with 50 employees or less are more likely to offer health insurance in areas with low unemployment. Since the tightness of the labor market has been shown to affect the small business’ decision to offer health insurance, our models will include controls for unemployment rates.

Nichols et al. (1997) point out that employers in specific industries or occupational categories compete for workers in distinct labor markets. Therefore, this may influence the decision to offer insurance by employers in these markets. Small businesses may be concentrated in industries and occupations where health benefits are not necessary to attract good workers. Marquis and Long (2001a) also find small employers are more likely to offer insurance if the local market is characterized by a smaller share of workers in regulated industries.

\footnotetext{
${ }^{55}$ Various surveys offer support for these motivating factors (Robert Wood Johnson Foundation, 2008; Fronstin et al., 2003; Holve et al., 2003). Also see Currie and Madrian (1999).
} 
Additional characteristics of the employer or its local market may also influence the decision to offer insurance. ${ }^{56}$ Using MSA-level data from the 1993 National Employer Health Insurance Survey and the 1997 Robert Wood Johnson Foundation Employer Health Insurance Survey, Marquis and Long (2001a) find that small employers' decision to offer ESI is influenced by local market conditions. More specifically, they find small employers are more likely to offer insurance in markets with more unionization, a greater share of workers in big business, and less concentration in the labor market.

\subsection{Insurance markets and products}

2.3.1. Access. Young businesses, which are small, may not have access to insurance. ${ }^{57}$ This is because insurers will not offer policies until they are sure the business has not been established in order to get coverage for individuals with poor health. Young businesses may face access issues related to insurer reluctance or their own concerns regarding survivability. The percent of establishments offering insurance is smallest in the youngest firms (less than 5 years) at less than 28 percent in 2005 and largest in the oldest firms (20 years or older) at almost 67 percent (AHRQ 2005). As noted earlier, the largest significant decrease from 2000 to 2005 in the percent of establishments offering health insurance belonged to the youngest firms.

\footnotetext{
${ }^{56}$ For example, Morrisey et al. (1994) find that small businesses (50 employees or less) that are incorporated are more likely than unincorporated businesses to offer health insurance. The authors also find that small employers located in urban areas are more likely to offer this benefit than employers in rural locations.

${ }^{57}$ Surveying businesses with less than 50 workers in 1993, Morrisey et al. (1994) find access is not an issue in this earlier time period, perhaps because consolidation in the insurance industry and state-level reforms had not yet taken place.
} 
Small employers may also have limited access to insurance carriers due to the dwindling number in the small group market, although this market has been described as the most profitable area of the health insurance industry (Abelson 2009). Table 2.7 shows the number of carriers by state. To avoid risk and adverse selection, some insurers may not cover workers in small businesses or employers in some industries. In addition, some may not cover businesses with less than 10 workers and some insurers impose exclusions on pre-existing conditions. Businesses also cannot purchase health insurance from carriers in other states, which prevents interstate competition (Neese, 2009). ${ }^{58}$

Small businesses can also face limited choices for insurers if insurers leave states where they believe they cannot be competitive (Carpenter, 2003). ${ }^{59}$

GAO (2009) provides 2008 survey results on the number and market share of carriers in the small group health insurance market by state (see Table 2.7). ${ }^{60}$ While the median number of carriers is 27 , North Dakota has 10 carriers and market share for the largest carrier is 91 percent. In contrast, Arizona has 32 carriers and New York has 31. Focusing on our four states, it is interesting to note that the number of carriers does not always reveal market share for the largest carrier. That is, although Tennessee has 33

\footnotetext{
${ }^{58}$ The National Association of Insurance Commissioners and The Center for Insurance Policy and Research, however, argue that allowing interstate sales would allow insurers to chose states and associated regulations. This would help insurers to pursue those with the healthiest risk and potentially raising premium costs for others.

${ }^{59}$ Blue Cross Blue Shield provides the majority of coverage for small businesses (Actuarial Research Corporation, 2003). This report looks at different data sources using different size definitions and suggests reasons why fewer insurers may lead to lower costs since the remaining carriers have higher market shares and economies of scale. These economies can be realized in the processing of claims and enrollment data. With fewer competitors, marketing needs and associated costs are reduced. Finally, lower commissions may be realized also from the reduced need for underwriting since fewer insurers leads to reduced turnover among insurers for small business coverage.

${ }^{60}$ Market share is usually based on the number of covered lives (GAO 2009). GAO (2009) defines a carrier as an entity (either an insurer or managed health care plan) that bears the risk for and administers a range of health benefit offerings. 33 of the 47 responding states defined small group as 2 to 50 employees, 12 states defined small as 1 to 50 employees, and the remaining states used other definitions (GAO 2009).
} 
carriers, market share for the largest in the small group market is 68 percent. With comparable numbers of carriers, New York (31 carriers) and Arizona (32 carriers) have market shares for their top carriers equal to 26 percent and 21 percent, respectively. Part of the explanation may be related to the largest Blue Cross and Blue Shield carrier in both North Dakota and Tennessee being ranked number one, whereas they are ranked number two in New York and Arizona. Across the country, Blue Cross and Blue Shield is named the top carrier in 36 of the 44 responding states.

This GAO (2009) report also compared findings with previous reports done in 2002 and 2005. These comparisons provide evidence of increased concentration of carriers in the small group health insurance market. While the largest small group carrier had a median market share of 33 percent in 2002 and 43 percent in 2005, this rose to 47 percent in 2008.

\subsubsection{Insurance options with lower premium costs. High-deductible or} consumer-directed health plans may provide a lower cost option for small businesses to provide ESI, ${ }^{61}$ because they are generally associated with lower premium costs. High deductible health plans are an important feature of consumer-directed health plans and often combined with personal health savings accounts or health savings accounts. ${ }^{62}$ Some report, however, that consumer-directed health plans have not improved access or affordability of health insurance for small businesses (KRI, 2007).

\footnotetext{
${ }^{61}$ Consumer-directed health plans force consumers to be more financially aware and responsible when seeking health care services, especially costly ones. The idea is that this should lead to less expensive insurance coverage and possible lower health care costs.

${ }^{62}$ Health savings accounts allow individuals to place pretax earnings in an account from which they can pay for deductibles and copayments.
} 
After their introduction, health savings accounts appeared more popular with small businesses but have been adopted more by large employers in recent years (KRI, 2007). According to the National Small Business Association's 2003 Benefits Survey of 256 business owners, 73 percent of small businesses report interest in health savings accounts (Gencarelli, 2005), other surveys find that small businesses are less likely to keep consumer-directed health plan offerings from year to year (Gates et al. 2007). While benefits under health savings accounts and high-deductible health plans offered in small and large firms have been found to be quite similar, annual deductibles are a bit higher in small firms (America’s Health Insurance Plans, 2006).

Small employers and insurers have reported that educating and communicating with employees about the benefits of high-deductible health plans is important for take up (Gates et al. 2007), yet small employers may not have the resources to promote these lower cost options. Another factor may be how small employers gather information about health insurance options. As noted earlier, evidence suggests small employers consult with brokers and agents about coverage. These individuals have little incentive to promote low cost options, since this would lower their commissions that are based on premiums.

\subsection{Health Insurance Regulatory Environment}

2.4.1 Legislation, insurance offers, and business size. It is important to understand the regulatory environment for the small group insurance market. These factors can influence employers' decisions to provide coverage and the premium costs they face. Of particular interest to our analyses are findings that regulations may influence small 
business growth. Decisions regarding benefits and size can subsequently impact the small businesses' ability to compete in the labor market against large employers and the growth and survival of small businesses.

In KRI (2007), Gates and Leuschner point out that basically no research has examined the impact of health insurance regulation on business size and suggest how these laws may influence the growth of small businesses. For example, small businesses may not want to grow beyond a particular size, that is, the size at which legislation no longer protects small business health insurance coverage. These may be firms with high expected health care costs that value the access and breadth of coverage provided under reform even at a higher premium cost (Kapur et al. 2006). Alternatively, some small businesses may wish to grow large enough in order to self-insure and avoid state regulations on small business coverage that may potentially raise premiums and reduce availability. This latter response may be particularly true for small firms with young, healthy workers who have low expected health care costs and high turnover and therefore do not value coverage offered under reform (Kapur 2004; KRI, 2007). ${ }^{63}$

Researchers find that small businesses do increase their size to avoid the more regulated small group market (KRI, 2007). Firms with a size close to the threshold in the regulations more easily adjusted their size to avoid the reforms (Kapur et al. 2006) and many states adjusted their thresholds. During the initial surge in state-level small group health insurance reform in the early 1990s, most states had 25 or 50 employees as the upper size threshold. By 1997, states had raised their thresholds and no state had 25 as the upper threshold any longer (Kapur et al. 2006).

\footnotetext{
${ }^{63}$ Kapur (2004) defines a small firm as having less than 25 workers.
} 
Similar to our study, the research presented in this section examines the growth of small businesses. But the focus in these studies is on the influence of regulations and regulatory thresholds on changes in business size, whereas our work will focus on the impact of rising health care costs proxied using insurance offers on the growth of small businesses. In addition, our research will focus on the post-reform period of the 1990s using more recent data from the MEPS-IC and longitudinal information available from the Longitudinal Business Database. This past research, however, highlights the potential influence of workforce characteristics and the regulatory environment faced by small businesses and the importance of analytical models including controls for these factors.

2.4.2 State reform. Many states passed reform measures during the 1990s to improve small businesses’ access and affordability to health insurance, including guaranteed-issue and guaranteed-renewal laws, pre-existing condition exclusion laws, portability reforms, premium rating reforms, and reinsurance provisions. ${ }^{64}$ These reforms help small businesses by restricting the use of health status in determining premiums; however, claims experience and the health characteristics of subscribers do still lead to wide variations in state premiums (GAO 1995). The Health Insurance

\footnotetext{
${ }^{64}$ Under the Federal Health Insurance Portability and Accountability Act (HIPAA) and state law, insurance plans sold to small employers with 2 to 50 employees are sold as guaranteed issue and insurers cannot deny these small businesses coverage based upon health status of workers. Guaranteed renewal means the small employer may continue to renew health insurance benefits at their own discretion and prohibits insurers from denying coverage except under certain conditions including unpaid premiums or fraud. Pre-existing condition exclusions refers to an individual having specified medical conditions existing 6 months prior to enrollment, and these conditions would not be covered or excluded from coverage up to 12 months after enrollment. Under portability provisions, insured individuals changing employers would not have these conditions excluded from coverage. Under premium rating, rules are established identifying which characteristics of covered individuals may or may not be used to set premiums. Reinsurance has been called the insurance for insurance companies and refers to insurance companies protect themselves from the risk of losses by using other insurance companies.
} 
Association of America estimates that 2 to 4 percent of premium costs are associated with guaranteed issue requirements (KRI, 2007). These reforms as well as mandated benefits ${ }^{65}$ have been found by some to increase the price of health insurance (Kaestner and Simon 2002; Neese 2009) with the highest premium costs found in the most highly regulated states (Neese 2009). In general, however, health insurance regulations have been found to have little effect on premiums or coverage (KRI, 2007; Monheit and Schone 2003; Buchmueller and DiNardo 2002).

On the other hand, the impact of these regulations may not be truly realized if it is difficult for states to enforce the laws (Abelson 2009) or small businesses are unaware of the legislation intended to increase the affordability and accessibility of ESI. The 2002 Small Employer Health Benefits Survey ${ }^{66}$ found more than 60 percent of small businesses (2-50 workers) did not know that insurers could not refuse to provide coverage even if the health status of the employers' workforce is poor (Fronstin et al. 2003). ${ }^{67}$ The authors point out that this lack of knowledge among small employers could lead to lower offer rates.

As discussed earlier, our empirical model will control for the location of a small business since different states have different health insurance regulatory environments and costs. In 2006, the Council for Affordable Health Insurance (CAHI) developed an

\footnotetext{
${ }^{65}$ States can pass regulations requiring health insurance plans to cover certain medical conditions, treatments, and health care providers.

${ }^{66}$ This survey defines small businesses as those with 2 to 50 employees and in 2002 conducted telephone surveys with 502 companies with health benefits and 498 companies without health benefits (Fronstin et al., 2003). The survey is co-sponsored by Blue Cross and Blue Shield Association, Employee Benefit Research Institute, and the Consumer Health Education Council. The authors admit to being unable to quantify errors associated with sampling, nonresponse, and survey design. Despite these possible shortcomings, the survey provides some information on small employers unavailable elsewhere (e.g., their knowledge of tax advantages for offering insurance).

${ }^{67}$ The authors break this down further reporting that 60 percent of those offering coverage were unaware versus 68 percent of small businesses (2 to 50 workers) not offering coverage (Fronstin et al. 2003).
} 
index (maximum 100 points for best score) that provides an indication of the health insurance environment in each state (Matthews et al. 2006). Six factors are used to calculate the index measure: 1) Percent uninsured (10 points maximum for low percentage), 2) Number of state mandates (10 points maximum for low number), 3) State regulatory environment (20 points maximum), 4) High risk pools (20 points maximum), 5) Premiums in individual market (20 points maximum), 6) Premiums in small group market (20 points maximum).

States with a high index score are expected to have a competitive health insurance market and lower premiums, while states with low scores indicating an unattractive health insurance environment are expected to have fewer insurers and higher premiums. Figure 2.6 shows the ranges for this index by state. This map shows that the lowest index scores are seen only in states in the Northeast. New York has the lowest score with 5, and premium costs for single coverage among the highest (over \$4200 per 2005 MEPSIC). ${ }^{68}$ The highest index scores are primarily found in the West and Midwest regions of the country. Contrary to expectations (Matthews et al., 2006), North Dakota has one of the highest CAHI scores with 75 , but relatively low premiums of $\$ 3,438$. This state’s premium costs are \$553 less than the national average in 2005 based on MEPS-IC data and may reflect other factors not captured in the index.

\footnotetext{
${ }^{68}$ Arizona and Tennessee have lower scores with 45 and 35, respectively. Like New York, Arizona has premium costs for single coverage over $\$ 4,200$. In contrast, Tennessee with its lower score also has lower than premium costs (i.e., $\$ 3,822$ ), which is below the national average of $\$ 3,991$. Premium costs based on MEPS-IC data.
} 


\subsubsection{Health Insurance Mandates. Some states mandate insurance policies cover}

particular health care services, providers, and persons. ${ }^{69}$ While this legislation can

increase the comprehensiveness of policies, they can also increase costs and discourage

businesses from offering insurance to workers. ${ }^{70},{ }^{71}$ According to the Council for

Affordable Health Insurance (2005), approximately 100 different mandates exist and total

over 1,800 when summed across states. Mandates for mental health parity and

prescription drugs are each estimated to contribute 5 to 10 percent to premium costs, while in vitro fertilization and coverage for dentists each have estimated costs of 3 to 5

percent. 22 of the mandates have estimated costs of 1 to 3 percent, while the balance of the mandates have estimated costs less than 1 percent. Figure 2.7 shows the number of mandated benefits by their cost estimate for each state (Bunce and Wieske, 2005) ${ }^{72}$ and a cost-weighted index. ${ }^{73}$

Figure 2.7 illustrates that differences in the costs of mandates can impact the financial burden of employers differently regardless of the number of mandates. For example, the cost-weighted index for Arizona and North Dakota are very close at 46.5

\footnotetext{
${ }^{69}$ Some mandated coverage may be typical and likely to be contained in a standard insurance policy.

${ }^{70}$ Many employers would offer benefits even if not mandated (GAO 2003). If plans voluntarily offer the mandated benefits, it is difficult to evaluate the additional cost to premiums attributed to state mandates.

${ }^{71}$ Gruber (1994) finds that mandates increase premium costs by a small percentage, while other researchers find a larger effect. Lee (2002) notes that Gruber's analysis was conducted in the early 1990s before many mandates had been passed by states, but that work in this area by others was methodologically weaker than Gruber's.

${ }^{72}$ The cost-range estimates are calculated as if the mandate were added to a comprehensive family policy that did not include the coverage (Bunce and Wieske, 2005). The authors caution that each piece of mandate legislation needs to be fully evaluated in detail as well as other regulations in order to determine the impact of mandates in an individual state.

${ }^{73}$ The cost-weighted index is calculated for each state by summing across the number of mandated benefits contributing 5 to 10 percent multiplied by a weight of 7.5, the number contributing 3 to 5 percent multiplied by a weight of 4 , the number contributing 1 to 3 percent by a weight of 2 , and those contributing less than 1 percent by a weight of 1 . Estimates of the percent contributed towards costs by the mandates are from Bunce and Wieske (2005).
} 
and 47.5, respectively. However, Arizona has legislated only 28 mandates compared to 33 for North Dakota.

Pierron and Fronstin (2008) report that small firms are less likely to offer insurance because of the cost added to coverage as a result of state mandates and small employers are more price sensitive than large employers. ${ }^{74} 18$ percent of small businesses without coverage would likely sponsor coverage but for mandates (Jensen and Morrisey 1999), and other studies provide similar results (Gabel and Jensen 1989; Jensen and Gabel 1992). ${ }^{75}$ Some states have passed legislation to bypass concerns that mandates may make health insurance less affordable for small employers, including allowing small employers to offer plans exempt from premium taxes and not covering mandated benefits (Gencarelli 2005). States have the primary responsibility in overseeing policies sold by insurers, however, and a lot of variation may be seen across states in mandated benefits and regulations on premiums.

State insurance mandates may also impact the growth of small businesses, although little research has been conducted to study this. The only known study is Mathur (2008), which uses demographic rather than business data and the data pre-dates the passage of mandate legislation in a number of states. Using the Survey of Income and Program Participation data from 1993-1995, Mathur finds that the probability that a self-employed person will be a significant employment generator decreases with the

\footnotetext{
${ }^{74}$ The authors look at firms of different sizes: 3-1999, 200-999, 1,000-4,999, and 5,000 or more employees.

${ }^{75}$ The results of studies examining the effect of mandates on insurance coverage, offers, and premiums show a small effect or no effect (Sloan and Conover 1998; Jensen and Morrisey 1999; Zecherman and Rajan 1999; Monheit and Schone 2004; Buchmueller and DiNardo 2002; Marquis and Long 2001a, 2001b) or modest effects in different directions (Uccello 1996; Hing and Jensen 1999; Simon 2005;

Buchmueller and Jensen 1997).
} 
number of health insurance mandates in a state. ${ }^{76}$ The author finds that the probability of owning a business with at least one employee goes down about 10 percentage points (i.e., from 0.45 to 0.34 ) as the number of mandates increases from 0 to 16 . This change in mandates reduces the probability of owning a firm with more than 2 employees by almost 50 percent and owning a firm with 6 or more employees by about 35 percent.

\subsection{Concluding Remarks}

While rising health care costs can impact the insurance premium cost for small employers, other costs associated with risk factors and plan administration can raise the cost of ESI. As stated in the 2009 Council of Economic Advisors Report to the President, higher costs can make ESI prohibitively expensive for small employers and lead them to not offer this benefit. If small employers are unable to afford offering health insurance to workers or can only offer plans at a much higher cost than larger employers, this can put them at a disadvantage for recruiting and retaining skilled workers who could impact their growth and survival.

The focus of our empirical analysis is on the growth and survival of small businesses and not the reasons for offering health insurance. However, because offering health insurance may be endogenous in the model predicting business performance, we predict offers of health insurance using the MEPS-IC, which is the premier data source on employer-sponsored insurance. Unlike some studies, we use predicted premiums to predict the offers in order to develop the cost faced by both offering and non-offering

\footnotetext{
${ }^{76}$ Mathur finds these results hold when models control for the total sum of mandates or using a cost weighted measure of the most expensive mandates.
} 
businesses. As highlighted in this chapter, employee demand for insurance can also factor into the decision to offer this benefit and workforce characteristics are included in the models. Finally, given the potential influences of the small group insurance market and the regulatory environment, our models control for the business's geographic location. 


\section{Employer Reactions to Rising Health Care Costs}

Employers may adopt different business strategies when faced with rising compensation costs associated with health insurance. These include dropping coverage altogether, eliminating coverage for particular health care services, increasing employee cost sharing or switching to premium reimbursement, or reducing labor inputs. Adoption of one or more of these approaches may impact the growth and survival of small businesses if these strategies reduce productivity and/or worker morale.

\subsection{Discontinuing health insurance benefits}

Rising premium costs may lead to some employers dropping ESI to workers altogether (Morrisey, et al. 1994) or small employers to never provide this benefit. Since ESI is the primary source of coverage for people in the U.S., lack of coverage through small employers can exacerbate the nation's concerns regarding the uninsured and access to health care. A 2008 Kaiser Family Foundation report states that more than half the uninsured are employees and dependents of small businesses. ${ }^{77}$

Just as the regulatory environment across states can vary, health care expenditures and coverage rates can also vary. In a macro-level examination, workers in states with higher per capita healthcare expenditures are found to be less likely to lack private health insurance coverage (Econometrica 2007). The percent increase in per capita personal health care expenses by state of residence from 2000 to 2004 varies from a low of 26

\footnotetext{
${ }^{77}$ More than 60 percent of the 43.6 million uninsured are from families headed by someone working for a small business or self-employed (Carpenter, 2003). The author notes that definitions of small can vary from less than 50 to less than 500 employees.
} 
percent to a high of 44 percent. The increase during this time period for the entire U.S. is 30.8 percent (Centers for Medicare and Medicaid and U.S. Department of Commerce, 2007). The percent increase in the four states we are following are a bit higher than this national average. North Dakota has the largest increase at 37 percent, while New York has the lowest increase at 32 percent. These differences may relate to variations in the efficiency of the state’s health care delivery system (Baicker and Chandra, 2009).

While health care and premium costs have been rising, offer rates by small employers have not decreased dramatically. Carpenter (2003) suggests the drop in employers offering coverage may have not been dramatic because employers do not want to reduce worker morale or productivity and may not want to make hiring more difficult. Research by Short and Lesser (2002) also suggests that while small employers may not drop coverage, they may raise employee out-of-pocket costs (e.g., deductibles, copayments), switch products and carriers, and/or reduce benefits. Workers at small firms have been found to be more likely to face deductibles than workers at larger firms and the deductibles tend to be higher in small firms (Gabel et al., 2006: Morrisey et al., 1994).

Projections on small employers dropping coverage were included in the Council of Economic Advisors’ 2009 report to the President. They project less than 20 percent of small employers ${ }^{78}$ will offer coverage by 2040. This is a decrease from 43.4 percent of employers this size offering health insurance in 2005 based on MEPS-IC estimates (AHRQ, 2005). ${ }^{79}$

\footnotetext{
${ }^{78}$ The report defines small employers as those with less than 50 workers.

${ }^{79}$ From a different perspective, the 2002 Small Employer Health Benefits Survey revealed than 11 percent of small employers not offering health insurance benefits are either extremely or very likely to start
} 
As discussed earlier, small businesses may offer health insurance to recruit and retain employees. However, high costs can lead to small employers not offering this benefit. This may disadvantage small businesses in competition with large employers for skilled workers, who could potentially make a positive impact on the growth and survival of the small business.

\subsection{Reducing Benefits}

Small employers may try to combat rising health care costs by reducing benefits (Short and Lesser, 2002). ${ }^{80}$ For example, these businesses may drop coverage for fertility treatment, reduce coverage for mental illness, discontinue retiree health insurance benefits, and extend the waiting period for employee eligibility. GAO (2001) also reports that workers covered by small firms are less likely to receive prescription drug coverage, prenatal care, out-patient and inpatient mental health, well-baby care, adult physicals, chiropractic care, oral contraceptives, and acupuncture. ${ }^{81.82}$ Another strategy establishes three-tiered drug cost sharing for prescription drugs (Short and Leser, 2002). Finally, employers may respond to rising health insurance costs by reducing non-insurance benefits. For example, businesses may cut back on benefits such as vacation time rather than reducing employment and/or hours. By offering less generous benefit packages, small businesses may be at a disadvantage in attracting skilled workers.

offering them in the next two years and 22 percent are somewhat likely to start offering them (Fronstin et al. 2003). However, the authors also report that 66 percent of small employers not offering benefits are not likely to offer them in the next 2 years.

${ }^{80}$ Small is defined as less than 50 employees (Short and Lesser, 2002).

${ }^{81}$ Gruber (2000) points out that traditionally small employers offer less generous plans.

${ }^{82}$ As discussed earlier, small businesses in some states may be mandated to cover particular services in plans offered. 
3.3 Increasing employee contributions towards premiums

While some employers may discontinue benefits or reduce the generosity of health plans offered, others may increase the employee's out-of-pocket expense of health insurance when faced with rising premium costs associated with escalating health care costs (Short and Lesser, 2002; Gabel and Pickreign 2004). ${ }^{83}$ According to a 2008 report by the Robert Wood Johnson Foundation, 36 percent of small companies ${ }^{84}$ (3 to 50 employees) stated that in the future they are likely to no longer pay for any portion of health insurance benefits for their workers. Increasing the employee’s financial burden for insurance can potentially lower their morale and reduce their work performance, hindering the ultimate growth and survival of a small business.

In 2000 and 2005, employees at smaller establishments actually contribute less for single coverage than employees at the larger firms in both levels and as a percent of premium costs (see Figures 3.1 and 3.2). Based on MEPS-IC data, the average total employee contribution for single coverage in establishments belonging to the smallest firms in 2005 are \$577 and \$657 for small firms with 10-24 employees. Average contributions in this same year for the largest firms are \$737, which is significantly greater than the contributions required in the smallest firms. ${ }^{85}$ As Figure 3.1 shows,

\footnotetext{
${ }^{83}$ By adopting this strategy, small employers may reduce participation rates in offered health plans below required minimums. Minimum participation rates may be required to reduce the risk of adverse selection and these rates can be required by insurers to ensure a large enough risk pool.

${ }^{84}$ Defined as 3 to 50 employees (Robert Wood Johnson Foundation, 2008).

85 This pattern also holds for 2000 and 2005 when small businesses with less than 50 employees are compared with those with 50 or more workers.
} 
employee contributions for single coverage increased from 2000 to 2005 across all firm sizes and increases for single coverage are smaller than the increases for family coverage.

Figure 3.2 shows the percent of the premium cost contributed by employees. In 2005, employees from firms with less than 10 workers and 10-24 workers contribute approximately 13 percent and 16 percent of premium costs for single coverage, respectively. In this same year, employees from establishments belonging to the largest firms contribute about 18.6 percent of the premium cost, which is significantly different from the percent contributed by employees in the smallest firms ${ }^{86}$ Figure 3.2 shows that the percent contributed by employees for single coverage remained virtually the same for the smallest and largest firm sizes from 2000 to 2005. Short and Lesser (2002) find that more small employers switch to a fixed dollar contribution towards premiums rather than contributing a percentage of the premium cost. With this approach, the employee is then picking up the burden of increases in the premium cost.

Contributions required may also vary by wages, which are generally lower in small firms. In both 2000 and 2005 and across all firm sizes, the MEPS-IC data shows the percent of the premium for single coverage contributed by employees in low-wage establishments is greater than the percent contributed by employees in high-wage establishments. ${ }^{87}$ The differences, however, grow smaller from 2000 to 2005 in the smallest firms (see Figure 3.3).

Though uncommon, a some small employers require little or no premium cost sharing from employees. Occasionally small employers may adopt this practice in order

\footnotetext{
${ }^{86}$ Again, this pattern holds for 2000 and 2005 and also when small businesses with less than 50 employees are compared with those with 50 or more workers.

${ }^{87}$ The 2003 report for the Small Business Administration shows this same pattern.
} 
to offer a competitive insurance program, to meet minimum participation requirements, ${ }^{88}$ to give employees the benefits of tax-sheltered compensation, and/or to avoid adverse selection concerns. Zawacki and Taylor (2005) find that small employers are far more likely than large employers to require no contribution towards the premium cost from employees. A very linear pattern is observed between firm size and establishments that offer insurance offering a plan requiring no employee contribution (see Figure 3.4). These patterns hold in both 2000 and 2005 and for both single and family coverage (AHRQ 2000 and 2005).

Employers may be more reluctant to change single coverage benefits, which may be workers' only source of coverage for themselves, than family coverage. In their study of smaller employers’ responses to increasing premium costs, Short and Lesser (2002) find that employers may eliminate family coverage when insurance costs increase. Other small employers may adjust their cost sharing for family plans. Figure 3.1 shows that the average total employee contribution for family coverage has increased considerably from 2000 to 2005 for all firm sizes. In establishments belonging to the smallest firms, the increase has been smaller than for all other firm sizes.

The percent of the premium cost for family coverage contributed by the employee in the smallest firms actually decreased significantly from 23.9 percent in 2000 to 19.7 percent in 2005 (See Figure 3.2). ${ }^{89}$ The decrease from 2000 to 2005 in the percent of establishments offering at least one plan requiring no employee contribution for family

\footnotetext{
${ }^{88}$ Insurers' minimum participation requirements may require a certain number of an employer's workers to enroll and may set employer contribution amounts (including no employee contribution) to help meet this requirement.

${ }^{89}$ In establishments belonging to firms with less than 50 employees (data not shown), MEPS-IC estimates show the percent of total premiums contributed by employees enrolled in family coverage at private-sector establishments remained the same at 27.6 percent from 2000 to 2005 . Using this definition for small firms, the percent contributed by employees in smaller firms dropped.
} 
coverage is greatest for those belonging to the smallest firms at almost 9 percentage points (see Figure 3.4). In contrast, the decrease is less than one half percentage points for establishments belonging to the largest firms (AHRQ 2000 and 2005).

While some employers may respond to rising health care costs by discontinuing direct offers of ESI, they may provide premium reimbursement. This compensates employees purchasing health insurance on their own rather than through a business. An employee might purchase non-group coverage or use the funds towards the premium cost of a spouse’s plan. In 2007, about 34 percent of small businesses dropping direct provision of benefits in the previous 3 years moved to premium reimbursement and about 10 percent of small employers offering health insurance offer premium reimbursement (Dennis 2007).

\subsection{Labor market responses}

Higher premium costs for employers offering insurance to employees raise the fixed costs of employment, and businesses can choose from among different strategies to cope with rising costs. As discussed earlier, economic theory posits that employers pass along the cost of health insurance to workers in the form of reduced wages. Since many small firms have a large proportion of low-wage workers, minimum wage constraints prevent the employer from reducing wages below a certain level. High premium costs, therefore, can potentially create a greater financial burden for low wage firms.

While reduced wages may be evidenced in the long run in firms of any size, rising costs may lead to changes in the labor market in the short run. With compensation costs 
representing a larger share of business expenses, owners may offset this by reducing labor inputs. For example, employers may decrease employment, have employees work more hours rather than increasing employment, use more part-time or temporary workers, and/or increase reliance on outsourcing. Baicker and Chandra (2005) show this using employer as well as household data. Findings indicate that rising premium costs affect both the number and structure of jobs, including reductions in employment and converting full-time workers with benefits to part-time status without insurance.

Since part-time and temporary employees are generally less likely to be offered or eligible for ESI (Morrisey et al., 1994), employers may react to rising health care costs by hiring more workers under part-time or temporary status. Baicker and Chandra (2006) find that a 10 percent increase in premiums increases the likelihood that a worker is employed only part-time by 1.9 percentage points. ${ }^{90}$ Buchmueller (1999) finds that firms that offer more generous fringe benefits make greater use of low wage part-time workers, while no significant relationship is found between these benefits and the proportion of high-wage workers employed part-time. Regarding temporary workers, 2.4 million people worked for temporary agencies in July of 2004, an increase of 9 percent from a year earlier according to the Bureau of Labor Statistics (Porter, 2004).

Since health insurance benefits are a fixed cost, some employers may react to rising health care costs by keeping the same number of employees but increasing the number of hours worked by employees. Cutler and Madrian (1998) found rising health insurance costs in the 1980s led to employees with health insurance working more hours. The authors also cite work by Ehrenberg and Schumann (1982) who find a 10 percent

\footnotetext{
${ }^{90}$ Buchmueller (1999) and Schultz and Doorn (2009) find similar patterns.
} 
increase in fringe benefit costs leads to a 5 to 17 percent increase in overtime hours per worker.

Another labor market approach that employers may adopt involves who they hire. As noted earlier, small employers may be reluctant to offer health insurance because premiums can vary greatly from year to year. Part of this variation may be attributable to the health status of their workers. Kapur (2004) notes that small firms may try to reduce premium variability by maintaining a workforce that is comprised of workers who have low expected health costs. If inquiries are related to a prospective employee's ability to perform a job, employers with less than 15 workers can inquire about employee health. Larger employers are unable to obtain this health information per the 1990 Americans with Disabilities Act. Evidence suggests small ${ }^{91}$ insured firms are less likely to employ workers with conditions likely leading to denial of insurance coverage or workers with families that had conditions that led to higher premiums compared to large insured firms (Kapur, 2004). Since decision making is quite centralized in a small business, Kapur notes that it is relatively easy for an entrepreneur to screen out individuals with high expected health costs. This hiring strategy may relate to findings cited earlier showing small businesses are more likely than larger businesses to have younger (i.e., healthier) or older (i.e., Medicare-eligible) workers.

\section{Wages and Health Insurance Offering}

Currie and Madrian (1999) provide a concise discussion on both the theoretical and empirical models of the relationships between health insurance and wage levels.

\footnotetext{
${ }^{91}$ Less than 25 workers (Kapur, 2004).
} 
Most models are done in a compensating differential framework. That is, firms compete for workers in a competitive market and provide a total compensation package (wages and benefits) that is high enough to attract workers but not so high that it drives the firm out of business. Because benefits are costly to the firm, the wages offered will be lower by the cost of the benefit to the firm. The end result is that firms competing in the same labor pool offer a spectrum of total compensation packages differing in their mixtures of wages and benefits - and firms offering higher benefits offer lower wages. Workers then sort themselves across the firms according to their wage and benefit preferences.

A number of explanations have been offered to explain the lack of empirical evidence for a wage-benefit tradeoff. The simplest is that it requires very specialized data to capture. Current empirical studies are forced to rely on proxies and estimates for several key variables, limiting their ability to capture the relationship. These studies have found either no evidence of a wage-benefit tradeoff or at best mixed results. ${ }^{92}$ The main evidence found in favor of the model is that changes in health insurance status may be correlated with changes in wages but Currie and Madrian (1999) raise concerns over their ability to control for serious simultaneity issues.

Similar difficulties have been faced in the pension literature and an alternative explanation borrowed from that literature is that while employees may be willing to accept wage reductions for more generous insurance packages, they would not be sympathetic to the idea of lowering their wages to offset higher administrative costs faced by the employing firm - and these costs are a major component of the total cost of insurance faced by particularly small employers. This would potentially drive a wedge

${ }^{92}$ Leibowitz (1983), Ehrenberg (1971), Buchmueller and Lettau (1997), Olson (1992), Miller (1995), Ryan (1997) 
between the costs paid by the firm for health insurance and the wage reduction accepted in the labor market.

An alternative explanation offered by Currie and Madrian for the positive correlation observed between wage levels and health insurance coverage is that some firms choose to employ higher ability workers and must pay a higher level of total compensation to attract and retain their workers. If the total compensation is split between wages and benefits, it would explain the positive correlation found in the empirical literature. We believe that it also provides a plausible explanation for many of our findings.

\subsection{Concluding Remarks}

The evidence presented in this chapter shows that small businesses may adjust their benefit offerings or their labor demand in response to rising health insurance premium costs associated with escalating health care costs. If the employer discontinues or decides not to offer insurance, or reduces covered benefits, or imposes more financial burden on the employee in the form of higher contributions towards premiums, this can result in the small business offering a compensation package that is less attractive than packages offered by large businesses. If small businesses increase their reliance of parttime workers or ask employees to work more hours, this may negatively impact on their performance and may reduce the probability that the small business will grow and survive.

Our empirical analyses help provide additional information on employer responses to rising health care costs both in how predicted premiums influence the 
decision to offer insurance benefits and changes in business performance. More specifically, performance is measured in our models using longitudinal data on size and payroll. Our study builds upon the existing evidence presented in this chapter on labor market responses by examining whether rising health care costs result in changes in size and payroll, while controlling for the employer's percent of workers who are part-time and workforce characteristics (e.g., percent of older workers, 50 years of age or older). 


\section{Growth and Survival of Small Businesses}

This chapter begins with a discussion of factors other than rising health care costs that often affect the growth and survival of a small business - and how our analyses try to control for these influences. In the following section of this chapter we look at the relationship between health insurance coverage and business performance. Since most businesses start out small, they warrant a separate discussion. The last section, therefore, presents evidence on the role of firm age.

\subsection{Business Environment}

A number of macro-patterns affected both business performance and the average likelihood of offering insurance. Perhaps the most obvious is the general strength of the economy, which was weaker due to the recession during our study period resulting in lower overall demand. The economic downturn may also have accelerated the decline of the manufacturing sector, which traditionally offered employees health insurance. Firms in the faster growing sectors of the economy, services and retail, are less likely to offer employees health insurance (Glied et al., 2003). Similarly, the erosion of unionization in the private sector from industry shifts and offshoring may have also impacted offers of ESI (Buchmueller et al., 2002 Fronstin, 2009). Finally, employee age affects their demand for health insurance (Currie and Madrian 1999) and the age distribution of the U.S. workforce has been changing as baby boomers age.

We focus on the period from 2001 to 2005, which includes the National Bureau of Economic Research-dated recession from March 2001 to November 2001. Davis et al. 
(2006) report that job creation rates ${ }^{93}$ began to slide in late 1999 before the recession began and continued a long downward slide until mid-2003, well after the end of the recession. In general, recessions have been characterized by increased job destruction and decreased job creation, particularly of less productive businesses (Davis et al., 1996; Davis and Haltiwanger 1999). The economic downturn early in the decade may have meant small businesses were struggling, growing slower and closing more often. ${ }^{94}$

Also, the economic downturn in 2001 is associated with slower job growth, but higher unemployment could have helped small businesses hire qualified workers. Using data from the Bureau of Labor Statistics to study job growth, Shierholz (2008) finds job growth was slower during the 2000s business cycle (i.e., only 0.6 percent per year) compared to an annual job growth averaging 1.8 percent during the $1990 \mathrm{~s}^{95}$ If businesses use insurance offering to lure better qualified, more productive workers, then the effects of the recession may have muted the differences in worker quality between businesses that offer insurance and those that do not.

Our analyses will include geography-based variables to control for a number of key effects. For example, we use state dummies to control for differences in local insurance requirements and regulations. We also use local employment growth and

\footnotetext{
${ }^{93}$ Davis et al. (1996) define gross job creation at time $t$ to be equal to employment gains summed over all plants that expand or start up between $t-1$ and $t$. The authors define gross job destruction at time $t$ as employment losses summed over all plants that contract or shut down between $t-1$ and $t$. Net job creation takes employment losses into account and equals the job creation rate minus the job destruction rate. ${ }^{94}$ A 2004 New York Times article discussing rising health insurance costs and the lack of job growth following the 2001 recession provides evidence of interest in this relationship. In this article, Porter provides examples from various business owners on their increased use of temporary workers and the reluctance to hire more workers due to health insurance costs. Based on interviews, Porter also points out that some industries with more generous benefits (e.g., manufacturing) than others (e.g., food service) may be more reluctant to invest in additional human capital and international competition may restrain capital investments.

${ }^{95}$ The author measures the 2000 cycle from March 2001 to December 2007 (presumed peaks in business) and the 1990 cycle from July 1990 to March 2001 (Shierholz 2008).
} 
unemployment rates at various points of our analysis. The potential influence from these factors are easy to illustrate. Unemployment statistics provide a good example of how the business environment at the local level can vary leading to possible effects on job creation and employer demand for workers. There are fairly persistent differences in unemployment rates across states and metropolitan areas and these differences could be due to a wide range of local labor market factors like, for instance, more recession-proof industry mixes. For example, Figure 4.1 shows the unemployment rates of the Detroit, Michigan and Bethesda, Maryland MSAs from 1991 to 2007. There is clearly a large, persistent difference between the unemployment rates in the two metropolitan areas. It ranges from $-1.1 \%$ to $-6.1 \%$ and averages $-3.4 \%$ over the period. We control for these types of factors by using local unemployment rates.

These persistent difference can also be observed at the state level. According to the Bureau of Labor Statistics, U.S. unemployment rose 1.2 percent from 2000 to 2005. While New York's unemployment rate during this time period rose less than the national average or 0.7 percent, Tennessee's unemployment rate rose 3 faster than New York's (by 2.2 percent). Business success also often depends on local demand for its products particularly for the retail and service sector. A recent study by Haltiwanger, Jarmin and Krizan (2010) showed that local market conditions (within 5 miles) were key factors to the success and survival of retail establishments. It is beyond the scope of this project to control for market forces at that level of detail. Instead, we use local employment growth as a proxy for changes in local economic conditions, particularly demand.

In addition to economic fluctuations and health care costs rising over the decades, the industrial characteristics of the economy have been changing. That is, the U.S. 
economy has been moving away from manufacturing and towards service industries. ${ }^{96}$ The MEPS-IC frame reflects this shift. According to estimates from the MEPS-IC, the number of establishments in mining and manufacturing dropped 10.5 percent from 2000 to $2005,{ }^{97}$ and the number of employees in this sector decreased almost 18 percent (AHRQ 2000 and 2005). In the past, establishments in the manufacturing sector have been more likely to offer health insurance than employers in most other sectors. ${ }^{98}$ This is true in 2000, when almost 78 percent of establishments in manufacturing offer health insurance but does not hold in 2005. In this year, wholesale trade takes the lead with almost 72 percent of establishments offering health insurance, compared to 70 percent of manufacturing establishments (AHRQ 2000 and 2005). In addition, Davis and Haltiwanger (1999) summarize various U.S. studies and find that rates of job creation (and destruction) are often much higher for non-manufacturing than for the manufacturing sector. Our empirical models will control for industry, which is particularly important given these changes in the economy.

The movement away from the manufacturing sector also impacts unionization, since union workers are more likely to work in this sector. Reduced unionization in the private sector impacts ESI offers because union workers are more likely to be offered benefits than nonunion workers (Buchmueller et al., 2002) and across all job characteristics (Fronstin, 2009). With respect to small firms, the Survey of Income and

\footnotetext{
${ }^{96}$ This is easily seen in any time series of industry employment shares. For example, according to County Business Pattern data, the share of manufacturing employment fell from about $16 \%$ in 1998 to about $11 \%$ in 2008. (see http://www.census.gov/econ/cbp/index.html)

${ }^{97}$ Davis et al. (1996) report that in 1988, manufacturing accounts for only 19 percent of U.S. employment.

${ }^{98}$ The shift away from manufacturing has been found to increase the share of uninsured in large firms (Glied et al., 2003).
} 
Program Participation shows that 70 percent of union workers in small firms ${ }^{99}$ had ESI in their own name in 2007, compared with 38 percent among nonunion workers in small firms (Fronstin, 2009).

Along with these changes in industrial sectors, many U.S. businesses may be outsourcing jobs to other countries to take advantage of less expensive manufacturing abilities. This may change the makeup of the U.S. workforce in these plants and the influence of unions. Evidence indicates that union-protected wages and benefits have eroded, especially for lower skilled industries (Econometrica 2007). Historically unionization was associated with a higher probability of insurance coverage (Buchmueller et al. 2002) and more generous benefits regardless of firm size. Table 2.5, however, shows establishments with union workers and belonging to the smallest firms saw a large and significant decrease from 2000 to 2005 in the percent offering insurance from 62.6 percent to 42.1 percent (AHRQ 2000 and 2005). Our study includes controls for whether or not the establishment is unionized to control for these effects.

Finally, the proportion of U.S. workers who are older (e.g., fifty years old or more) has increased (see Eberts and Hobbie, 2008 for a discussion of labor market trends), in large part by the aging of the baby boom cohort combined with increases in longevity. The U.S. saw a 101 percent increase in the employment of workers 65 years of age or older from 1977 to 2007, as well as an increase in the full-time work status of older workers (Bureau of Labor Statistics, 2008). Older individuals can be expected to have a higher demand for health insurance and while these individuals may be eligible for Medicare, many may also opt for ESI. Older individuals are associated with higher

\footnotetext{
${ }^{99}$ Less than 25 workers.
} 
healthcare costs. If a small business has primarily older workers this may lead to higher ESI costs than if they employed mostly younger, healthier workers. Our model will include a measure for the percent of the establishment's workers 50 years of age or older, since this may impact employee demand and an employer’s offers of insurance.

\subsection{Small business origination and health insurance}

Although business startups in the private-sector represent a small fraction of overall employment, they have been shown to be important for the creation of new jobs in the U.S. economy. From 1980 to 2005, new firms in the private sector account for about 3 percent of employment per year ${ }^{100}$ and these are all new jobs (U.S. Census Bureau, 2009a). 3 percent is large relative to the average annual net employment growth rate of about 1.8 percent for the entire private sector during this same time period (U.S. Census Bureau, 2009a). New or entrepreneurial firms have also been found to create positive externalities in the form of more employment in older, larger, incumbent firms (Van Praag and Versloot, 2007).

Little research has been conducted on the relationship between entrepreneurship and health insurance. Results to date from studies examining concerns about health insurance in the transition from employment to self-employment have been mixed (Holtz-Eakin, Penrod, and Rosen 1996; Wellington 2001). The 1993 National Employer Health Insurance Survey shows that of the 4.5 million self-employed individuals with no employees, most had health insurance coverage. 38 percent had

${ }^{100}$ This percentage can be interpreted as the employment-weighted startup rate for the United States (U.S. Census Bureau, 2009a). 
coverage through other employment-related sources mostly through a spouse and 28 percent directly purchased health insurance and 5 percent had coverage through a public source. The remaining 31 percent were uninsured (Allen and Park, 1999). ${ }^{101}$

An individual's age in addition to access to health insurance coverage may be very important when examining who starts a business and its relationship to health care costs. Based on the Kauffman Index of Entrepreneurial Activity, the 55-64 age group has the highest entrepreneurial activity from 2007 to 2008 (Fairlie, 2009). Insurance coverage can be particularly valuable to these older individuals who may incur more health care costs than younger, healthier individuals.

Because coverage is highly valued by older persons who may be in poorer health and incur more health care costs, they may be more likely to ensure they have coverage before venturing into starting a new business that can be fraught with business-related financial risks. This is perhaps borne out by (Fairlie et al., 2009) who show having spousal insurance coverage or Medicare eligibility is related to an increase in business ownership and individuals with spousal coverage are more likely to start a new business than individuals with their own employer insurance. ${ }^{102}$ Part of the explanation for these findings may relate to individuals not wanting to lose their own ESI or take on business ownership without health insurance because even COBRA coverage would eventually end. Other possible factors include the risk of incurring high health care costs if

\footnotetext{
${ }^{101}$ Forty-nine percent of respondents in a National Federation of Independent Business poll report providing insurance to give the owner the ability to obtain coverage through the business (Morrisey 2003). The poll also finds that if the owner has coverage, there is a fifty percent chance that the business will offer coverage to employees. If the owner does not have coverage, the business will almost never offer this benefit.

${ }^{102}$ The 1993 National Employer Health Insurance Survey also shows that 86 percent of the self-employed without employees who had other employment related insurance obtained coverage from their spouse's employment (Allen and Park, 1999).
} 
uninsured or they may not have coverage for pre-existing conditions or they may have to wait before eligible for coverage (Fairlie et al., 2009).

The self-employed are less likely to have health insurance than wage/salary, unemployed, and part-time workers (Fairlie et al., 2009). High heath care costs can lead to prohibitively high premium costs in the individual market, which may be the only viable source of coverage for some self-employed persons who may not have spousal coverage. As health care costs rise, this can only lead to even higher coverage costs for the self-employed, possibly affecting the growth and survival of their business venture.

Lower cost insurance options introduced in recent years (e.g., consumer-directed health plans, health savings accounts), and greater tax deductibility for premium costs, however, may help increase coverage for the self-employed. In 2003, self-employed individuals could begin deducting 100 percent of the health insurance premium costs from their taxes, previously in 1996 they could only deduct 30 percent. Selden (2009) shows that this change increased private insurance coverage from 1.1 to 1.7 million selfemployed workers and their spouses. In addition, this tax advantage has been shown to affect the survival of the business. Gurley-Calvez (2006) finds that even the original legislation establishing the tax subsidy at only 25 percent for the self-employed positively affected entrepreneurial survival.

While the focus of this monograph is to study the effect of health care costs proxied using insurance offers on the growth and survival of small businesses, it is interesting to look at the relationship between health insurance and the hiring of workers 
by the self-employed. ${ }^{103}$ While more recent business data may reveal different trends, household data from the 1993-1995 Survey of Income and Program Participation shows that if the self-employed business owner is insured, he is 11 percent more likely to employ 2 workers, 22 percent more likely to employ 3-5 workers, and 36 percent more likely to employ 6 or more workers (Mathur, 2008). ${ }^{104}$

4.3 Job growth and survival of young and small businesses

As noted earlier, young businesses are usually small - but small businesses are either very young or very old (Haltiwanger, et al. 2009). Young firms are more likely to close than are older firms but if they survive, young firms have higher employment growth rates (U.S. Census Bureau, 2009c). Our computations using the Census Bureau's Business Dynamics Statistics data show that establishments belonging to firms less than 1 year old have a net employment growth rate of 15 percent conditional on survival compared to 4 percent for continuing firms 29 years of age or older. ${ }^{105}$

In our models analyzing the growth of small businesses, we include controls for both the size and age of the firm. Both variables, and their interactions, have been shown to be strongly correlated with business performance. For example, Davis et al. (1996) find smaller businesses show higher gross job creation rates, while larger employers have

\footnotetext{
103 Extensive discussion of the self-employed is out of scope for this monograph. Also, many selfemployed do not migrate to being employers (Davis et al., 2009).

${ }^{104}$ The study also finds that the self-employed are at the peak of their ability to create jobs at age 50 and the self-employed in manufacturing and construction sectors are more likely to create jobs than those in personal services.

${ }^{105}$ Similar findings are reported by Haltiwanger, et al. (2009), National Research Council of the National Academies (2007), and Bartelsmann et al. (2005).
} 
higher net job creation rates. ${ }^{106}$ Similarly, Haltiwanger and Krizan (1999) show that young establishments exhibit high average net employment growth rates and high volatility of growth rates relative to large, mature establishments. They also find that among young establishments, net employment growth rates do not exhibit any systematic patterns by size while among mature establishments, net employment growth increases with size. Also, Luque (2002) finds that small, young plants are more likely to adopt new technologies relative to small, old plants. More recently, Haltiwanger et al. (2009) used the Census Bureau’s Business Dynamics Statistics, based on the 1976-2005 Longitudinal Business Database, and found no systematic relationship between firm size and growth after controlling for firm age. That is, there was no evidence of an inverse relationship between growth and size.

They also report evidence of an "up or out” pattern among new businesses where up to 40 percent of new firms disappear but those that do not grow rapidly. They argue that these are indications of learning effects in new businesses. Similar patterns have been found in other studies. For example, several studies (Bartelsman and Doms 2000; Foster, Haltiwanger, and Krizan 2002) have found that less productive and less profitable businesses tend to exit, while more productive, more profitable businesses are more likely to survive and expand. Such productivity (and presumably profitability) differences may be correlated with businesses' likelihood of offering health insurance. That is, better performing establishments may be more likely to offer insurance and doing so may make them even more productive if it makes their employees more motivated or healthier.

\footnotetext{
${ }^{106}$ Some publications interpret data to show small businesses create more jobs. See Davis et al. (1996) for a discussion of the statistical concerns with some of these estimates.
} 
Concerns about such endogeneity motivates our use of an instrumental variables model in the following section.

If, because of tax differences, offering insurance is less expensive than offering equivalent wage increases, it could be a way for small businesses to compete for workers. However, as discussed earlier, small firms tend to have lower wages than large firms which may make it more difficult for them to compete for top quality workers in the labor market. If small firms can only hire lower quality workers, it could negatively affect their productivity and lower their probability of growth and survival (Brown and Medoff 1989).

Finally, we note that as the size and age of a business increases, its chances of survival increase. Newly created jobs have been shown to be more likely to survive or persist at larger employers and establishments belonging to multi-unit firms (Davis et al. 1996) while plant failure rates and growth rates for surviving businesses decline with size and age (Dunne et al. 1989). As an illustration we offer Perline et al. (2006) results on establishments surviving from 1998 to 2003. They provide the following partial distribution of survival rates over the 5-year period: 1 -person: 61.4 percent; 2-3 employees: 70.1 percent; 4-7 employees: 75.3 percent; 512-1,023 employees: 84.2 percent.

\subsection{Concluding Remarks}

The growth and survival of a small business may be affected by a multitude of factors, both macro and micro. While job creation declines during recessionary periods 
such as our study period, there is also substantial evidence that age and size are strongly correlated with business performance. We attempt to control or account for many of these factors in our empirical work.

We also note that between 2001 and 2005 health insurance costs grew substantially. By definition small businesses also constitute small individual insurance risk pools. A single sick employee can influence the premiums faced by the entire firm while large employers' rates would be affected much less. Given the continued aging of the U.S. workforce, this may further reduce small businesses ability to offer their employees insurance they could realistically afford. ${ }^{107}$

\footnotetext{
${ }^{107}$ It is beyond the scope of this manuscript to analyze how ACA will change the ability and probability of small businesses to offer health insurance to their employees.
} 


\section{Data}

As mentioned in the introduction, in this project we plan to link two unique datasets not publicly available: the Longitudinal Business Database (LBD) from 2000 to 2005, and the 2001 Medical Expenditure Panel Survey-Insurance Component (MEPSIC). These linked data allow us to move beyond the limitations faced by others in studying the effect of health insurance offering on small businesses.

\subsection{The Longitudinal Business Database}

The LBD covers virtually all non-farm private sector establishments and firms with employees. It is composed of annual files for the years 1975 through 2005 that are linked together by an establishment identifier. ${ }^{108}$ To improve the linkages and reduce spurious plant births and deaths, Jarmin and Miranda (2002) supplemented the longitudinal numeric identifiers assigned by the Census Bureau with name and address matching to repair broken linkages. Each annual file has information on about 7.5 million establishments, making a total of over 232 million observations.

The LBD’s data items come from the Business Register, which gets information from administrative record sources including the Internal Revenue Service and the Social Security Administration. For our purposes, the LBD’s key data items include employment, payroll, location, industrial activity and firm affiliation. In particular, we use the longitudinal nature of the LBD to calculate our dependent variables (i.e., growth

\footnotetext{
${ }^{108}$ An establishment refers to the physical location where business activity takes place. A firm is comprised of one or more establishments under common ownership.
} 
measures and business survival). While the LBD is useful as a stand-alone research dataset, it can be used in conjunction with other Census Bureau establishment and firm level micro data. The LBD contains a key numeric identifier that allows it to be linked to all the Census Bureau’s censuses and surveys over time, including the MEPS-IC.

The firm identifiers combined with the LBD’s coverage of all non-agricultural sectors of the economy allows researchers to construct firm-level data by aggregating the information on all the firms' individual establishments under the firm-level identifier. That means we can calculate the firms' number of establishments or age, allowing us to construct firm as well as establishment level variables. It is easy to imagine that, for instance, two restaurants with otherwise similar characteristics may behave differently if one is independent while the other is part of a large multiunit (MU) firm. Table 5.1 illustrates the layout of the LBD data. ${ }^{109}$

The table shows several important characteristics of the LBD. First, as mentioned above, there are both establishment and firm identification variables that allows us to construct firms from the establishment-level data. For example, in 2000 firm number 10001 has 3 separate establishments making it a multi-unit firm. Note also that in 2001 it has added a fourth establishment. By contrast, in the year 2000 there are two single unit establishments (Firm IDs 10002 and 10003). In the next year firm number 10002 has ceased operations but another small single-unit firm, number 10004 has entered the market. A second property of the LBD illustrated by Table 5.1 is the ability to calculate employment changes for both establishments and firms. In the year 2000 firm number

\footnotetext{
${ }^{109}$ All the figures and identifiers presented in tables illustrating the LBD are fictional. However, they illustrate important aspects and attributes of the LBD.
} 
10001's establishment number 0001 had 15 employees but by 2001 it had added two people for a total employment of 17 .

While firm affiliation is an important factor when considering an establishment's size, it is also important when considering its likelihood of growth and survival. For example, while most research has shown that young establishments are more likely to shrink or fail than are older ones, it is unlikely that a brand-new national chain restaurant, with completely updated technology, is at a disadvantage when compared to the 20 year old diner it is located next door to.

To further illustrate the types of results that can be obtained from the LBD, Table 5.2 shows net job growth rates and firm and employment shares for firms by size class. Several interesting, previously documented, patterns emerge. First note that there are far more small firms than large firms in the economy yet they account for a far smaller share of employment. Next, it is clear that the net employment and growth rates in the number of firms differ by size category. Employment growth is highest among small firms for the 2000-2005 period (likely because of the recession in the midst of the period). Large firms lost employees on net during the 5 year timeframe. On the other hand, the number of large firms increased by 14 percent compared to only 4 percent for small firms. Finally, note that Table 6 is performed at the firm level. It is also possible (in fact more traditional) to perform the same exercise at the establishment level and also by other categories such as age, multi-unit/single-unit, and insurance offerings. 


\subsection{Medical Expenditure Panel Survey - Insurance Component}

The MEPS-IC has been collected since 1996. Each year of the MEPS-IC samples a representative cross-section of establishments across size and industry classes and provides cross-sectional information on health insurance premium costs and a longitudinal measure of whether establishments discontinued their health insurance offering during the last five years. The MEPS-IC is an annual survey sponsored by the Agency for Healthcare Research and Quality and collected by the U.S. Census Bureau. This survey permits national and state-level estimates and provides data on health plan information, establishment characteristics, and workforce characteristics.

All establishments in the MEPS-IC sample are asked whether or not they offer health insurance. Data is also provided on worker out-of-pocket costs for employee contributions, deductibles, co-payments, and coinsurance. If an employer does not offer insurance benefits, data is collected on a reduced number of items describing their establishment and workforce characteristics. If the employer does make health insurance benefits available, the MEPS-IC provides information on up to four health plans offered by the establishment. Data is contained on premium costs for single and family coverage, enrollment, and type of provider arrangement (i.e., exclusive, any, or mixture of providers). For example, Table 5.3 shows the change from 1996 to 2004 in premium costs faced by establishments of different sizes. The smallest businesses have both higher premium costs as well as bigger cost increases. 
The sample for the MEPS-IC is drawn from the Business Register and can be linked using establishment identifiers to the LBD, which (as mentioned above) is also constructed from the Business Register.

\subsection{Analytical Dataset}

We focus on the 2001-2005 period since the 1990s were a period of considerable federal and state reforms such as guaranteed coverage and rate restrictions (GAO, 2000; Glover et al., 2000) introduced to increase health insurance availability. In addition, 2005 was the last year where LBD data was available at the time our analysis was conducted.

To construct our analytical dataset, we first linked 2001 MEPS-IC establishments to the 2001 LBD using the numeric establishment identifier contained in both files. We successfully linked 27,595 establishments out of the 29,107 contained in the 2001 MEPS. We then keep firms with more than 1 employee to ensure no self-employed firms are included in the sample resulting in an analytical dataset of 24,545 MEPS 2001 establishments. In our growth regressions, we use "continuers"; that is, establishments that we can observe in both 2001 and 2005 (a total of 19,695 establishments). In our survival analysis, our sample consists of 2001 MEPS establishments that are then "followed" through time and can be observed up to 2005. Some of these establishments survive the entire 4-year period while others do not. 


\subsection{Concluding Remarks:}

We link two unique micro datasets not publicly available: the LBD and the MEPS-IC. The LBD is a longitudinal dataset providing us with business growth measures and survival while the MEPS-IC provides detailed information on insurance coverage, premium costs and workforce characteristics. These linked data allow us to move beyond the limitations faced by others in studying the effect of offering health insurance on small businesses. 


\section{Methodology}

The next two sections cover our empirical methodology in estimating the effects of health insurance offering on the performance of small businesses. This first part details our methodology, and the second our models. Our main obstacle is the previously mentioned endogeneity between offering insurance and performance. The issue is somewhat complicated by the dichotomous nature of health insurance offering.

\subsection{Endogeneity}

Our primary research question, "How does offering health insurance affect the performance of small firms?” is plagued with endogeneity issues, and therefore, it is crucial we exercise care to avoid confusing observed correlated outcomes. It may be that only successful firms offer insurance (perhaps as part of an efficiency wage) and/or it may also be that offering insurance affects firm performance perhaps for the better - via employee health and moral - or for the worse - because of the high costs of providing it. When we observe a poor performer not offering health insurance at a given point in time, is it the case that the slow or negative growth led the firm to stop offering health insurance? Or is the fact that the firm did not offer health insurance one of the factors that led to the poor performance of the firm?

Thus, the question at hand is a good candidate for a treatment effects model. Such models measure the impact of a change or "treatment" on agents such as people or businesses. The ideal way to measure those effects is to observe the subject at a single point in time as both treated and untreated - but of course this is impossible to do. We do not have information on the subjects' state both with and without treatment. Given that, 
one way to interpret the experiment is as a problem of missing data. Researchers such as Heckman $(1992,1997)$ have done just that and developed several methodologies to proxy for the missing information. Wooldridge $(2002,2009)$ provides an excellent overview of some of the more popular methodologies and we rely heavily on his work for the following discussion.

According to Wooldridge (2002), ${ }^{110}$ treatment effects models often focus on measuring either the "Average Treatment Effect” (ATE) or the “Average Treatment Effect on the Treated" $\left(\mathrm{ATE}^{1}\right)$. The ATE is the expected outcome of the treatment on a randomly drawn person from the population while the $\mathrm{ATE}^{1}$ is the mean effect for those who actually participated in the program. We follow Wooldridge's notation and define the outcomes of the untreated and treated groups as $\mathrm{y}_{0}$ and $\mathrm{y}_{1}$ respectively, $\mathbf{x}$ as a vector of covariates, and $w$ as a binary treatment indicator where $w=1$ is the treated and $w=0$ is the untreated group. Then we can write the ATE as:

$$
\mathrm{ATE}=\mathrm{E}\left(\mathrm{y}_{1}-\mathrm{y}_{0}\right)
$$

And the observed outcomes can be written as:

$$
\text { (1) } \quad \mathrm{y}=(1-w) \mathrm{y}_{0}+w \mathrm{y}_{1}=\mathrm{y}_{0}+w\left(\mathrm{y}_{1}-\mathrm{y}_{0}\right)
$$

If the treatment is randomized across the population, the ATE could be measured by simply subtracting the mean of the untreated from the mean of the treated group but treatment is rarely randomized. In fact, there is almost always self-selection into treatment so researchers must get around the problem by making an assumption to help identify the effects of interest. One of the most common assumptions, "ignorability of treatment” was introduced by Rossenbaum and Rubin (1983). They defined it as:

\footnotetext{
${ }^{110}$ Just Wooldridge from this point on.
} 
Conditional on $\mathbf{x}$ :

$w$ and $\left(\mathrm{y}_{0}, \mathrm{y}_{1}\right)$ are independent.

Or, in a weaker, conditional mean independence form:

$$
\begin{gathered}
\text { (A) } \mathrm{E}\left(\mathrm{y}_{0} \mid \mathbf{x}, w\right)=\mathrm{E}\left(\mathrm{y}_{0} \mid \mathbf{x}\right) \\
\text { and } \\
\text { (B) } \mathrm{E}\left(\mathrm{y}_{1} \mid \mathbf{x}, w\right)=\mathrm{E}\left(\mathrm{y}_{1} \mid \mathbf{x}\right)
\end{gathered}
$$

Wooldridge’s intuitive explanation for the ignorability of treatment is: “...if we can observe enough information (contained in $\mathbf{x}$ ) that determines treatment, then $\left(\mathrm{y}_{0}, \mathrm{y}_{1}\right)$ might be mean independent of $w$, conditional on $\mathbf{x}$. Loosely, even though $\left(\mathrm{y}_{0}, \mathrm{y}_{1}\right)$ and $w$ might be correlated, they are uncorrelated once we partial out $\mathbf{x} .{ }^{\prime 111}$

Most parametric approaches to the problem begin by separating the two types of outcomes into separate decompositions of mean and random effects. That is:

$$
\begin{aligned}
& \mathrm{y}_{0}=\mu_{0}+0, \quad \mathrm{E}\left({ }_{0}\right)=0 \\
& \mathrm{y}_{1}=\mu_{1}+1, \quad \mathrm{E}\left({ }_{1}\right)=0
\end{aligned}
$$

When we plug these expressions into equation (1) then we get:

$$
\text { (2) } \quad \mathrm{y}=\mu_{0}+\left(\mu_{1}-\mu_{0}\right) w \quad 0+w\left(\begin{array}{ll}
1- & 0
\end{array}\right)
$$

If the ignorability of treatment assumption is valid, then Wooldridge suggests two popular regression approaches from the literature. The first he calls a "kitchen sink" or "saturated model" approach which is to add enough controls in $\mathbf{x}$ so that w and $\left(\mathrm{y}_{0}, \mathrm{y}_{1}\right)$ are "appropriately unrelated". That is, use x to proxy for the unobservables correlated with $w$ that affect $\left(\mathrm{y}_{0}, \mathrm{y}_{1}\right)$. He also notes that even when measuring ATE, it is important to exclude classes of agents that would never realistically be expected to participate in

\footnotetext{
${ }^{111}$ Wooldridge (2002) p. 607.
} 
treatment. That is, millionaires would never realistically participate in a program to retrain unemployed persons as bookkeepers.

The second approach is the propensity score method based on Rosenbaum and Rubin (1983). The propensity score method models the probability of treatment given the covariates. That is, $\mathrm{p}(\mathbf{x})=\mathrm{P}(\mathrm{w}=1 \mid \mathbf{x})$ where $\mathrm{p}(\mathbf{x})$ is the response probability for treatment. As with the kitchen sink approach it is important to exclude the units that have very little chance of receiving treatment when calculating the propensity score. Rosenbaum and Rubin (1983) suggest using a flexible logit model featuring a robust set of covariates, interactions, and quadratics to estimate the propensity score. Once calculated, the propensity score is often included as a regressor in a separate model where it serves as a summary control function for the nonrandom selection effects.

This approach shares many similarities to the kitchen sink model and Wooldridge points out that if you estimate the propensity score with a linear probability model instead of a logit, the results are identical to those obtained with the saturated model. On the other hand, the two approaches are different in the assumptions they require for consistency so that neither clearly dominates the other - although Wooldridge does express a preference for the linearity assumption of the standard regression model by the end of his discussion.

Both the kitchen sink model and the propensity score approach depend on the ignorability of treatment assumption. If that assumption is violated, as in our case, then neither method is appropriate. Because of the endogeneity between health insurance offering and business performance, we cannot simply condition on a set of covariates to make the treatment (offering health insurance) and outcome variables (growth, survival) 
independent of one-another. This problem also precludes us from using a difference-indifference approach.

Instead we adopt an instrumental variables approach that is slightly different from the conventional case because of our binary endogenous regressor. Following Wooldridge, we assume the existence of an instrument instead of assuming that ${ }_{0}$ and 1 are mean independent of $w$ given $\mathrm{x}$ (assumptions (A) and (B) above). According to Wooldridge, if we can assume that $\mathrm{ATE}=\mathrm{ATE}^{1}$, then we can use standard IV techniques under “fairly week assumptions”. Specifically, we need to assume:
(A) $\quad 0 \quad 1$
(B) $\mathrm{E}\left(0_{0} \mid \mathbf{x}, \quad \mathrm{L}\left(0_{0} \mid \mathbf{x}\right)\right.$
(C) $\mathrm{P}(\mathrm{w}=1 \mid \mathrm{x}, \mathrm{z}) \wedge=\mathrm{P}(\mathrm{w}=1 \mid \mathrm{x})$ and $\mathrm{P}(\mathrm{w}=1 \mid \mathrm{x}, \mathrm{z})=\mathrm{G}(\mathrm{x}, \mathrm{z} ; \quad)$
where $\mathrm{G}$ is a known parametric form, usually a probit or logit.
(D) $\quad \operatorname{ar}\left({ }_{0} \mid \mathrm{x}, \mathrm{z}\right)=\sigma_{0}^{2}$

As mentioned above, condition (A) is met if $\mathrm{ATE}=\mathrm{ATE}^{1}$. In our case this seems reasonable if we can provide an adequate set of controls such as industry, firm age, etc.. Conditional on such controls, there is little reason to suspect that the effects of HIO will be different for the establishments offering it and the population of businesses in general. Assumption (B) holds if the instrument, $\mathrm{z}$, is independent of $\left(\mathrm{y}_{0}, \mathbf{x}\right)$. It also assumes that $\mathrm{E}\left(\mathrm{o}_{0} \mid \mathbf{x}, \mathrm{z}\right)$ is linear and does not hold for non-linear models. For this reason we will use a linear probability model rather than a probit or proportional hazard model for our survival analysis. Assumption (C) is fairly standard and says that $\mathrm{z}$ has predictive power in the linear projection on $(\mathbf{x}, \mathbf{z})$ and we test this assumption in our results section. Finally, assumption (D) implies that the variance is constant. 
According to Wooldridge, given these four fairly weak assumptions, we can use the following “2-step” (really 3 steps) estimator, which he labels “Procedure 18.1”: Step 1: $\quad$ Estimate the binary response model $\mathrm{P}(\mathrm{w}=1 \mid \mathbf{x}, \mathbf{z}) \quad(\mathrm{x}, \quad, \quad)$ by maximum likelihood (usually a probit) and obtain the fitted probabilities G-hat.

Step 2: $\quad$ Begin IV/ 2SLS estimation using the fitted probabilities from the first step in the first stage of the 2SLS regression.

Wooldridge stresses that this is NOT the same as using the fitted probabilities in (a) as the first stage of 2SLS. However, when properly done, the estimator has several advantages. First, the usual 2SLS standard errors and test statistics are asymptotically valid. Also, the estimator is asymptotically efficient in the class of estimators where the IVs are functions of $(\mathbf{x}, \mathbf{z})$.

Perhaps most importantly though, he notes that ${ }^{112}$ Procedure 18.1 has an important robustness property. Because we are using $\mathrm{G}_{\mathrm{i}}$-hat as an instrument for $w_{\mathrm{i}}$, the model $\mathrm{P}(\mathrm{w}=1 \mid \mathbf{x}, \mathbf{z})$ does $n o t^{113}$ have to be correctly specified. For example, if we specify a probit model for $\mathrm{P}(\mathrm{w}=1 \mid \mathbf{x}, \mathbf{z})$, we do not need the probit model to be correct. Generally, what we need is that the linear projection of $w_{i}$ onto $[\mathbf{x}, G(\mathbf{x}, \mathbf{z}, \quad$ ) actually depends on $G(\mathbf{x}, \mathbf{z}, \quad)$, where we use to denote the plim of the maximum likelihood estimator when the model is misspecified (see White 1982a). These requirements are fairly weak when $\mathrm{z}$ is partially correlated with $w .{ }^{114}$ As he notes:

\footnotetext{
${ }^{112}$ Wooldridge (2002) pages 623-24.

${ }^{113}$ His emphasis

${ }^{114}$ Our emphasis
} 
Technically, $\alpha$ and $\beta$ are identified even if we do not have extra exogenous variables excluded from $\mathbf{x}$. But we can rarely justify the estimator in that case... ${ }^{115}$

Because of this, we have a great deal of latitude in our choice of instruments for HIO. We do not need to correctly specify our first probit model, all we need is for there to be partially correlation between our instrument and HIO for the IV procedure to work. Or, in his words: ${ }^{116}$

In summary, using fitted probabilities from a first-stage binary response model, such as probit or logit, as an instrument for $\mathrm{w}$ is an nice way to exploit the binary nature of the endogenous explanatory variable.

\subsection{Modeling}

Following Wooldridge (2002), we use a "2SLS” approach comprised of 3 equations:

(3) $P(\text { offer })_{i}=G_{i}=Z_{i}+\boldsymbol{\beta}^{1} \mathbf{X}^{1}{ }_{i}+\mu_{i}$

(4) $P\left(\right.$ offer $_{i}=G_{i} \quad$-hat $1_{i}+\boldsymbol{\beta}^{2} \mathbf{X}_{i}^{2}+\gamma_{i}$

(5) $\mathrm{Y}_{\mathrm{i}} \quad$-hat2 ${ }_{\mathrm{i}}+\boldsymbol{\beta}^{3} \mathrm{X}^{2}{ }_{\mathrm{i}}+{ }_{\mathrm{i}}$

Where $\mathbf{Z}_{\mathrm{i}}$ is a vector of instruments and $\mathbf{X}_{\mathrm{i}}^{\mathbf{1}}$ is a set of control variables. Equation (3) is estimated using a probit and its predicted probabilities, G-hat $1_{\mathrm{i}}$, are used as regressors in equation (4) - which is estimated via Ordinary Least Squares (OLS). Finally, equation 4's predicted probabilities, G-hat $2_{\mathrm{i}}$, become the final estimated probabilities used in the equations of $\mathrm{Y}_{\mathrm{i}}$ - firm performance (5).

As our literature review showed, developing a model, particularly an empirical model for Equation (3) - a businesses' decisions to offer health insurance - is far from

\footnotetext{
${ }^{115} \alpha$ and $\beta$ are the model's parameters. Page 624 .
}

${ }^{116}$ Wooldridge (2002) page 625. 
trivial. Some of the best work in this area has been done by Feldman, Dowd, Leitz, and Blewett (1997) and was subsequently modified by Nichols, Blumberg, Cooper, and Vistnes (2001). Their methodologies start with the assumption that firms' decisions to offer health insurance is based on their need to offer a cost-minimizing combination of wages and benefits that maintains employees' utility at a high enough level to allow them to be competitive in the labor market. The solution to the firm's problem generates an inverse demand function for insurance and firms will offer insurance if the price is less than its reservation price for a relatively parsimonious wage/benefit package.

Nichols et al. (2001) begins with the following description of workers' demand for health insurance where worker demand for health insurance is $\mathrm{HI}^{\mathrm{dw}}$, WP is the net (relative) price of health insurance to the worker, B is the benefits and cost sharing package offered by the firm, $\mathrm{s}$ is the employer's share of the premium $\mathrm{P}, \mathrm{T}$ is the sum of the worker's marginal tax rate (federal, state, and workers payroll), and $w$ is the net reduction in wages the worker must accept to get the employer to offer the insurance.

(6) $\mathrm{HI}^{\mathrm{dw}}=\mathrm{f}(\mathrm{WP}, \mathrm{V}(\mathrm{B}))$,

where

(7) $\mathrm{WP}=(1-\mathrm{s}) \mathrm{P}+(1-\mathrm{T}) \mathrm{W}$

They go on to note that according to (Pauly 1998), economists have not developed a well-accepted theory of how firms aggregate worker preferences and their willingness to forego wages into firms’ health insurance purchase decisions. Nevertheless, Nichols et al. (2001) offer the following “reasonable” demand/probability of offer equation:

(8) (offer) ( $\mathrm{P}, \mathrm{HI}^{\mathrm{dw}}$, SIZE, COMPETITION) 
where FP is the firm's price of health insurance, SIZE equals firm size, and

COMPETITION refers to pressures faced by the firm to offer health insurance in order to remain competitive in the market for workers. This variable could be proxied by anything from labor market tightness to workers' mobility to transfer among firms (because of unionization).

The firm's price of health insurance is a function of both administrative costs and how much they can offset it with wage cuts. Wage flexibility is related to the degree of the proposed wage cut (the premium) and also on the workers' willingness to accept wage reductions at all. They point out the wage distribution as a particularly important determinant of wage flexibility since higher wage workers face a higher marginal tax rate and also because health insurance is a normal good, $V(B)$ is higher for higher wage workers. Finally, worker willingness to pay reduced wages for health insurance is also determined by demographic factors that affect health insurance use - and need.

Firm size is included because insurance rates are lower for large firms because of lower administrative costs and a bigger pool of workers to spread risk over for insurers. Nichols and Garrett (1999) make the important point that because total insurance premiums for workers at small firms are more than those at large firms, small firms operating in the same labor market as large firms must either bear part of the cost of providing health insurance themselves or provide workers with additional compensating differentials to remain competitive in the market for workers. 


\subsection{Selectivity and Final Algorithm}

We need information on the price of health insurance for all firms in order to estimate equation (8) but we can observe it only for those firms that actually make the offer. If we were to include only data on firms offering insurance our estimates would be biased (Kennedy (2008)) so we follow Feldman et al. (1997) and Nichols et al. (2001) and use a

five step process to estimate a firm's probability of offering health insurance where steps 1-3 are essentially Heckman's correction for selection bias. In our case we also include our instruments (discussed below) in step (5) in order to begin the 3-step "2SLS" estimation technique outlined by Wooldridge. Therefore our entire empirical procedure, incorporating corrections for selectivity on insurance prices and endogeneity between measures of firm performance and HIO can be summarized as:

(1) Estimate a reduced form probability of offer equation which does not include premiums as explanatory variables since they are not observable for the firms that do not offer insurance.

(2) Calculate self-selection terms for offering and non-offering firms

(3) Estimate a premium or supply price equation for the offering firms using the selfselection term as an explanatory variable

(4) Predict premiums for all firms using the ratio of the selection terms and the results from (3)

(5) Estimate a probit equation of the probability of offering health insurance for all firms using the predicted premiums and state dummies as instruments as well as control variables (described below). 
(6) Use the predicted values for HIO probabilities as the next stage in our "2SLS" estimation: an OLS regression of HIO probability on our control variables from (7) below.

(7) OLS regression of firm performance on control variables and predicted HIO from (6).

We use Stata 2SLS estimation to estimate steps (6) and (7) above in order to obtain correct standard errors.

\subsection{Empirical Implementation}

Our first four steps follow Nichols et al. (2001) but we diverge from them for the remaining steps. We begin by specifying the reduced form offer equation as:
(9) (offer)
$\left(\begin{array}{ll}\mathbf{X} & \mathrm{e}\end{array}\right)$

where $E(e)=0$, and $\mathbf{X}$ is a vector of both supply and demand-side variables including: State-specific dummies to control for state-specific benefit mandate and regulatory heterogeneity, as well as economic and health infrastructure differences; establishment size variables to capture underwriting effects related to insurance group size and the economic performance of the location; firm size dummies to proxy for economic performance and overall insurance pool size; multi-unit dummy; a measure of the percent of the workforce that is union as a proxy for the collective bargaining power of the workforce, and possibly labor mobility; firm age; industry; legal form of organization of the business; worker demographics (shares of full-time, female, and older workers) which are associated with workers’ demand for health care and insurance and therefore both 
their willingness to trade wages for health insurance and the characteristics of the benefits package; dummies for whether or not the percent of low wage (below $\$ 6.50 / \mathrm{hr}$.) is above or below half, less than ten, or somewhere in-between; measures of county-level economic factors that could affect labor market conditions including: the lagged unemployment rate, the share of manufacturing firms, and the share of employment accounted for by big firms.

The results from the probit are used to calculate self-selection terms which are included in the premium equation:

$$
\ln (\text { premium })_{\mathrm{p}}=\mathrm{S}_{\mathrm{ps}} \quad \mathrm{p}-\mathrm{o} \quad \mathrm{p}
$$

The unit of observation for (10) is health insurance plans and $\mathrm{S}_{\mathrm{ps}}$ is the subset of supplyside controls from equation (9). It includes everything except for firm size and unionization which are assumed to affect only the demand side. $Q_{p}$ is the benefits package supplied by the firm and it includes information on factors that affect the premium such as whether or not the plan is self-insured, whether the establishment is part of a multi-employer purchasing arrangement, whether the plan is an HMO, PPO, etc., the deductible, prenatal and maternity care, prescription benefits etc. ${ }^{117}$ inally, o is the selection correction term for offering firms.

Once the equation is estimated, we calculate a dollar premium that can be used as one of the instruments in step (5), the first stage in our 3-step estimation. We also include the state-specific effects in this first stage but not in the remaining two equations. Both should be correlated with HIO. Premium prices are a key determinant of the offering decision and we now have estimated premiums for all (both offering and non-

117 See Nichols et al. (2001) for a complete description of the variables included. 
offering) establishments. And, as Nichols et al. (2001) note, state regulatory, infrastructure, and economic environments affect HIO decisions. Furthermore, neither is likely to be correlated with the error term.

Explicitly, our covariates for the probit equation in step (5) include our predicted premium and state dummies as instruments as well as a variety of control variables; namely, firm size, a multi-establishment firm indicator, union indicator, firm age, industry dummies, legal form of organization of the business; worker demographics (shares of full-time, female, and older workers); dummies for whether or not the percent of low wage is above or below half, less than ten, or somewhere in-between; measures of county-level economic factors that could affect local labor market conditions including: the lagged unemployment rate, the share of manufacturing firms, and the share of employment accounted for by big firms.

\subsection{Specifications}

In our final step, we use several metrics ${ }^{118}$ for our dependent variable Y: growth in employment, growth in payroll, growth in average wage, and survival. ${ }^{119}$ Following Wooldridge, our $\mathbf{X}^{2}{ }_{\mathrm{i}}$ vector includes the control variables in step (5) above, ${ }^{120}$ (see Table 6.1 for variables means) and in addition, we include MSA-level employment growth as a measure of local economic conditions.

\footnotetext{
${ }^{118}$ Payroll is deflated. Revenue or profits would have been a better measure of business performance. Unfortunately, the LBD does not have this type of data.

${ }^{119}$ Our analysis is conducted at the establishment level. Size and age are firm-level variables.

${ }^{120}$ These variables have also proven effective in predicting establishment outcomes (such as multi/single establishment status, firm age and sector). See, for example, Dunne Roberts, and Samuelson (1989), Davis, Haltiwanger and Schuh (1995), and Haltiwanger, Jarmin, and Krizan (2010).
} 
We conduct separate estimations for small and large firms independently to better assess the potential effects of health insurance offering on small compared to large firms. ${ }^{121}$ We define small firms as those having 50 or less employees. We chose this cutoff point for a variety of reasons: i) Although each state has their own set of regulations that determine what size of business falls into the classification of "small business," making them eligible for small group health insurance, the common size for a small group classification is between 2 and 50 employees; ii) it is the threshold used in 2010 ACA to define small businesses that are exempt from the bill's shared responsibility requirement, and thus, not required to pay a penalty if not offering health insurance; iii) it is often used in MEPS publications. ${ }^{122}$

Our growth in employment, payroll and average wage measures are calculated using Davis, Haltiwanger and Schuh’s (1996) approach :

$$
\left(2005-Y_{2001}\right) /\left(\left(Y_{2001}+Y_{2005}\right) / 2\right)
$$

As they point out, this percentage change formula not only approximates log differences, it also has several advantages. Perhaps most importantly, it is bounded by -2 and 2 . This means that expansions and contractions are treated symmetrically. By contrast, when the base year is used in the denominator, the resulting changes are bounded by -1 and infinity. ${ }^{123}$

The dependent variable of our survival analysis is a $1 / 0$ indicator that takes the value of 1 if the establishment still exist in year $t$, and is 0 otherwise. In the last two steps

\footnotetext{
${ }^{121}$ We also compute robust standard errors.

${ }^{122}$ See for example MEPS Statistical Brief \#207 (2008).

${ }^{123}$ Although not applicable to our sample of continuers, this methodology can handle births and deaths while log differences cannot.
} 
of our analysis (where we use 2SLS) and following Wooldridge methodology, we employ a linear probability model since the 3-step estimation properties outlined by Wooldridge would not apply were we to run a non-linear model (e.g., probit) in our last stage.

Given extensive literature (Dunne, Roberts and Samuelson (1989), Davis Haltiwanger and Schuh (1996), Luque (2002), Haltiwanger, Jarmin and Miranda (2010)) highlighting the importance of the interaction between size and age in business outcomes, we explore this dimension in our analysis by conducting estimations by firm size and age. That is, we produce four separate sets of results by firm size and age: small-young, small-old, large-young and large-old. We consider a firm to be old if it has been in existence for more than 5 years as of 2001.

\subsection{Measurement Improvement Considerations}

An instrumental variables approach has an additional potential benefit in this context. The original HIO variable in our data is binary. It does not allow for any gradations in response. That is, firms must either offer or not offer - and insurance packages come in fairly lumpy bundles. If a business wants to offer a little insurance, it must either choose none or a full package at a given price and will choose zero if the price is not low enough to prompt the business to offer insurance. In that case, our dichotomous variable mismeasures the firm's choice by the amount of insurance it wanted to buy. If it were to choose to purchase the larger package, the measurement error would be the difference between the desired package and that purchased. 
Our instrument, the estimated premium for all (both offering and non-offering) establishments, is a continuous variable estimated for all businesses, and as such offers a finer measure of health insurance offering than the 0-1 indicator. Just as an IV estimator can be used to eliminate measurement error by eliminating extraneous information (the error term associated with the variable), in this case it may improve our estimates by providing more accurate information than the dichotomous variable.

\subsection{Concluding Remarks:}

According to Wooldridge, given four fairly weak assumptions, we can use a robust “2-step” (really 3 steps) IV estimator to estimate the effect of HIO. We need information on the price of health insurance for all firms in order to estimate our first step equation, but we have it only for those firms that actually make the offer. Since including only data on firms offering insurance would bias our estimates, we follow Feldman et al. (1997) and Nichols et al. (2001) and use a five step process to estimate a firm’s probability of offering health insurance where steps 1-3 are essentially Heckman’s correction for selection bias. 


\section{Results}

This section presents the results of our empirical analyses where we examine the effect of offering health insurance on business performance by firm size as well as firm size-age interactions.

\subsection{Size Effects}

We are primarily concerned with estimating the effects of health insurance offering on firm performance and examining whether that effect varies for small vs. large firms. We measure performance by growth in employment, payroll and average wages as well as survival, but are also interested in looking at how employment, payroll and average wages levels are affected by HIO and how that effect may vary by firm size. Table 7.1 displays our levels (in logs) results. Like much of the literature, we find a large, positive and highly significant relationship between employment, payroll and average wages, and health insurance offering, which seems to exist for establishments in both small and large firms. For example, offering establishments in small firms have almost 300\% more employees than similar firms not offering insurance while establishments in large HIO firms have about $80 \%$ more people working in them than their large non-offering counterparts.

Our payroll and average wage results indicate that businesses - whether small or large - offering health insurance offer larger total compensation packages than do similar businesses that do not offer coverage to their workers. Currie and Madrian (1999) hypothesis that some firms seek to hire better qualified workers than other similar firms 
and thus must pay a higher level of total compensation for them seems a plausible explanation for this finding.

Table 7.1 also displays uncorrected (no IV) OLS results. These have the same sign and are lower in magnitude than our IV estimates. Our expectation was that using IV to correct the endogeneity bias would reduce the size of the coefficients relative to OLS. However, this is not the case. Our coefficients are very large, both in absolute terms and relative to the OLS results. Their magnitude does not seem reasonable.

This suggests that either our instruments are poor - which we test in a later section - and/or that the differences are due to the reduction of measurement error by the IV methodology. In models developed by Feldman, Dowd, Leitz, and Blewett (1997) and Nichols, Blumberg, Cooper, and Vistnes (2001), firms are assumed to offer insurance if the price of offering health insurance is less than their reservation price for a particular package of benefits. As mentioned earlier, some firms may wish to purchase a less generous package than what is offered on the regulated markets and are instead observed as purchasing zero insurance. One of the main advantages of our instrument for HIO is that it includes the imputation of premiums for all (offering and non-offering) firms and is a continuous variable that reveals information about non-offering firms.

Next we turn our attention to the regressions with growth as the dependent variables and display the results in Table 7.2. ${ }^{124}$ Although the levels regressions showed strong positive correlations between employment, payroll and average wage and health insurance offering, the percentage change results show weaker correlations for both small and large firms. Nevertheless, the effects are substantial. Employment and payroll at

\footnotetext{
${ }^{124}$ Recall also that 2005 is the last year that the LBD is currently available.
} 
establishments of small firms that offer insurance grow $12 \%$ and $8 \%$ faster on average respectively than do similar small businesses that do not.

Although the coefficients for large firms tend to be larger in magnitude, they are less likely to be significant (our IV estimates indicate that only employment growth is statistically significantly impacted by HIO). The relationship between $\mathrm{HIO}$ and growth in average wage does not seem to be statistically significant for either small or large firms. This is the case because although offering health insurance seems to be positively correlated with growth in employment and payroll, the corresponding percentage increase in employment is (statistically significant and) larger in magnitude than the one in payroll (which is not significant for large firms).

Taken together, these results indicate that small as well as large businesses offering insurance are bigger and pay higher wages than those that do not. Also, their employment grows faster than that of other firms and for small firms, so does their payroll. However, although they have higher levels of compensation and employment, their rate of average wage growth is not significantly different from non-offering businesses. Nevertheless, their employees are still paid better (particularly considering they also have health insurance, and thus, a higher compensation package) relative to other firms and the absolute difference will grow over time as long as the rates of change are indistinguishable. Offering relatively better overall compensation than other firms would make offering firms more appealing to workers than their competitors who offer lower wages and benefits.

Of course these businesses would expect a return on their investment in their workers, and thus, we would expect to see it reflected in their profits. Unfortunately, we 
cannot observe profits (or revenue) in our data and cannot directly measure them.

Nevertheless, in our results we have seen signs of better performance in the form of higher employment growth, and also payroll for small firms. As noted by Currie and Madrian (1999), the literature suggests we might expect to see insurance-offering firms growing faster than non-offering businesses because people may hesitate to leave a job offering insurance if they are uncertain they can obtain it when they find a new position (“job lock”). We usually think of job changes as occurring when the value of a new job is higher than the value of the existing one, but if changing jobs means changing, or possibly losing, health insurance, then the individual will factor this into their decision as well. This may be particularly applicable to sick employees who may fear that they will become uninsurable should they try to change jobs. This is not an unreasonable fear given that small employers’ premiums can be very sensitive to the wellness of their labor pool. $^{125}$

Job lock could impact the net job creation rates of groups of businesses. Assume there are two groups of businesses, one with job lock and another without it. Assume also that all the businesses in both groups have reached a stable employment equilibrium that they do not wish to change. That is, they want to keep employment at current levels. If employees in both groups experience random shocks prompting them to change jobs randomly, the firms they leave would temporarily be below their equilibrium employment levels until they can hire replacements. However, if some employees experience job lock and are more resistant to these shocks, then the firms offering insurance could be expected to lose fewer workers and have higher employment levels

\footnotetext{
${ }^{125}$ It is beyond the scope of this manuscript to assess how new regulations regarding employer offered health insurance under ACA will impact these findings.
} 
and higher (less negative) growth rates. We could perform the same logic to firms that want to shrink or grow so that, overall, we would expect groups of firms that have a tighter lock on their employees would grow faster than those that do not.

We turn next to examining the effects of health insurance offers on a different performance measure, survival rates (Table 7.2). Our results indicate that offering health insurance is correlated with about a $10 \%$ greater four-year survival rate for establishments in small firms and about a 58\% increase for those in large firms. These coefficients are highly significant, suggesting that offering insurance is an important factor contributing to firm survival for establishments in both large and small firms. Since firm age has long been shown to be a major factor in performance and survival, offering health insurance seems to be highly correlated to whether or not the establishment survives. Together with our earlier findings on wage levels and employment growth, we believe that this provides evidence consistent with the theory that firms offering insurance (and higher wages) are hiring better performing workers which is positively affecting firm performance.

\subsection{Size-Age Effects}

The importance of firm size and age is well documented in the literature (Dunne, Roberts and Samuelson (1989), Davis Haltiwanger and Schuh (1996), Luque (2002), etc.). Recent work by Haltiwanger, Jarmin and Miranda (2010) sheds additional light on the interaction of these two important factors in business growth. They find that the commonly held belief that growth is inversely related to size (that is, small businesses account for most of net job creation) largely disappears once one properly adjusts for 
regression to the mean biases and once firm age is controlled for it may even reverse itself.

These patterns are particularly important at start-ups. Haltiwanger et al. (2010) find evidence of an "up or out” pattern among start-up businesses where up to 40 percent of new firms disappear shortly after their creation but that those that survive grow rapidly. They argue that these results help highlight the connection between business formation, experimentation, and learning. ${ }^{126}$ They also point-out that large businesses are important players in overall employment growth, noting that they account for 45 percent of total job creation.

Although all of our results control for age, given the importance of the size and age interaction, we re-ran our earlier regressions by both categories and obtained some interesting patterns (Table 7.3). The level effects for small firms are nearly identical to the original small-firm results from Table 7.1. Age does not seem to change the earlier results for small firms. That is, small firms, whether young or old, tend to have larger establishments and offer higher wages than small businesses that do not offer health insurance. Large firms, however, seem to differ according to their age when it comes to average wages. It appears that older large firms are primarily responsible for the positive correlation between offering health insurance and average wage levels.

In the results for growth in employment, payroll and wages, the age effect seems to dominate the size effect (Table 7.4). That is, older firms (both small and large) offering health insurance have higher growth rates in payroll and employment. We do not observe a statistically significant relationship between health insurance offering and

\footnotetext{
${ }^{126}$ See Foster Haltiwanger and Krizan (2006) for evidence of selection and learning effects in young businesses.
} 
employment or payroll growth among young firms (regardless of size). As before, there does not seem to be a statistically significant relation between offering health insurance and growth in average wages. Finally, survival is positively and significantly correlated with offering insurance for all but young large firms.

These results substantiate many of our previous findings. In particular, they point to a consistent pattern where health insurance offering firms (whether small or large) tend to offer higher total compensation packages to their employees and are also more likely to survive - indicating that they are already more productive and/or that they get a productivity boost out of offering insurance to their employees (the exception is young large businesses). Regarding the relationship between health insurance offering and business growth, our main finding from our age-size categorization is that only older businesses (whether small or large) show a statistically significant correlation between offering insurance and changes in employment and payroll.

This could be in-part because of the selection and learning effects noted by studies such as those done by Haltiwanger et al. (2010). That is, all young businesses go through a selection and learning effect and, assuming they survive, experience substantial productivity gains as they age (Foster, Haltiwanger and Krizan (2006)). Since our percentage change results condition on survival, ${ }^{127}$ when we select establishments owned by young firms, we are selecting businesses whose productivity is growing. Such establishments would also be expected to grow faster, so it is not surprising that we are unable to discern an additional effect from offering health insurance when we focus on their establishments. The normal gains from selection and learning may be

${ }^{127}$ That is, our businesses are all continuers. 
indistinguishable from any additional benefit of offering insurance. By contrast, we observe large positive effects for older firms of both sizes which have presumably already had enough time to mature so that the selection and learning effects are less substantial.

\subsection{Sensitivity Analysis}

Although Wooldridge's methodology is less sensitive to the choice of instruments, we test the robustness of our results by re-running some of the models using alternative instruments. Our alternative instrument sets include: (i) county-level Medicare costs and state dummies, (ii) the percent of firms in the county that have 1000 or more employees nationwide, the county's share of employment from firms with 100 or more employees, the county's percent of manufacturing employment (this set is hereafter referred to as "county-level controls") and county Medicare costs, (iii) county-level controls and state dummies, (iv) county-level controls.

The results in Table 7.5 indicate that our initial results are quite similar to those obtained with the alternative specifications. The signs, magnitudes, and significance levels of the coefficients from the alternatives are quite similar to our baseline model which used the estimated premiums and state dummies as instruments. The patterns of our findings are robust to a wide range of instruments.

\subsection{Instrument Tests}

Our use of IV estimation is predicted on the belief that growth in employment and payroll (and firm performance in general) is correlated with HIO. To test this assumption, 
we performed Wu-Hausman tests of the endogeneity of health insurance with payroll and employment. As expected, we found strong evidence that both variables are endogenous in our models.

The biggest difficulty in running an instrumental variables model is finding a valid instrument. While Wooldridge's methodology allows for a great deal of leeway in the specification of our initial probit (see the Methodology section for details), this is still the most difficult part of successfully using IV. A standard test of the strength of the instruments is an F-test of their joint significance. We report the results of both F-tests of the joint significance of the instruments as well as the probability value (p-value) of the null that one of the instruments is in fact endogenous. Table 7.6 shows the results.

The F values for small firms are close to 10 for our baseline model as well as for the Medicare costs/state and county-level instruments, indicating a strong correlation between the instruments and the endogenous variable. However, the F values for large firms are generally hovering around 2. This may indicate that our instruments are weaker for large firms. Our concern about this is tempered by the fact that our primary focus is on estimating the effects of $\mathrm{HIO}$ on small business performance.

Finally we tried to perform Sargan overidentification tests of the instruments. The intuition of the Sargan test is that when you estimate an equation using IV, the instruments should not be correlated with the errors for two reasons. First, they are not supposed to be explanatory variables in the original relationship and secondly, valid instruments are not supposed to be correlated with the errors. The test tests the dual null hypotheses that the instruments are uncorrelated with the errors and that they did not belong in the estimation equation as explanatory variables themselves. 
Usually the test is performed following 2SLS where the errors in stage 2 are regressed on the instruments. However, our methodology is more complex and this complicates standard test methodologies and their interpretation in a variety of ways. First, our instruments reside in the first stage and the second stage contains the estimated probabilities. Given this, it was not entirely clear which instruments and which error term should be used and we were unable to find clear direction in the literature. We ran the test at the end of a traditional 2SLS estimation with our core instruments, not the predicted probabilities, in the first stage.

Second, our next hurdle was that Stata does not allow the computation of the Sargan test with weighted data, noting that the appropriateness of the critical values is unclear. ${ }^{128}$ We were able however to force the test to be run, but note that given the methodological uncertainties regarding the tests, the test results should be interpreted with caution. The usually accepted benchmark p-value is 0.10 . While many of our instruments perform above this threshold in a large share of the specifications, no one set of instruments achieves it throughout all of them. They mainly fall below 0.10 for the large firm specifications.

Third, recall that we are using a large number of instruments in most cases, and test of overidentification are known to be very sensitive to the number of instruments (Bekker (1994), Lee and Okui (2009), Chao, Hausman, Newey, Swanson, and Woutersen (2010)). Thus, the p-values may be unreliable when a large number of instruments are being tested. With this in mind, we ran a second set of overidentification tests using only states dummies as instruments and found that even these p-values were below 0.10 in several

\footnotetext{
${ }^{128}$ See http://www.stata.com/help.cgi?ivregress+postestimation\#estatoverid and http://www.stata.com/statalist/archive/2010-12/msg01018.html for details.
} 
specifications. We note also that when we use the fewest number of instruments (in the county-level instrument set) we achieve the highest p-values. It seems likely then that in some cases our low p-values are due to using a large number of instruments and not to an endogeneity problem.

Overall, given the uncertainty of standard testing methodologies as applied to our 3step IV approach, the potential inappropriateness of the critical values, and the sensitivity of the procedure to large numbers of instruments, we interpret the test results with caution.

\subsection{Concluding Remarks}

We have reservations about the reasonableness of the magnitude of some of our coefficients, particularly as they compare to our OLS benchmarking. However, the patterns within our results indicate that businesses offering health insurance, particularly small businesses, offer larger total compensation packages than do similar businesses that do not offer insurance. These businesses also grow faster and survive longer. Again, the evidence was stronger for small firms.

When we break the results out by age and size, young businesses (both large and small) that offer health insurance grow at not significantly different rates as those that do not, possibly due to selection effects. ${ }^{129}$ However, older businesses (whether small or large) offering health insurance seem to have higher establishment employment and payroll growth. Finally, survival was strongly, positively correlated with HIO for older establishments at both large and small firms (with the exception of young large firms).

\footnotetext{
${ }^{129}$ All results control for age and size. In some cases we use dummy variables, in other we run the models by age categories.
} 
These results suggest that young small businesses offering health insurance seem to be more likely to survive, and once they have been in business for a while, offering health insurance seems to increase their chances of success (as measured by employment and payroll growth).

We tested the robustness of these findings to a variety of instruments and found that the patterns hold across all our instrument sets. When we tested the strength and endogeneity of our instruments (and the alternatives) the results were weak for large firms in particular. However, we also note a number of concerns about the appropriateness of the testing methodology in our context. Still, while our findings for large firms mirror those obtained for small firms, the results from the instrument tests, as well as the magnitudes of our coefficients in general, suggest that the results should be interpreted cautiously. 


\section{Conclusions}

Rising health care costs, risk factors, and administrative costs can make ESI prohibitively expensive for small employers. While not all employees want insurance, particularly if it meant accepting a reduction in wages, many do. Firms unable to offer it could be at a disadvantage when competing for qualified workers and may have to adjust their other benefit offerings or change their labor demand, for instance by relying more heavily on part-time workers, investing in additional capital or scaling-back their production goals.

The focus of our work is on how offering insurance affects the growth and survival of small businesses. Small business performance can be affected by a multitude of factors and we attempt to control for as many as possible, both macro and micro. An additional complication is the endogenous nature firm growth and health insurance offering.

Because of the bivariate nature of our endogenous variable we are not able to use conventional instrumental variables techniques. Instead we rely on a technique developed by Wooldridge (2002). According to Wooldridge, given four fairly weak assumptions, we can use a robust 3-step IV estimator to estimate the effect of HIO. In our baseline regressions we use a predicted premium as our instrument. The estimate for the non-offering firms is obtained by following Feldman et al. (1997) and Nichols et al. (2001) and using a five step process to estimate a firm’s probability of offering health insurance where steps 1-3 are essentially Heckman's correction for selection bias. 
Our models are run on data obtained from linking the LBD and the MEPS-IC. The LBD is a longitudinal dataset providing us with business growth measures and survival while the MEPS-IC provides detailed information on insurance coverage, premium costs and workforce characteristics. These linked data allow us to move beyond the limitations faced by others in studying the effect of offering health insurance on small businesses.

When we ran our models, we were surprised by the magnitude of the regression coefficients, particularly as they compared to plain OLS results. They seemed to be far too large and were larger, not smaller, than the presumably biased OLS output.

With that important caveat, we note that the patterns in our results indicate that businesses offering health insurance, particularly small businesses, offer larger total compensation packages than do similar businesses that do not offer insurance coverage to their workers. These businesses also grow faster and survive longer. Again, the evidence was stronger for small firms.

When we break the results out by age and size, young businesses (both large and small) that offer health insurance grow at not significantly different rates as those that do not, possibly due to selection effects. However, older businesses (whether small or large) offering health insurance seem to have higher establishment employment and payroll growth. Finally, survival was strongly, positively correlated with HIO for older establishments at both large and small firms (with the exception of young large firms).

These results suggest that young small businesses offering health insurance seem to be more likely to survive, and once they have been in business for a while, offering 
health insurance seems to increase their chances of success (as measured by employment and payroll growth).

We tested the robustness of these findings to a variety of instruments and found that the patterns hold across all our instrument sets. When we tested the strength and endogeneity of our instruments (and the alternatives) the results were weak for large firms in particular. However, we also note a number of concerns about the appropriateness of the methodology in our context. Nonetheless, while our findings for large firms mirror those obtained for small firms, the results from the instrument tests, as well as the magnitudes of many of the coefficients themselves, indicate that caution should be exercised when interpreting our results. 


\section{Bibliography}

Abelson, Reed. 2009. "Health Insurers Balk at Some Changes.” The New York Times, June 3, 2009.

Abraham, Jean Marie, Thomas DeLeire, and Anne Beeson Royalty. 2009. “Access to Health Insurance at Small Establishments: What Can We Learn from Analyzing Other Fringe Benefits?” Inquiry 46: 253-273.

Actuarial Research Corporation. 2003. "Study of the Administrative Costs and Actuarial Values of Small Health Plans.” Report prepared for the Small Business Administration, Office of Advocacy.

Agency for Healthcare Research and Quality. 2000 and 2005. Medical Expenditure Panel Survey-Insurance Component National-Level Summary Tables.

http://meps.ahrq.gov/mepsweb/data_stats/quick_tables_search.jsp?component=2\&subco $\underline{\text { mponent }=1}$

Allen, K. and C. Park. 1999. "Health Insurance Coverage for the Self-Employed with No Employees.” National Center for Health Statistics. Hyattsville, MD.

America’s Health Insurance Plans. 2006. "January 2006 Census Shows 3.2 Million People Covered by HSA Plans.” As of December 11, 2009: http://www.ahipresearch.org/pdfs/HSAHDHPReportJanuary2006.pdf

Baicker, Katherine and Amitabh Chandra. 2009. "A Trillion-Dollar Geography Lesson.” Health Affairs 28(5): 1448-1451.

. 2006. "The Labor Market Effects of Rising Health Insurance Premiums." Journal of Labor Economics 24(3): 609-634.

. 2005. "The Consequences of the Growth of Health Insurance Premiums." American Economic Review 95(2): 214-218.

Bartelsman, Eric J. and Mark Doms. 2000. "Understanding Productivity: Lessons from Longitudinal Microdata.” Journal of Economic Literature 38: 569-594.

Bartelsman, E., S. Scarpetta, and F. Shivardi. 2005. "Comparative Analysis of Firm Demographics and Survival: Evidence from Micro-level Sources in OECD Countries." Industrial and Corporate Change 14: 365-391.

Bekker, Paul. 1994. "Alternative Approximations to the Distributions of Instrumental Variables Estimators.”, Econometrica, Vol. 62, No. 3: 657-681. 
Belfield, Clive R. and Xiangdong Wei. 2004. "Employer Size-Wage Effects: Evidence from Matched Employer-Employee Survey Data in the UK.” Applied Economics 36: 185-193.

Blumberg, Linda J. 2007. “Increasing Health Insurance Coverage of Workers in Small Firms: Challenges and Strategies.” Statement before the Finance Committee, United States Senate, October 25, 2007.

Brown, Charles and James Medoff. 1989. “The Employer Size-Wage Effect.” The Journal of Political Economy 97 (5): 1027-1059.

Buchmueller, Thomas. 1999. "Fringe Benefits and the Demand for Part-time Workers." Applied Economics 31 (5): 551.

Buchmueller, Thomas and John DiNardo. 2002. “Did Community Rating Induce an Adverse Selection Death Spiral? Evidence from New York, Pennsylvania, and Connecticut.” American Economic Review 92 (1): 280-294.

Buchmueller, Thomas C., John DiNardo, and Robert G. Valletta. 2002. "Union Effects on Health Insurance Provision and Coverage in the United States.” Industrial and Labor Relations Review 55 (4): 610-627.

Buchmueller, Thomas C. and Gail A. Jensen. 1997. "Small Group Reform in a Competitive Managed Care Market: The Case of California, 1993 to 1995.” Inquiry 34 (3): 249-263.

Buchmueller, Thomas C. andM.K. Lettau 1997. "Estimating the Wage-Health Insurance Tradeoff: More Data Problems?” monograph University of California Irvine.

Bunce, Victoria Craig and J.P. Wieske. 2005. "Health Insurance Mandates in the States: 2005.” Report prepared for the Council for Affordable Health Insurance, Alexandria, VA.

Bundorf, M. Kate and Mark Pauly. 2006. "Is Health Insurance Affordable for the Uninsured?” Journal of Health Economics 24(4): 650-673.

Bureau of Labor Statistics. 2008. "BLS Spotlight on Statistics: Older Workers.” www.bls.gov/spotlight

Cantor, Joel, Stephen Long, and Susan Marquis. 1995. "Private Employment-Based Health Insurance in Ten States.” Health Affairs 14 (2, Summer): 197-211.

Carpenter, David. 2003. "Why Small Business is Sick over Health Costs.” Hospitals and Health Networks 77(11): 38-46. 
Centers for Medicare and Medicaid and U.S. Department of Commerce. 2009. National Health Expenditures Aggregate. Table 1.

http://www.cms.hhs.gov/NationalHealthExpendData/downloads/tables.pdf

Chao, J., Hausman, J., Newey W., Swanson, N., and Tiemen Woutersen. 2010. “Testing Overidentifying Restrictions with Many Instruments and Heteroskedasticity.” Mimeo.

Collins, Sara R., Cathy Schoen, Diane Colasanto, and Deirdre A. Downey. 2003. On the Edge: Low-Wage Workers and Their Health Insurance Coverage. New York: The Commonwealth Fund.

Congressional Budget Office. 2000. Increasing Small-Firm Health Insurance Coverage Through Association Health Plans and Healthmarts. Washington, D.C.: Congressional Budget Office.

Congressional Research Service. 1988. "Costs and Effects of Extending Health Insurance Coverage.” U.S. Government Printing Office, Washington, D.C.

Conwell, Leslie Jackson. 2002. “The Role of Health Insurance Brokers: Providing Small Employers with a Helping Hand.” Center for Studying Health System Change Issue Brief No. 57, October 2002.

Council of Economic Advisors. 2009. “The Economic Case for Health Care Reform.” Executive Office of the Present, Council of Economic Advisors.

Currie, Janet and Brigitte C. Madrian. 1999. "Health, Health Insurance, and the Labor Market." Handbook of Labor Economics, Volume 3. Edited by O. Ashenfelter and D. Card. Amsterdam: Elsevier Science.

Cutler, David M. 1994. "Market Failure in Small Group Health Insurance.” Working Paper No. 4879, National Bureau of Economic Research, Inc., Cambridge, MA.

Cutler, David M. and Brigitte C. Madrian. 1998. "Labor Market Responses to Rising Health Insurance Costs: Evidence on Hours Worked.” The Rand Journal of Economics 29 (3): 509-530.

Davis, Steven J., John Haltiwanger, Ronald S. Jarmin, C.J. Krizan, Javier Miranda, Alfred Nucci, and Kristin Sandusky. 2009. "Measuring the Dynamics of Young and Small Business: Integrating the Employer and Nonemployer Universes.” In Producer Dynamics: New Evidence from Micro Data, edited by Timothy Dunne, J. Bradford Jensen, and Mark J. Roberts. The University of Chicago Press, Chicago.

Davis, Steven J., R. Jason Faberman, and John Haltiwanger. 2006. “The Flow Approach to Labor Markets: New Data Sources and Micro-Macro Links.” Journal of Economic Perspectives 20 (3): 3-26. 
Davis, Steven J., John C. Haltiwanger, and Scott Schuh. 1996. Job Creation and Destruction. The MIT Press, Cambridge, MA.

Davis, Steven J. and John C. Haltiwanger. 1999. “Gross Job Flows.” In Handbook of Labor Economics, Volume 3B, edited by Orley Ashenfelter and David Card. Elsevier Science, New York.

Dennis Jr., William J. 2007. “Purchasing Health Insurance.” National Federation of Independent Business, National Small Business Poll, Volume 7, Issue 3.

. 2000. "Wages, Health Insurance and Pension Plans: The Relationship Between Employee Compensation and Small Business Owner Income.” Small Business Economics 15 (4): 247-263.

Dunne, Timothy, Mark J. Roberts, and Larry Samuelson. 1989. "The Growth and Failure of U.S. Manufacturing Plants.” The Quarterly Journal of Economics 104 (4): 671-698.

Eberts, Randall W. and Richard A. Hobbie. 2008. Editors, Older and Out of Work: Jobs and Social Insurance for a Changing Economy. W.E. Upjohn Institute for Employment Research, Kalamazoo, Michigan.

Eberts, Randall W. and Edward Montgomery. 1995. “Cyclical Versus Secular Movements in Employment Creation and Destruction.” National Bureau of Economic Research Working Paper No. 5162. Cambridge, MA.

Econometrica. 2007. "Structural Factors Affecting the Health Insurance Coverage of Workers at Small Firms." Report developed for the Small Business Administration, Office of Advocacy under contract number SBAHQ-05-M-0436.

Ehrenberg, Ronald G. 1971, "The Impact of Overtime Premium on Employment and Hours in Su.S. Industry.”, Western Economic Journal 9. pp 199-207.

Ehrenberg, Ronald G. and Paul L. Schumann. 1982. Longer Hours or More Jobs. New York State School of Industrial and Labor Relations, Cornell University: Ithaca, N.Y.

Eibner, Christine. 2008. “The Economic Burden of Providing Health Insurance: How Much Worse Off Are Small Firms?” Technical Report, Kauffman-Rand Institute for Entrepreneurship Public Policy.

Fairlie, Robert W. 2009. Kauffman Index of Entrepreneurial Activity 1996-2008. Ewing Marion Kauffman Foundation: Kansas City, Missouri. 
Fairlie, Robert W., Kanika Kapur, and Susan Gates. 2009. “Is Employer-Based Health Insurance a Barrier to Entrepreneurship?” University College Dublin Centre for Economic Research, Working paper series WP09/03.

Feldman, Roger, Bryan Dowd, Scott Leitz, and Lynn A. Blewett. 1997. “The Effect of Premiums on Small Firms' Decision to Offer Health Insurance.” The Journal of Human Resources 32(4): 635-658.

Foster, Lucia, John Haltiwanger, and C.J. Krizan. 2006. “The Link Between Aggregate and Micro Productivity Growth: Evidence from Retail Trade.” The Review of Economics and Statistics vol 88. 748-758.

Foster, Lucia, John Haltiwanger, and C.J. Krizan. 2001. “Aggregate Productivity Growth, Lessons from Microeconomic Evidence.” in New Developments in Productivity Analysis, Cambridge, MA, MIT Press pp 303-372.

Fronstin, Paul. 2009. “The Relationship Between Union Status and Employment-Based Health Benefits.” Employee Benefit Research Institute Notes, October 2009, Volume 30, Number 10.

Fronstin, Paul, Ruth Helman, Mathew Greenwald, and associates. 2003. "Small Employers and Health Benefits: Findings from the 2002 Small Employer Health Benefits Survey.” Employee Benefit Research Institute Issue Brief, Number 253.

Fronstin, Paul and Ruth Helman. 2000. "Small Employers and Health Benefits: Findings from the 2000 Small Employer Health Benefits Survey.” Washington, D.C.: Employee Benefit Research Institute Issue Brief, Number 226.

Gabel, Jon, Roland McDevitt, Laura Gandolfo, Jeremy Pickreign, Samantha Hawkins, and Cheryl Fahlman. 2006. "Generosity and Adjusted Premiums in Job-Based Insurance: Hawaii Is Up, Wyoming is Down.” Health Affairs 25 (3): 832-

Gabel, Jon R. and Jeremy Pickreign. 2004. Risky Business: When Mom and Pop Buy Health Insurance for Their Employees. The Commonwealth Fund Issue Brief. New York: The Commonwealth Fund.

Gabel, Jon R. and Gail A. Jensen. 1989. “The Price of State Mandated Benefits.” Inquiry 26: 419-431.

Garrett, Bowen, Len Nichols, and Emily Greenman. 2001. Workers Without Health Insurance: Who Are They and How Can Policy Reach Them? Washington, D.C.: The Urban Institute.

Gates, Susan M., Kanika Kapur, and Pinar Karaka-Mandic. 2007. "State Insurance Mandates, Consumer-Directed Health Plans, and Health Savings Accounts: Are They a Panacea for Small Businesses?” In the Name of Entrepreneurship? The Logic and 
Effects of Special Regulatory Treatment for Small Business, edited by Susan M. Gates and Kristin J. Leuschner.

Gencarelli, Dawn M. 2005. "Health Insurance Coverage for small Employers." National Health Policy Forum Background Paper, April 19, 2005. The George Washington University, Washington, D.C.

General Accounting Office (GAO). 2009. State Small Group Health Insurance Markets. GAO-09-363R.

. 2003. "Private Health Insurance: Federal and State Requirements Affecting Coverage by Small Businesses.”

. 2001. "Private Health Insurance: Small Employers Continue to Face Challenges in Providing Coverage.” GAO-02-8. Washington, D.C.

. 2000. Private Health Insurance: Small Employer Purchasing Cooperatives. GAO/HEHS-00-49. Washington, D.C.

. 1995. Health Insurance Regulation: Variation in Recent State Small Employer Health Insurance Reforms. GAO/HEHS-95-161FS. Washington, D.C.

Glied, Sherry, Jeanne Lambrew, and Sarah Little. 2003. The Growing Share of Uninsured Workers Employed by Large Firms. New York: The Commonwealth Fund.

Gruber, Jonathan. 2000. "Health Insurance and the Labor Market.” Handbook of Health Economics, Volume 1. Edited by A.J. Cuyer and J.P. Newhouse. Elsevier: North Holland.

. 1994. "State-Mandated Benefits and Employer-Provided Insurance." Journal of Public Economics 55 (3): 433-464.

Gruber, Jonathan and Michael Lettau. 2004. "How Elastic Is the Firm’s Demand for Health Insurance? Journal of Public Economics 88 (7-8): 1273-1293.

Gurley-Calvez, Tami. 2006. "Health Insurance Deductibility and Entrepreneurial Survival.” Small Business Association Research Summary No. 273.

Hadley, Jack and James D. Reschovsky. 2002. "Small Firms’ Demand for Health Insurance: The Decision to Offer Insurance.” Inquiry 39: 118-137.

Haltiwanger, John, Ron S. Jarmin, and C.J. Krizan. 2010. "Mom-and-Pop meet BigBox: Compliments or substitutes?” Journal of Urban Economics, Number 67, pp 116134. 
Haltiwanger, John, Ron S. Jarmin, and Javier Miranda. 2009. "Who Creates Jobs? Small vs. Large vs. Young.” Presented at the National Bureau of Economic Research, Inc. Summer Institute 2009.

http://www.nber.org/confer/2009/SI2009/ENT/Haltiwanger_Jarmin_Miranda.pdf

Haltiwanger, John and C.J. Krizan. 1999. "Small Business and Job Creation in the United States: The Role of New and Young.” In Are Small Firms Important?, edited by Zoltan J. Acs, Boston, Kluwer Academic Publishers p. 79-97.

Heckman, J.J. 1992. "Randomization and Social Program Evaluation.” In Evaluating Welfare and Training Programs, edited by C.F. Manski and J. Garfinkel. Cambridge, MA, Harvard University Press 201-230.

. 1997. "Instrumental Variables: A Study of Implicit Behavioral Assumptions

Used in Making Program Evaluations,” Journal of Human Resources 32, 441-462..

Headd, Brian. 2000. “The Characteristics of Small-Business Employees.” Monthly Labor Review 123 (4): 13-18.

Hing, Esther and Gail Jensen. 1999. "Health Insurance Portability and Accountability Act of 1996: Lessons from the States.” Medical Care 37 (7): 692-705.

Holtz-Eakin, Douglas, John R. Penrod, and Harvey S. Rosen. 1996. "Health Insurance and the Supply of Entrepreneurs.” Journal of Public Economics 62 (1-2): 209-235.

Holve, E., G. Claxton, Jon Gabel, et al. 2002. Employer Health Benefits, 2002. Publication 3251, Menlo Park, CA, Kaiser Family Foundation and the Health Research and Educational Trust.

Holve, Erin, Mollyann Brodie, and Larry Levitt. 2003. “Small Business Executive and Health Insurance: Findings from a National Survey of Very Small Firms.” Managed Care Interface 16 (9): 19-24.

Hwang, Hae-shin, W. Robert Reed, Carlton Hubbard. 1992. "Compensating Wage Differentials and Unobserved Productivity.” The Journal of Political Economy 100(4): 835-858.

Jensen, Gail A. and Jon R. Gabel. 1992. “State Mandated Benefits and the Small Firm’s Decision to Offer Insurance.” Journal of Regulatory Economics 4: 376-404.

Jensen, Gail A. and Michael A. Morrisey. 1999. "Research Papers: Small Group Reform and Insurance Provision by Small Firms, 1989-1995.” Inquiry 36 (2): 176-187.

Kaestner, Robert and Kosali Ilayperuma Simon. 2002. "Labor Market Consequences of State Health Insurance Regulation.” Industrial and Labor Relations Review 56 (1): 136159. 
Kaiser Family Foundation/Health Research Educational Trust. 2005. Employer Health Benefits: 2005. Annual Survey.

. 2004. Survey of Employer-Sponsored Health Benefits: 2004. Annual Survey . 2000. Survey of Employer-Sponsored Health Benefits: 2000. Annual Survey

Kaiser State Health Facts. 2009. http://www.statehealthfacts.org

Kapur, Kanika. 2004. “The Impact of the Health Insurance Market on Small Firm Employment.” Journal of Risk and Insurance 71 (1): 63-90.

Kapur, Kanika, Pinar Karaca-Mandic, Susan M. Gates, and Brent Fulton. 2006. "Do Small Group Health Insurance Regulations Influence Small Business Size?” Working paper from Kauffman-Rand Center for Study of Small Business and Regulation.

Kauffman-Rand Institute for Entrepreneurship Public Policy (KRI). 2007. In the Name of Entrepreneurship? The Logic and Effects of Special Regulatory Treatment for Small Business.” Edited by Susan M. Gates and Kristin J. Leuschner. As of December 17, 2009 available at http://www.rand.org/pubs/monographs/2007/RAND_MG663.pdf.

Kennedy, Peter, A Guide To Econometrics Malden, MA Blackwell Publishing 2008. Lee, Jason. 2002. “Are Health Insurance Premiums Higher for Small Firms?” The Robert Wood Johnson Foundation Research Synthesis Report No. 2.

Lee, Y. and Ryo Okui. 2009. “A Specification Test for Instrumental Variables Regression with Many Instruments.” Cowles Foundation Discussion Papers, Yale University No. 1741.

Leibowitz, A. 1983. "Fringe Benefits in Employee Compensation.” in J.E. Triplett, ed. The Measurement of Labor Cost, Chicago IL, University of Chicago Press pp. 371-389.

Levy, Helen. 1998. "Who Pays for Health Insurance? Employee Contributions to Health Insurance Premiums.” Working Paper. Princeton, N.J.: Industrial Relations Section, Princeton University.

Levy, Helen and Thomas DeLeire. 2008. “What Do People Buy When They Don’t Buy Health Insurance and What Does That Tell Us About Why They Are Uninsured?” Inquiry 45: 365-379.

Long, Stephen H. and M. Susan Marquis. 1993. "Gaps in Employer Coverage: Lack of Supply or Lack of Demand?” Health Affairs Supplement 1993: 282-293. . 2001. "Have Small-Group Purchasing Alliances Increased Coverage? Health Affairs 20 (1): 154-163. 
Luque, A., 2002, “An Option-Value Approach to Technology Adoption in U.S. Manufacturing: Evidence from Microdata," Economics of Innovation and New Technology, Vol. 11(6), pp. 543-568.

Marquis, Susan M. and Stephen H. Long. 2001a. "Employer Health Insurance and Local Labor Market Conditions.” International Journal of Health Care Finance and Economics (3-4): 273-292.

. 2001b. “To Offer or Not to Offer: The Role of Price in Employers' Health Insurance Decisions.” Health Services Research 36(5): 935-958.

Mathur, Aparna. 2008. "Health Insurance and Job Creation by the Self-Employed.” American Enterprise Institute for Public Policy Research online publication. http://www.aci.org/publication28507.

Matthews, Merrill, J.P. Wieske, and Victoria Craig Bunce. 2006. "State Health Insurance Index 2006: A 50-State Comparison of the Nation's Health Insurance Market. Report from the Council for Affordable Health Insurance. Alexandria, VA.

Miller, R.D., 1995. "Estimating Compensating Differentials for Employer-Provided Health Insurance Benefits.”, unpublished paper University of California Santa Barbara.

Miranda, Javier and Ron Jarmin. 2002. “The Longitudinal Business Database.” U.S. Census Bureau Center for Economic Studies Working Paper \#CES-WP-02-17. http://www.ces.census.gov/index.php/ces/cespapers?detail_key=101647

Monheit, Alan C. and Barbara Steinberg Schone. 2003. "How Has Small Group Market Reform Affected Employee Health Insurance Coverage?” Journal of Public Economics 88 (1): 237-254.

Monheit, Alan and Jessica Vistnes. 1994. "Implicit Pooling of Workers from Large and Small Firms.” Health Affairs Spring(I): 302-314.

. 1999. "Health Insurance Availability at the Workplace: How Important are Worker Preferences?” Journal of Human Resources 34 (4): 770-785.

. 2008. "Health Insurance Enrollment Decisions: Preferences for Coverage, Worker Sorting, and Insurance Take-Up.” Inquiry 45: 153-167.

Morrisey, Michael A. 2003. “Health Insurance.” National Federation of Independent Business, Small Business Poll. Volume 3, Issue 4. Edited by William J. Dennis Jr.

Morrisey, Michael, Gail A. Jensen, and Robert J. Morlock. 1994. "Small Employers and the Health Insurance Market.” Health Affairs: 149-161. 
National Association of Insurance Commissioners and The Center for Insurance Policy and Research. Interstate Health Insurance Sales: Myth vs. Reality. www.naic.org/documents/topics_interstate_sales_myths.pdf

National Research Council of the National Academies. 2007. Understanding Business Dynamics: An Integrated Data System for America's Future. Editors John Haltiwanger, Lisa M. Lynch, and Christopher Mackie. The National Academies Press, Washington, D.C.

National Small Business Association. 2003. “2003 Benefits Survey.” http://www.nsba.biz/docs/2003_benefits_survey.pdf

Neese, Terry. 2009. "Health Care Reform in a Struggling Economy: What is On the Horizon for Small Business?” Testimony before the Committee on Small Business, United States House of Representatives, February 4, 2009.

Nichols, Len M., Linda J. Blumberg, Gregory P. Acs, Cori E. Uccello, and Jill A. Marsteller. 1997. Small Employers: Their Diversity and Health Insurance. The Urban Institute, Washington, D.C.

Nichols, Len M., Linda J. Blumberg, Philip Cooper, and Jessica Vistnes, 2001, "Employer Demand for Health Insurance: Evidence from the Medical Expenditure Panel Survey - Insurance Component,” Conference Draft.

Nguyen, Sang and Alice Zawacki. 2009. "Health Insurance and Productivity: Evidence from the Manufacturing Sector.” Center for Economic Studies, U.S. Census Bureau, Working paper series CES-WP-09-27. http://www.ces.census.gov/index.php/ces/cespapers?detail_key=101876

Oi, Walter Y., and Todd L. Idson. 1999. “Firm Size and Wages.” Chapter in O. Ashenfelter and D. Card, editors, The Handbook of Labor Economics Volume III, Amsterdam: North-Holland.

Organisation for Economic Co-operation and Development (OECD). 2007. OECD Health Data 2007. http://www.ecosante.org/OCDEENG/18.html.

Pauly, Mark V. 1994. Health Benefits at Work: An Economic and Political Analysis of Employment-Based Health Insurance. The University of Michigan Press, Ann Arbor, Michigan.

Pauly, Mark V. 1998. “Managed Care, Market Power, and Monopsony,” Health Services Research Part 2, December, v.33 Iss 5, pp. 1439-60.

Perline, Rich, Robert Axtell, and Daniel Teitelbaum. 2006. "Volatility and Asymmetry of Small Firm Growth Rates Over Increasing Time Frames.” Report developed for the 
U.S. Small Business Administration, Office of Advocacy under contract number SBAHQ-05-Q-0018.

Pierron, William and Paul Fronstin. 2008. "ERISA Pre-emption: Implication for Health Reform and Coverage.” Employee Benefit Research Institute Issue Brief No. 314.

Porter, Eduardo. 2004. "Rising Cost of Health Benefits Cited as Factor in Slump of Jobs.” New York Times Thursday, August 19, 2004.

Robert Wood Johnson Foundation. 2008. "Key Findings from Qualitative and Quantitative Research Among America’s Small Business Owners.” http://www.rwjf.org/files/research/coveragesmallbizsurvey2008.pdf . 2009. "Geographic Variation and Health Care Cost Growth: Research to Inform a Complex Diagnosis.” Changes in Health Care Financing and Organization Policy Brief.

Rosenbaum, P.R. and D. B. Rubin, 1983. "The Central Role of the Propensity Score in Observational Studies for Causal Effects,” Biometrika 70, 41-55.

Royalty, Anne Beeson. 2008. “Estimating Workers’ Marginal Valuation of Employer Health Benefits: Would Insured Workers Prefer More Health Insurance or Higher Wages?” Journal of Health Economics 27: 89-105.

Ryan, S. 1997. "Employer-provided Health Insurance and Compensating Wage Differentials: Evidence from the Survey of Income and Program Participation.”, Unpublished paper University of Missouri.

Schultz, Jennifer Feenstra and David Doorn. 2009. "Employer Health Benefit Costs and Demand for Part Time Labor.” U.S. Census Bureau, Center for Economic Studies Working Paper Series CES 09-08.

Selden, Thomas M. 2009. "The Impact of Increased Tax Subsidies on the Insurance Coverage of Self-Employed Families: Evidence from the 1996-2004 Medical Expenditure Panel Survey.” Journal of Human Resources 44(1): 115-139.

Shierholz, Heidi. 2008. "Dismal Employment Trends Characterize 2000 Business Cycle.” Economic Policy Institute, Economic Snapshots, August 6, 2008.

Short, Ashley C. and Cara S. Lesser. 2002. "Cutting Back but not Cutting Out: Small Employers Respond to Premium Increases." Issue Brief No. 56, Findings from the Center for Studying Health System Change.

Simon, Kosali Ilayperuma. 2005. "Adverse Selection in Health Insurance Markets? Evidence from State Small-Group Health Insurance Reforms.” Journal of Public Economics 89 (9-10): 1865-1877. 
Sloan, Frank A. and Christopher J. Conover. 1998. "Research Papers: Effects of State Reforms on Health Insurance Coverage of Adults.” Inquiry 35 (3): 280-293.

Sommers, Benjamin D. 2005. "Who Really Pays for Health Insurance? The Incidence of Employer-Provided Health Insurance with Sticky Nominal Wages.” International Journal of Health Care Finance and Economics 5: 89-118.

Summers, Lawrence H. 1989. "What Can Economics Contribute to Social Policy? Some Simple Economics of Mandated Benefits.” The American Economic Review 79(2): 177183.

Uccello, Cori E. 1996. Firms' Health Insurance Decisions: The Relative Effects of Firm Characteristics and State Insurance Regulations. Washington, D.C.: Urban Institute.

U.S. Census Bureau. 2009a. “Jobs Created from Business Startups in the United States.” Business Dynamic Statistics Statistical Brief \#1. http://www.ces.census.gov/docs/bds/BDS_Jobs_Created_ces.pdf . 2009b. "Entrepreneurial Activity Across States.” Business Dynamic Statistics Statistical Brief \#2. http://www.ces.census.gov/docs/bds/bds_states_content.pdf . 2009c. "High Growth and Failure of Young Firms.” Business Dynamic Statistics Statistical Brief \#3. http://www.ces.census.gov/docs/bds/bds_high_growth_and_failure_ces.pdf

Van Praag, C. Mirjam and Peter H. Versloot. 2007. "What is the Value of Entrepreneurship? A Review of Recent Research.” Small Business Economics 29: 351382.

Wellington, N.J. 2001. "Health Insurance Coverage and Entrepreneurship.” Contemporary Economic Policy 19 (4): 465-478.

Wicks, Elliot K., Mark A. Hall, and Jack A. Meyer. 2000. “Barriers to Small-Group Purchasing Cooperatives.” Economic and Social Research Institute. Retrieved 11-3-09 from http://www.esresearch.org/Documents/HPC.pdf.

Wooldridge, Jeffrey M., Econometric Analysis of Cross Section and Panel Data, Cambridge, MA, The MIT Press 2002.

Zawacki, Alice and Amy Taylor. 2005. “Contributions to Health Insurance Premiums: When Does the Employer Pay 100 Percent?” Center for Economic Studies, U.S. Census Bureau, Working Paper Series CES-WP-05-27. 
Zuckerman, Stephen and Shruti Rajan. 1999. "Research Papers: An Alternative Approach to Measuring the Effects of Insurance Market Reforms.” Inquiry 36 (1): 4456. 


\section{Tables}


Table 2.1. Percent of private-sector establishments and employees with health insurance offers by firm size: U.S., 2000-2005

\begin{tabular}{|c|c|c|c|c|c|c|}
\hline Year & $\begin{array}{c}\text { All } \\
\text { establishments }\end{array}$ & $\begin{array}{c}\text { Less than } \\
10 \text { Employees }\end{array}$ & $\begin{array}{c}10-24 \\
\text { Employees }\end{array}$ & $\begin{array}{c}25-99 \\
\text { Employees }\end{array}$ & $\begin{array}{c}\text { 100-999 } \\
\text { Employees }\end{array}$ & $\begin{array}{c}1000+ \\
\text { Employees }\end{array}$ \\
\hline \multicolumn{7}{|c|}{ Percent of establishments that offer health insurance } \\
\hline 2000 & 59.3 & 39.6 & 69.3 & 84.5 & 95 & 99.2 \\
\hline 2001 & 58.3 & 38.6 & 67.4 & 83.2 & 95.4 & 99.4 \\
\hline 2002 & 57.2 & 36.8 & 67.8 & 82.4 & 95.4 & 98.8 \\
\hline 2003 & 56.2 & 35.6 & 66.2 & 81 & 93.5 & 98.6 \\
\hline 2004 & 55.1 & 34.1 & 64 & 81.2 & 94.3 & 98.9 \\
\hline 2005 & 56.3 & 35.7 & 64 & 82.6 & 94.2 & 98.9 \\
\hline \multicolumn{7}{|c|}{ Percent of employees in establishments that offer health insurance } \\
\hline 2000 & 89.4 & 53.2 & 75.2 & 88.4 & 97.3 & 99.4 \\
\hline 2001 & 88.8 & 48.1 & 72.5 & 87.5 & 96.7 & 99.8 \\
\hline 2002 & 88.3 & 47.3 & 71.5 & 86.5 & 96.6 & 99.4 \\
\hline 2003 & 86.8 & 45.8 & 70.6 & 84.1 & 95.8 & 98.7 \\
\hline 2004 & 86.7 & 45.5 & 68.4 & 84.2 & 94.8 & 99.5 \\
\hline 2005 & 86.9 & 43.7 & 68.2 & 85 & 93 & 99.4 \\
\hline
\end{tabular}

Source: Agency for Healthcare Research and Quality, Center for Cost and Financing Studies. 2000-2005 Medical Expenditure Panel Survey-Insurance Component. 
Table 2.2 Change in percent of private-sector establishments that offer health insurance by firm size and selected characteristics: 2000 to 2005

\begin{tabular}{|c|c|c|c|c|c|c|c|c|c|c|c|c|c|c|c|}
\hline & \multicolumn{15}{|c|}{ Firm Size (number of employees) } \\
\hline & \multicolumn{3}{|c|}{$<10$} & \multicolumn{3}{|c|}{$10-24$} & \multicolumn{3}{|c|}{$25-99$} & \multicolumn{3}{|c|}{$100-999$} & \multicolumn{3}{|c|}{$1000+$} \\
\hline & 2000 & 2005 & Change & 2000 & 2005 & Change & 2000 & 2005 & Change & 2000 & 2005 & Change & 2000 & 2005 & Change \\
\hline Industry & \multicolumn{2}{|c|}{ Percents } & & \multicolumn{2}{|c|}{ Percents } & & \multicolumn{2}{|c|}{ Percents } & & \multicolumn{2}{|c|}{ Percents } & & \multicolumn{2}{|c|}{ Percents } & \\
\hline $\begin{array}{l}\text { Agriculture, } \\
\text { fishing, forestry }\end{array}$ & 24.6 & 19.6 & -5 & 59.9 & 45.8 & -14.1 & 77.7 & 86.4 & 8.7 & 87.7 & 58.4 & -29.3 & 99.2 & 100 & 0.8 \\
\hline $\begin{array}{l}\text { Mining \& } \\
\text { manufacturing }\end{array}$ & 55 & 44.3 & -10.7 & 83.5 & 77 & -6.5 & 93.6 & 91.1 & -2.5 & 99.1 & 99.2 & 0.1 & 99.9 & 100 & 0.1 \\
\hline Construction & 35.9 & 34.1 & -1.8 & 75.8 & 68 & -7.8 & 86.4 & 84.6 & -1.8 & 90.1 & 90.6 & 0.5 & 99.4 & 100 & 0.6 \\
\hline $\begin{array}{l}\text { Utilities and } \\
\text { transportation }\end{array}$ & 39.6 & 29.9 & -9.7 & 66.1 & 72.9 & 6.8 & 89.2 & 83 & -6.2 & 99.7 & 90.6 & -9.1 & 97.7 & 99.3 & 1.6 \\
\hline $\begin{array}{l}\text { Wholesale } \\
\text { trade }\end{array}$ & 52.2 & 53 & 0.8 & 83.9 & 80.3 & -3.6 & 95.4 & 93.9 & -1.5 & 97.4 & 100 & 2.6 & 99.5 & 99.9 & 0.4 \\
\hline $\begin{array}{l}\text { Financial } \\
\text { services and } \\
\text { real estate }\end{array}$ & 42.3 & 38.9 & -3.4 & 84.5 & 83.1 & -1.4 & 95.9 & 93.7 & -2.2 & 97.6 & 97 & -0.6 & 99.9 & 98.3 & -1.6 \\
\hline Retail trade & 36.9 & 27.6 & -9.3 & 72.3 & 59.5 & -12.8 & 88.5 & 83 & -5.5 & 95.4 & 93.9 & -1.5 & 98.8 & 98.6 & -0.2 \\
\hline $\begin{array}{l}\text { Professional } \\
\text { services }\end{array}$ & 47.4 & 46.1 & -1.3 & 78 & 76.7 & -1.3 & 90.8 & 88.6 & -2.2 & 97.2 & 95.7 & -1.5 & 99.1 & 100 & 0.9 \\
\hline Other services & 31.5 & 28.3 & -3.2 & 48.9 & 46.4 & -2.5 & 70.5 & 68.7 & -1.8 & 90.5 & 89.2 & -1.3 & 99 & 98.5 & -0.5 \\
\hline \multicolumn{16}{|l|}{ Firm age } \\
\hline$<5$ years & 31 & 23.9 & -7.1 & 57 & 38.2 & -18.8 & 63.3 & 52.1 & -11.2 & 88.5 & 69.7 & -18.8 & 95 & 74 & -21 \\
\hline 5-9 years & 37.5 & 32 & -5.5 & 61.6 & 53.5 & -8.1 & 78 & 66.2 & -11.8 & 94.1 & 81.4 & -12.7 & 94.9 & 94 & -0.9 \\
\hline 10-19 years & 41.6 & 36.8 & -4.8 & 67.4 & 63.2 & -4.2 & 84.4 & 79.6 & -4.8 & 92.6 & 93.6 & 1 & 98.4 & 96.8 & -1.6 \\
\hline $20+$ years & 47.3 & 42.7 & -4.6 & 78.9 & 73.7 & -5.2 & 89.9 & 90.3 & 0.4 & 96.5 & 95.9 & -0.6 & 98.8 & 99.8 & 1 \\
\hline
\end{tabular}

Source: Agency for Healthcare Research and Quality, Center for Cost and Financing Studies. 2000 and 2005 Medical Expenditure

Panel Survey-Insurance Component. 
Table 2.3. Factors related to decision to offer health insurance

\begin{tabular}{|c|c|}
\hline $\begin{array}{c}\text { Factors related to } \\
\text { health insurance } \\
\text { offers }\end{array}$ & Select studies and reports \\
\hline \multicolumn{2}{|l|}{ Financial } \\
\hline $\begin{array}{l}\text { Price sensitivity and } \\
\text { Premium variability }\end{array}$ & $\begin{array}{l}\text { Gruber and Lettau, } 2004 \\
\text { Hadley and Reschovsky, } 2002 \\
\text { Feldman et al., } 1997 \\
\text { Nichols et al., } 1997 \\
\text { Cutler, } 1994\end{array}$ \\
\hline $\begin{array}{l}\text { Risk-related costs and } \\
\text { Participation rates }\end{array}$ & $\begin{array}{l}\text { Gencarelli, } 2005 \\
\text { Lee, } 2002 \\
\text { General Accounting Office, } 2001 \\
\text { Gruber, } 2000 \\
\text { Cantor et al., } 1995\end{array}$ \\
\hline Administrative costs & $\begin{array}{l}\text { Abraham, et al. } 2009 \\
\text { Pierron and Fronstin, } 2008 \\
\text { Actuarial Research Corporation, } 2003 \\
\text { Carpenter, } 2003 \\
\text { Marquis and Long, 2001b } \\
\text { Congressional Budget Office } 2000 \\
\text { Wicks, Hall, and Meyer, } 2000 \\
\text { General Accounting Office, } 2000 \text { and } 2001 \\
\text { Nichols et al., } 1997 \\
\text { Congressional Research Service, } 1988\end{array}$ \\
\hline Tax advantages & $\begin{array}{l}\text { Kauffman-RAND Institute for Entrepreneurship Public Policy, } 2007 \\
\text { Fronstin et al., } 2003\end{array}$ \\
\hline \multicolumn{2}{|l|}{ Labor market } \\
\hline $\begin{array}{l}\text { Characteristics of } \\
\text { employees } \\
\text { and } \\
\text { Demand for own } \\
\text { employer's health } \\
\text { insurance }\end{array}$ & $\begin{array}{l}\text { Abraham et al., } 2009 \\
\text { Econometrica, } 2007 \\
\text { Kaiser Family Foundation/Health Research Educational Trust, } 2004 \\
\text { Fronstin et al., } 2003 \\
\text { Glied et al., } 2003 \\
\text { Holve et al., } 2003 \\
\text { Lee } 2002 \\
\text { Garrett et al., } 2001 \\
\text { Headd, } 2000 \\
\text { Monheit and Vistnes, } 1999 \text { and } 1994 \\
\text { Nichols et al., 1997 } \\
\text { Long and Marquis, } 1993 \\
\end{array}$ \\
\hline $\begin{array}{l}\text { Recruitment and } \\
\text { retention }\end{array}$ & $\begin{array}{l}\text { Marquis and Long, 2001a } \\
\text { Nichols et al., 1997 }\end{array}$ \\
\hline
\end{tabular}


Table 2.3 continued. Factors related to decision to offer health insurance

\begin{tabular}{|c|c|}
\hline $\begin{array}{l}\text { Factors related to } \\
\text { health insurance } \\
\text { offers }\end{array}$ & Select studies and reports \\
\hline \multicolumn{2}{|c|}{ Insurance markets and products } \\
\hline Access & $\begin{array}{l}\text { Neese, } 2009 \\
\text { General Accounting Office, } 2009 \\
\text { Carpenter, } 2003\end{array}$ \\
\hline $\begin{array}{l}\text { Insurance options with } \\
\text { lower premium costs }\end{array}$ & $\begin{array}{l}\text { Kauffman-RAND Institute for Entrepreneurship Public Policy, } 2007 \\
\text { Gates et al., } 2007 \\
\text { America's Health Insurance Plans, } 2006 \\
\text { Gencarelli, } 2005\end{array}$ \\
\hline \multicolumn{2}{|c|}{ Health insurance regulatory environment } \\
\hline $\begin{array}{l}\text { Legislation, offers, and } \\
\text { business size }\end{array}$ & $\begin{array}{l}\text { Kauffman-RAND Institute for Entrepreneurship Public Policy, } 2007 \\
\text { Kapur et al., } 2006 \\
\text { Kapur, } 2004\end{array}$ \\
\hline State reform & $\begin{array}{l}\text { Neese, } 2009 \\
\text { Kauffman-RAND Institute for Entrepreneurship Public Policy, } 2007 \\
\text { Matthews et al., } 2006 \\
\text { Fronstin et al., } 2003 \\
\text { Monheit and Schone } 2003 \\
\text { Buchmueller and DiNardo } 2002 \\
\text { Kaestner and Simon, } 2002 \\
\text { General Accounting Office, } 1995\end{array}$ \\
\hline $\begin{array}{l}\text { Health insurance } \\
\text { mandates }\end{array}$ & $\begin{array}{l}\text { Pierron and Fronstin, } 2008 \\
\text { Bunce and Wieske, } 2005 \\
\text { Gencarelli, } 2005 \\
\text { Jensen and Morrisey, } 1999 \\
\text { Jensen and Gabel, } 1992 \\
\text { Gabel and Jensen, } 1989\end{array}$ \\
\hline
\end{tabular}


Table 2.4. National totals for cost of hospitalization and physician service health plans offered by employers in the U.S. private sector

\begin{tabular}{|l|c|c|c|}
\hline & 2000 & 2005 & $\begin{array}{c}\text { Percent increase } \\
\text { from 2000 to 2005 }\end{array}$ \\
\hline Total costs & \multicolumn{2}{|c|}{ (in millions of dollars) } & \\
\hline Employer contribution & 349,612 & 486,133 & $39.05 \%$ \\
$\quad \begin{array}{l}\text { Single coverage } \\
\text { Family coverage }\end{array}$ & 69,066 & 103,739 & $50.20 \%$ \\
Total employer contribution & 191,916 & 249,138 & $29.82 \%$ \\
\hline $\begin{array}{l}\text { Employee contribution } \\
\text { Single coverage } \\
\text { Family coverage }\end{array}$ & 260,982 & 352,877 & $35.21 \%$ \\
Total employee contribution & 88,630 & 133,256 & $50.35 \%$ \\
\hline
\end{tabular}

Source: Agency for Healthcare Research and Quality, Center for Cost and Financing Studies. 2000 and 2005 Medical Expenditure Panel Survey-Insurance Component. 
Table 2.5. Change in percent of private-sector establishments that offer health insurance by firm size and selected workforce characteristics: 2000 to 2005

\begin{tabular}{|c|c|c|c|c|c|c|c|c|c|c|c|c|c|c|c|}
\hline & \multicolumn{15}{|c|}{ Firm Size (number of employees) } \\
\hline & \multicolumn{3}{|c|}{$<10$} & \multicolumn{3}{|c|}{$10-24$} & \multicolumn{3}{|c|}{$25-99$} & \multicolumn{3}{|c|}{$100-999$} & \multicolumn{3}{|c|}{$1000+$} \\
\hline & 2000 & 2005 & Change & 2000 & 2005 & Change & 2000 & 2005 & Change & 2000 & 2005 & Change & 2000 & 2005 & Change \\
\hline \multicolumn{16}{|l|}{$\begin{array}{l}\text { Percent full- } \\
\text { time employees }\end{array}$} \\
\hline$<25 \%$ & 9.4 & 9.6 & 0.2 & 22.7 & 19.4 & -3.3 & 52.8 & 54.7 & 1.9 & 81.3 & 73.9 & -7.4 & 93.3 & 97.9 & 4.6 \\
\hline $25-49 \%$ & 36.3 & 28.8 & -7.5 & 55.2 & 51.7 & -3.5 & 73.5 & 74.8 & 1.3 & 95.7 & 89 & -6.7 & 99.9 & 98.8 & -1.1 \\
\hline $50-74 \%$ & 40.4 & 35.3 & -5.1 & 64.6 & 57.3 & -7.3 & 80.2 & 76.9 & -3.3 & 95.9 & 94.6 & -1.3 & 99.2 & 99.9 & 0.7 \\
\hline $75 \%$ or more & 47.4 & 43.1 & -4.3 & 78.9 & 74.4 & -4.5 & 91.3 & 88.3 & -3 & 96.4 & 96.8 & 0.4 & 99.5 & 98.7 & -0.8 \\
\hline \multicolumn{16}{|l|}{$\begin{array}{l}\text { Union } \\
\text { presence }\end{array}$} \\
\hline $\begin{array}{l}\text { No union } \\
\text { employees }\end{array}$ & 39.9 & 36.2 & -3.7 & 69.3 & 64 & -5.3 & 84.9 & 82.7 & -2.2 & 95.7 & 94.4 & -1.3 & 99.1 & 98.7 & -0.4 \\
\hline $\begin{array}{l}\text { Has union } \\
\text { employees }\end{array}$ & 62.6 & 42.1 & -20.5 & 81.7 & 85.9 & 4.2 & 92.5 & 91.8 & -0.7 & 98.4 & 95.1 & -3.3 & 99.8 & 99.9 & 0.1 \\
\hline \multicolumn{16}{|l|}{$\begin{array}{l}\text { Percent low- } \\
\text { wage } \\
\text { employees }\end{array}$} \\
\hline $50^{+} \%$ low wage & 25.4 & 18.8 & -6.6 & 46.3 & 37.5 & -8.8 & 73.5 & 63.3 & -10.2 & 94.2 & 88 & -6.2 & 96.4 & 98.3 & 1.9 \\
\hline $\begin{array}{l}<50 \% \text { low } \\
\text { wage }\end{array}$ & 50.2 & 42.9 & -7.3 & 83.4 & 76.5 & -6.9 & 92.4 & 91.6 & -0.8 & 96.9 & 97.3 & 0.4 & 99.4 & 99.1 & -0.3 \\
\hline
\end{tabular}

Source: Agency for Healthcare Research and Quality, Center for Cost and Financing Studies. 2000 and 2005 Medical Expenditure Panel Survey-Insurance Component. 
Table 2.6. Annual percent change in national totals for cost of hospitalization and physician service health plans offered by employers in the U.S. private sector by industry category

\begin{tabular}{|c|c|c|c|c|c|}
\hline & \multicolumn{5}{|c|}{ Percent change } \\
\hline Industry & 2000 to 2001 & 2001 to 2002 & 2002 to 2003 & 2003 to 2004 & 2004 to 2005 \\
\hline $\begin{array}{l}\text { Agriculture, fishing, } \\
\text { forestry }\end{array}$ & 26.02 & -0.29 & -26.60 & 74.33 & -26.02 \\
\hline $\begin{array}{l}\text { Mining or } \\
\text { manufacturing }\end{array}$ & -4.00 & 5.05 & 2.04 & 0.79 & 7.83 \\
\hline Construction & -4.98 & 1.87 & 16.97 & 11.87 & 12.93 \\
\hline $\begin{array}{l}\text { Utilities or } \\
\text { transportation }\end{array}$ & 11.22 & -0.29 & 3.44 & 23.91 & 2.07 \\
\hline Wholesale trade & -5.16 & 8.24 & 8.27 & 5.05 & 15.91 \\
\hline $\begin{array}{l}\text { Financial services } \\
\text { or real estate }\end{array}$ & 6.46 & 13.76 & 7.58 & 5.49 & 7.69 \\
\hline Retail trade & -6.20 & 10.98 & 16.83 & -1.7 & 10.14 \\
\hline $\begin{array}{l}\text { Professional } \\
\text { services }\end{array}$ & 7.38 & 14.33 & 21.97 & 11.88 & 3.51 \\
\hline Other services & 1.70 & -1.74 & 5.53 & 5.17 & 11.20 \\
\hline
\end{tabular}

Calculations based on data from Agency for Healthcare Research and Quality, Center for Cost and Financing Studies. 2000 and 2005 Medical Expenditure Panel Survey-Insurance Component. 
Table 2.7. Characteristics of state small group health insurance markets

\begin{tabular}{|c|c|c|c|c|c|}
\hline State & $\begin{array}{c}\text { Authorizes tax } \\
\text { credits or } \\
\text { deductions to small } \\
\text { employers offering } \\
\text { health insurance, } \\
2^{2008^{a}}\end{array}$ & $\begin{array}{c}\text { Number of } \\
\text { licensed } \\
\text { carriers for } \\
\text { small group } \\
\text { health } \\
\text { insurance } \\
\text { market, } 2008 \\
b, 130\end{array}$ & $\begin{array}{l}\text { Market share } \\
\text { of largest carrier } \\
\text { (percentage) in } \\
\text { small group } \\
\text { insurance } \\
\text { market, } 2008^{b}\end{array}$ & $\begin{array}{c}\text { Has COBRA } \\
\text { expansions, }^{132} \\
2009^{a}\end{array}$ & $\begin{array}{c}\text { Maximum } \\
\text { duration of } \\
\text { continuation } \\
\text { coverage } \\
\text { (months), } \\
2009^{a}\end{array}$ \\
\hline Alabama & No & 7 & 96 & No & NA \\
\hline Alaska & No & 11 & 77 & No & NA \\
\hline Arizona & Yes - credit & 32 & 21 & No & NA \\
\hline Arkansas & No & Not reported & Not reported & Yes & 4 \\
\hline California & No & 28 & 37 & Yes & 36 \\
\hline Colorado & No & 21 & 23 & Yes & 18 \\
\hline Connecticut & No & 33 & 46 & Yes & 36 \\
\hline Delaware & No & 14 & 58 & No & NA \\
\hline District of Columbia & No & 14 & NA & Yes & 3 \\
\hline Florida & No & 27 & 30 & Yes & 29 \\
\hline Georgia & Yes - credit & 211 & NA & Yes & 3 \\
\hline Hawaii & No & 7 & NA & Yes & 3 \\
\hline
\end{tabular}

${ }^{130}$ GAO (2009) defines a carrier as an entity (either an insurer or managed health care plan) that bears the risk for and administers a range of health benefit offerings. 33 of the 47 responding states defined small group as 2 to 50 employees, 12 states defined small as 1 to 50 employees, and the remaining states used other definitions.

${ }_{132}^{131}$ Market share is usually based on the number of covered lives (GAO 2009).

${ }^{132}$ COBRA refers to the Consolidated Omnibus Budget Reconciliation Act of 1985 that amended the federal law ERISA of 1974, which applied to firms with 20 or more employees. COBRA required temporary continuation of group health insurance to employees and their dependents when employment was terminated. As of 2009, 40 states subsequently established programs to extend COBRA coverage to firms with less than 20 workers. 


\begin{tabular}{|c|c|c|c|c|c|}
\hline State & $\begin{array}{c}\text { Authorizes tax } \\
\text { credits or } \\
\text { deductions to small } \\
\text { employers offering } \\
\text { health insurance, } \\
2^{2008^{a}}\end{array}$ & $\begin{array}{c}\text { Number of } \\
\text { licensed } \\
\text { carriers for } \\
\text { small group } \\
\text { health } \\
\text { insurance } \\
\text { market, 2008 }\end{array}$ & $\begin{array}{l}\text { Market share of } \\
\text { largest carrier } \\
\text { (percentage) in } \\
\text { small group } \\
\text { insurance } \\
\text { market, } 2008^{b}\end{array}$ & $\begin{array}{c}\text { Has COBRA } \\
\text { expansions, } \\
2009^{a}\end{array}$ & $\begin{array}{c}\text { Maximum } \\
\text { duration of } \\
\text { continuation } \\
\text { coverage } \\
\text { (months), } \\
2009^{a}\end{array}$ \\
\hline Idaho & Yes - credit & 18 & 49 & No & NA \\
\hline Illinois & No & 53 & 51 & Yes & 24 \\
\hline Indiana & No & 328 & NA & No & NA \\
\hline Iowa & No & 28 & 60 & Yes & 9 \\
\hline Kansas & Yes - credit & 22 & NA & Yes & 18 \\
\hline Kentucky & Yes - credit & 13 & 47 & Yes & 18 \\
\hline Louisiana & No & 403 & 53 & Yes & 12 \\
\hline Maine & Yes - credit & 8 & 56 & Yes & 12 \\
\hline Maryland & Yes - credit & 16 & 51 & Yes & 18 \\
\hline Massachusetts & Yes - credit & 28 & 44 & Yes & 36 \\
\hline Michigan & No & 49 & 47 & No & NA \\
\hline Minnesota & No & 17 & 42 & Yes & 36 \\
\hline Mississippi & No & Not reported & Not reported & Yes & 12 \\
\hline Missouri & No & 50 & 30 & Yes & 9 \\
\hline Montana & Yes - credit & 13 & 38 & No & NA \\
\hline Nebraska & No & 58 & NA & Yes & 12 \\
\hline Nevada & No & 28 & NA & Yes & 36 \\
\hline New Hampshire & No & 10 & 50 & Yes & 36 \\
\hline New Jersey & No & 13 & 28 & Yes & 36 \\
\hline New Mexico & No & Not reported & Not reported & Yes & 6 \\
\hline New York & No & 31 & 26 & Yes & 36 \\
\hline North Carolina & No & 27 & 65 & Yes & 18 \\
\hline
\end{tabular}




\begin{tabular}{|c|c|c|c|c|c|}
\hline State & $\begin{array}{c}\text { Authorizes tax } \\
\text { credits or } \\
\text { deductions to small } \\
\text { employers offering } \\
\text { health insurance, } \\
2^{2008^{a}}\end{array}$ & $\begin{array}{c}\text { Number of } \\
\text { licensed } \\
\text { carriers for } \\
\text { small group } \\
\text { health } \\
\text { insurance } \\
\text { market, 2008 }\end{array}$ & $\begin{array}{l}\text { Market share of } \\
\text { largest carrier } \\
\text { (percentage) in } \\
\text { small group } \\
\text { insurance } \\
\text { market, } 2008^{b}\end{array}$ & $\begin{array}{c}\text { Has COBRA } \\
\text { expansions, } \\
2009^{a}\end{array}$ & $\begin{array}{c}\text { Maximum } \\
\text { duration of } \\
\text { continuation } \\
\text { coverage } \\
\text { (months), } \\
2009^{a}\end{array}$ \\
\hline North Dakota & No & 10 & 91 & Yes & 36 \\
\hline Ohio & Yes - deduction & 180 & 35 & Yes & 6 \\
\hline Oklahoma & Yes - credit & 25 & 51 & Yes & 6 \\
\hline Oregon & Yes - deduction & 15 & 44 & Yes & 6 \\
\hline Pennsylvania & No & Not reported & Not reported & No & NA \\
\hline Rhode Island & No & 4 & 84 & Yes & 18 \\
\hline South Carolina & No & 27 & 47 & Yes & 6 \\
\hline South Dakota & No & 15 & 62 & Yes & 36 \\
\hline Tennessee & No & 33 & 68 & Yes & 15 \\
\hline Texas & Yes - deduction & 46 & 27 & Yes & 36 \\
\hline Utah & No & 31 & 39 & Yes & 6 \\
\hline Vermont & No & 5 & 45 & Yes & 12 \\
\hline Virginia & No & 36 & NA & No & NA \\
\hline Washington & No & 10 & 45 & No & NA \\
\hline West Virginia & No & 27 & 52 & Yes & 18 \\
\hline Wisconsin & No & 41 & 32 & Yes & 18 \\
\hline Wyoming & No & 12 & 51 & Yes & 12 \\
\hline
\end{tabular}

${ }^{a}$ Source: The Henry J. Kaiser Family Foundation State Health Facts. http://www.statehealthfacts.org

${ }^{b}$ Source: General Accounting Office, Private Health Insurance: 2008 Survey Results on Number and Market Share of Carriers in the Small Group Health Insurance Market, GAO-09-363R. Washington, DC. February 27, 2009. 
Table 5.1 LBD Data Illustration (mock data)

\begin{tabular}{|c|c|c|c|c|c|}
\hline Year & Firm ID & Establishment ID & Employment & Multi/Single Unit Firm? & Zip Code \\
\hline \hline 2000 & 10001 & 0001 & 15 & MU & 11758 \\
\hline 2000 & 10001 & 0002 & 322 & MU & 11758 \\
\hline 2000 & 10001 & 0003 & 183 & SU & 01984 \\
\hline 2000 & 10002 & 0001 & 10 & SU & 20024 \\
\hline 2000 & 10003 & 0001 & 53 & MU & 23336 \\
\hline 2001 & 10001 & 0001 & 17 & MU & 11758 \\
\hline 2001 & 10001 & 0002 & 352 & MU & 11758 \\
\hline 2001 & 10001 & 0003 & 201 & MU & 01984 \\
\hline 2001 & 10001 & 0004 & 14 & SU & 20688 \\
\hline 2001 & 10003 & 0001 & 51 & SU & 33324 \\
\hline 2001 & 10004 & 0001 & 3 & & \\
\hline
\end{tabular}


Table 5.2 Sample LBD Statistics

\begin{tabular}{|c|c|c|c|c|}
\hline Firm Size & $\begin{array}{c}\text { Employment } \\
\text { Share 2005 }\end{array}$ & $\begin{array}{c}\text { Net Employment } \\
\text { Growth 2000-2005 }\end{array}$ & $\begin{array}{c}\text { Number of } \\
\text { Firms Share 2005 }\end{array}$ & $\begin{array}{c}\text { Net Growth in } \\
\text { \# of Firms 2000-2005 }\end{array}$ \\
\hline \hline 1 to 9 & $12 \%$ & $6 \%$ & $82 \%$ & $4 \%$ \\
10 to 24 & $9 \%$ & $1 \%$ & $11 \%$ & $3 \%$ \\
25 to 99 & $14 \%$ & $1 \%$ & $5 \%$ & $6 \%$ \\
100 to 999 & $21 \%$ & $4 \%$ & $2 \%$ & $17 \%$ \\
1000 plus & $44 \%$ & $-2 \%$ & $0 \%$ & $14 \%$ \\
\hline
\end{tabular}


Table 5.3 Average Total Single Premium per Enrolled Employee at Private-sector Establishments that Offer Health Insurance by Firm Size

\begin{tabular}{|c|c|c|c|c|c|}
\hline & Less than 10 & & & 100-999 & $\mathbf{1 0 0 0}$ or more \\
employees & $\mathbf{1 0 - 2 4}$ employees & $\mathbf{2 5 - 9 9}$ employees & $\begin{array}{c}\mathbf{1 0 9} \\
\text { employees }\end{array}$ & $\$ 2,015$ \\
\hline 1996 & $\$ 2,229$ & $\$ 2,016$ & $\$ 1,923$ & $\$ 1,901$ & $\$ 3,684$ \\
\hline
\end{tabular}

Source: Agency for Healthcare Research and Quality, Center for Financing, Access and Cost Trends. 1996 and 2004 Medical Expenditure Panel Survey-Insurance Component. 
Table 6.1: Means of Dependent Variable and Establishment Characteristics by Size

\begin{tabular}{|c|c|c|}
\hline Variable & $\begin{array}{l}\text { Continuer } \\
\text { Establishments } \\
\text { in Small Firms }\end{array}$ & $\begin{array}{l}\text { Continuer } \\
\text { Establishments } \\
\text { in Large Firms }\end{array}$ \\
\hline Health Insurance Offering & $56.8 \%$ & $97.0 \%$ \\
\hline \# Employees (2001) & 10.4 & 285.9 \\
\hline Payroll (2001) \$1000 & 1.7 & 64.2 \\
\hline Average wage (2001) & 16.1 & 19.3 \\
\hline Firm age & 12.2 & 18.1 \\
\hline Multi-establishment firm & $6.0 \%$ & $76.8 \%$ \\
\hline Percent women & $45.7 \%$ & $36.4 \%$ \\
\hline Percent over 50 & $22.4 \%$ & $13.5 \%$ \\
\hline Percent unionized & $1.5 \%$ & $7.2 \%$ \\
\hline Non-profit & $13.1 \%$ & $16.2 \%$ \\
\hline For-profit & $64.8 \%$ & $72.9 \%$ \\
\hline Percent low-wage employees & $25.6 \%$ & $20.2 \%$ \\
\hline Manufacturing & $6.5 \%$ & $15.9 \%$ \\
\hline Utilities/Transportation & $2.5 \%$ & $4.5 \%$ \\
\hline Construction & $11.9 \%$ & $3.9 \%$ \\
\hline Wholesale & $5.7 \%$ & $5.7 \%$ \\
\hline Retail & $13.4 \%$ & $14.3 \%$ \\
\hline Professional services & $24.0 \%$ & $23.4 \%$ \\
\hline Finance/Real Estate & $7.0 \%$ & $11.6 \%$ \\
\hline Other & $26.2 \%$ & $19.9 \%$ \\
\hline $\mathrm{N}$ & 11509 & 8186 \\
\hline
\end{tabular}


Table 7.1 IV \& OLS Results on the Effect of Health Insurance Offering on Employment, Payroll and Average Wage Levels by Firm Size

\begin{tabular}{|c|c|c|c|c|c|c|}
\hline \multirow[b]{3}{*}{$\begin{array}{l}\text { Small Firms } \\
(\mathrm{N}=11,509)\end{array}$} & \multicolumn{3}{|c|}{ IV } & \multicolumn{3}{|c|}{ OLS } \\
\hline & Employment $^{\mathrm{a}}$ & Payroll & $\begin{array}{c}\text { Average } \\
\text { Wage } \\
\end{array}$ & Employment $^{\mathrm{a}}$ & Payroll & $\begin{array}{c}\text { Average } \\
\text { Wage }\end{array}$ \\
\hline & $2.9894^{\star \star \star}$ & $3.7382^{\star \star \star}$ & $0.7488^{\star \star \star}$ & $0.4564^{\star \star \star}$ & $0.7964^{\star \star *}$ & $0.3401^{\star \star \star}$ \\
\hline \multirow{3}{*}{$\begin{array}{l}\text { Large Firms } \\
(\mathrm{N}=8,186)\end{array}$} & $(0.1060)$ & $(0.1251)$ & (0.0491) & (0.0190) & (0.0242) & $(0.0157)$ \\
\hline & $0.8079^{\star}$ & $1.5778^{\star \star \star}$ & $0.7699^{\star \star \star}$ & $0.2655^{\star \star \star}$ & $0.4873^{\star \star \star}$ & $0.2218^{\star \star \star}$ \\
\hline & $(0.4313)$ & $(0.5634)$ & $(0.2629)$ & $(0.1023)$ & $(0.0974)$ & $(0.0727)$ \\
\hline
\end{tabular}

amployment, Payroll and Average Wage are in logs form.

Note: Robust standard errors in parenthesis.

$\left.{ }^{*}{ }^{* *}\right)\left({ }^{\star \star \star}\right)$ Significant at the $10 \%(5 \%)(1 \%)$ level. 
Table 7.2: IV \& OLS Results on the Effect of Health Insurance Offering on Employment, Payroll \& Average Wage Growth and Establishment Survival by Firm Size

\begin{tabular}{|c|c|c|c|c|c|c|c|c|}
\hline \multirow{3}{*}{$\begin{array}{l}\text { Small Firms } \\
\mathrm{N}_{\text {growth }}=11,509\end{array}$} & $\begin{array}{c}\text { \% Change } \\
\text { Employment }^{\mathrm{a}}\end{array}$ & $\begin{array}{c}\text { \% Change } \\
\text { Payroll }\end{array}$ & $\begin{array}{c}\text { IV } \\
\text { \% Change } \\
\text { Average } \\
\text { Wage } \\
\end{array}$ & Survival & $\begin{array}{c}\text { \% Change } \\
\text { Employment }^{\mathrm{a}}\end{array}$ & $\begin{array}{c}\text { \% Change } \\
\text { Payroll }\end{array}$ & $\begin{array}{c}\text { OLS } \\
\text { \% Change } \\
\text { Average } \\
\text { Wage }\end{array}$ & Survival \\
\hline & 0.1249 *** & $0.0809 *$ & -0.0424 & $0.0956^{\star \star *}$ & $0.0445^{\star * *}$ & 0.0105 & $-0.0367^{\star \star \star}$ & $0.0347^{\star \star \star *}$ \\
\hline & $(0.0410)$ & $(0.0454)$ & (0.0393) & $(0.0183)$ & $(0.0139)$ & $(0.0150)$ & $(0.0132)$ & $(0.0071)$ \\
\hline & $0.4677^{*}$ & 0.3884 & -0.2206 & $0.5832^{\star \star *}$ & $0.1048^{\star *}$ & $0.0858^{*}$ & -0.0303 & $0.0602^{\star \star *}$ \\
\hline & $(0.2543)$ & $(0.2334)$ & $(0.2053)$ & $(0.0711)$ & $(0.0468)$ & $(0.0438)$ & $(0.0381)$ & $(0.0250)$ \\
\hline
\end{tabular}

$\left.{ }^{\star \star \star}\right)\left({ }^{\star \star \star}\right)$ Significant at the 10\% (5\%) (1\%) level.

Note: Robust standard errors in parenthesis. 
Table 7.3 IV Results on the Effect of Health Insurance Offering on Employment, Payroll and Average Wage Levels by Firm Size \& Age

\begin{tabular}{|c|c|c|c|c|}
\hline & & Employment $^{a}$ & Payroll & Average Wage \\
\hline \multirow[t]{4}{*}{ Small Firms } & Young & $2.8694^{\star \star \star}$ & $3.6244^{\star \star *}$ & $0.7550^{\star \star \star}$ \\
\hline & & $(0.2024)$ & $(0.2395)$ & $(0.1000)$ \\
\hline & Old & $3.0831^{\star \star \star}$ & $3.8515^{\star \star *}$ & $0.7684^{\star \star \star}$ \\
\hline & & $(0.1213)$ & $(0.1461)$ & $(0.0559)$ \\
\hline \multirow[t]{4}{*}{ Large Firms } & Young & 1.5781 & $2.1806^{\star}$ & 0.6025 \\
\hline & & (1.1018) & $(1.2469)$ & $(0.4020)$ \\
\hline & Old & 0.6649 & $1.4559^{\star \star \star}$ & $0.7909^{\star \star \star}$ \\
\hline & & $(0.4896)$ & $(0.6640)$ & $(0.3393)$ \\
\hline
\end{tabular}

a Employment, Payroll and Average Wage are in logs form.

$\left.{ }^{*}{ }^{\star \star}\right)\left({ }^{\star \star \star}\right)$ Significant at the 10\% (5\%) (1\%) level.

Note: Robust standard errors in parenthesis. 
Table 7.4 IV Results on the Effect of Health Insurance Offering on Employment, Payroll \& Average Wage Growth and Establishment Survival by Firm Size and Age

\begin{tabular}{|c|c|c|c|c|c|}
\hline & & $\begin{array}{l}\text { \% Change } \\
\text { Employment }\end{array}$ & \% Change Payroll & $\begin{array}{c}\% \text { Change Average } \\
\text { Wage }\end{array}$ & Survival \\
\hline \multirow[t]{4}{*}{ Small Firms } & Young & -0.021 & -0.1278 & -0.1349 & $0.1438^{\star \star \star}$ \\
\hline & & $(0.0931)$ & (0.1058) & $(0.0874)$ & $(0.0365)$ \\
\hline & Old & $0.1636^{\star \star *}$ & $0.1373^{\star \star \star}$ & -0.0118 & $0.1162^{\star \star \star}$ \\
\hline & & $(0.0422)$ & $(0.0442)$ & $(0.0405)$ & $(0.0205)$ \\
\hline \multirow[t]{4}{*}{ Large Firms } & Young & -0.4683 & -0.0895 & 0.3993 & 0.1166 \\
\hline & & $(0.5034)$ & $(0.4086)$ & $(0.4737)$ & $(0.1749)$ \\
\hline & Old & $0.7089^{\star \star \star}$ & $0.5353^{*}$ & -0.386 & $0.3895^{\star \star \star}$ \\
\hline & & $(0.2996)$ & $(0.2854)$ & $(0.2296)$ & $(0.0798)$ \\
\hline
\end{tabular}

$\left.{ }^{\star}{ }^{(\star}\right)\left({ }^{* \star \star}\right)$ Significant at the $10 \%(5 \%)(1 \%)$ level.

Note: Robust standard errors in parenthesis. 
Table 7.5: Alternative IV Specifications

\begin{tabular}{|c|c|c|c|}
\hline & & Small Firms & Large Firms \\
\hline Employment & $\begin{array}{l}\text { Baseline Model } \\
\text { Medicare \& State } \\
\text { Medicare \& County-level Variables } \\
\text { County-Level Controls \& State } \\
\text { County-Level Controls }\end{array}$ & $\begin{array}{c}2.9687^{\star \star \star} \\
(0.1066) \\
3.4345^{\star \star \star} \\
(0.1302) \\
4.1787^{\star \star \star} \\
(0.1711) \\
3.3654^{\star \star \star} \\
(0.1262) \\
4.2083^{\star \star \star} \\
(0.1730)\end{array}$ & $\begin{array}{c}0.5836 \\
(0.4134) \\
1.1336^{\star \star} \\
(0.5035) \\
1.1745^{\star \star} \\
(0.5122) \\
1.1279^{\star \star} \\
(0.5035) \\
1.1923^{\star \star} \\
(0.5205)\end{array}$ \\
\hline Payroll & $\begin{array}{l}\text { Baseline Model } \\
\text { Med Medicare \& State } \\
\text { Med Medicare \& County-level Vars } \\
\text { County-Level Controls \& State } \\
\text { County-Level Controls }\end{array}$ & $\begin{array}{c}3.7064^{\star \star \star} \\
(0.1259) \\
3.9666^{\star \star \star} \\
(0.1434) \\
4.8296^{\star \star \star} \\
(0.1875) \\
3.9159^{\star \star \star} \\
(0.1395) \\
4.8837^{\star \star \star} \\
(0.1901)\end{array}$ & $\begin{array}{c}1.2239^{\star \star} \\
(0.5295) \\
1.4249^{\star \star \star} \\
(0.5418) \\
1.6064^{\star \star \star} \\
(0.5644) \\
1.4546^{\star \star \star} \\
(0.5436) \\
1.6413^{\star \star \star} \\
(0.5768)\end{array}$ \\
\hline Average Wage & $\begin{array}{l}\text { Baseline Model } \\
\text { Med Medicare \& State } \\
\text { Med Medicare \& County-level Vars } \\
\text { County-Level Controls \& State } \\
\text { County-Level Controls }\end{array}$ & $\begin{array}{c}0.7377^{\star \star \star} \\
(0.0492) \\
0.5321^{\star \star \star} \\
(0.0512) \\
0.6509^{\star \star \star} \\
(0.0577) \\
0.5504^{\star \star \star} \\
(0.0505) \\
0.6754^{\star \star \star} \\
(0.0579)\end{array}$ & $\begin{array}{c}0.6403^{\star \star} \\
(0.2508) \\
0.2913 \\
(0.2403) \\
0.4320 \\
(0.2631) \\
0.3267 \\
(0.2385) \\
0.4491^{\star} \\
(0.2580)\end{array}$ \\
\hline
\end{tabular}


Table 7.5 Cont.: Alternative IV Specifications

\begin{tabular}{|c|c|c|c|}
\hline & & Small Firms & Large Firms \\
\hline \multirow[t]{7}{*}{ \% Change Employment } & Baseline Model & $\begin{array}{c}0.1407^{* * *} \\
(0.0415)\end{array}$ & $\begin{array}{l}0.4841^{*} \\
(0.2546)\end{array}$ \\
\hline & Med Medicare \& State & $\begin{array}{c}0.1669^{\star \star \star} \\
(0.0450)\end{array}$ & $\begin{array}{l}0.5338^{\star *} \\
(0.2415)\end{array}$ \\
\hline & Med Medicare \& County-level Vars & $\begin{array}{c}0.1925^{\star \star \star} \\
(0.0496)\end{array}$ & $\begin{array}{l}0.5495^{\star \star} \\
(0.2468)\end{array}$ \\
\hline & County-Level Controls \& State & $0.1546^{\star \star \star}$ & $0.5327^{\star *}$ \\
\hline & & $(0.0442)$ & $(0.2414)$ \\
\hline & County-Level Controls & $0.1813^{\star \star *}$ & $0.5478^{\star \star}$ \\
\hline & & $(0.0496)$ & $(0.2469)$ \\
\hline \multirow[t]{8}{*}{$\%$ Change Payroll } & Baseline Model & $\begin{array}{l}0.1116^{\star \star} \\
(0.0458)\end{array}$ & $\begin{array}{l}0.4267^{*} \\
(0.2320)\end{array}$ \\
\hline & Med Medicare \& State & $\begin{array}{c}0.1440 * \star \star \\
(0.0494)\end{array}$ & $\begin{array}{c}0.5833^{\star * *} \\
(0.2256)\end{array}$ \\
\hline & Med Medicare \& County-level Vars & $0.1403^{\star \star \star *}$ & 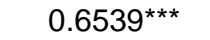 \\
\hline & & $(0.0531)$ & $(0.2368)$ \\
\hline & County-Level Controls \& State & $0.1301^{\star \star \star}$ & $0.6053^{\star *}$ \\
\hline & & $(0.0486)$ & $(0.2243)$ \\
\hline & County-Level Controls & $0.1288^{\star *}$ & $0.6513^{\star \star \star}$ \\
\hline & & $(0.0531)$ & $(0.2356)$ \\
\hline \multirow[t]{10}{*}{$\%$ Change Average Wage } & Baseline Model & -0.0261 & -0.1937 \\
\hline & & $(0.0394)$ & $(0.2063)$ \\
\hline & Med Medicare \& State & -0.0191 & -0.0672 \\
\hline & & $(0.0417)$ & $(0.2223)$ \\
\hline & Med Medicare \& County-level Vars & -0.05 & -0.013 \\
\hline & & $(0.0448)$ & $(0.2301)$ \\
\hline & County-Level Controls \& State & -0.0206 & -0.0399 \\
\hline & & $(0.0411)$ & $(0.2244)$ \\
\hline & County-Level Controls & -0.0492 & -0.0128 \\
\hline & & $(0.0449)$ & $(0.2297)$ \\
\hline
\end{tabular}


Table 7.6 IV F-Tests

\begin{tabular}{|c|c|c|c|c|c|}
\hline & \multirow[t]{2}{*}{ Model Tested } & \multicolumn{2}{|c|}{ Small Firms } & \multicolumn{2}{|c|}{ Large Firms } \\
\hline & & F-Stat & $\begin{array}{l}\text { Overid } \\
p \text {-Value }\end{array}$ & F-Stat & $\begin{array}{c}\text { Overid } \\
p \text {-Value }\end{array}$ \\
\hline \multirow[t]{5}{*}{ Employment } & Baseline Model & 9.21 & 0.00 & 1.83 & 0.00 \\
\hline & Med Medicare \& State & 9.09 & 0.12 & 1.82 & 0.00 \\
\hline & Med Medicare \& County-level Vars & 2.98 & 0.00 & 1.24 & 0.00 \\
\hline & County-Level Controls \& State & 9.46 & 0.00 & 2.00 & 0.00 \\
\hline & County-Level Controls & 0.14 & 0.53 & 1.07 & 0.46 \\
\hline \multirow[t]{5}{*}{ Payroll } & Baseline Model & 9.21 & 0.00 & 1.83 & 0.00 \\
\hline & Med Medicare \& State & 9.09 & 0.00 & 1.82 & 0.00 \\
\hline & Med Medicare \& County-level Vars & 2.98 & 0.00 & 1.24 & 0.00 \\
\hline & County-Level Controls \& State & 9.46 & 0.00 & 2.00 & 0.00 \\
\hline & County-Level Controls & 0.14 & 0.04 & 1.07 & 0.00 \\
\hline \multirow[t]{5}{*}{ Average Wage } & Baseline Model & 9.21 & 0.00 & 1.83 & 0.00 \\
\hline & Med Medicare \& State & 9.09 & 0.00 & 1.82 & 0.00 \\
\hline & Med Medicare \& County-level Vars & 2.98 & 0.00 & 1.24 & 0.00 \\
\hline & County-Level Controls \& State & 9.46 & 0.00 & 2.00 & 0.00 \\
\hline & County-Level Controls & 0.14 & 0.00 & 1.07 & 0.00 \\
\hline \multirow[t]{5}{*}{ \% Change Employment } & Baseline Model & 9.21 & 0.22 & 1.83 & 0.00 \\
\hline & Med Medicare \& State & 9.09 & 0.14 & 1.82 & 0.00 \\
\hline & Med Medicare \& County-level Vars & 2.98 & 0.18 & 1.24 & 0.01 \\
\hline & County-Level Controls \& State & 9.46 & 0.26 & 2.00 & 0.00 \\
\hline & County-Level Controls & 0.14 & 0.29 & 1.07 & 0.00 \\
\hline \multirow[t]{5}{*}{ \% Change Payroll } & Baseline Model & 9.21 & 0.08 & 1.83 & 0.00 \\
\hline & Med Medicare \& State & 9.09 & 0.05 & 1.82 & 0.00 \\
\hline & Med Medicare \& County-level Vars & 2.98 & 0.00 & 1.24 & 0.02 \\
\hline & County-Level Controls \& State & 9.46 & 0.02 & 2.00 & 0.00 \\
\hline & County-Level Controls & 0.14 & 0.10 & 1.07 & 0.01 \\
\hline \multirow{6}{*}{$\begin{array}{l}\% \text { Change Average } \\
\text { Wage }\end{array}$} & & & & & \\
\hline & Baseline Model & 9.21 & 0.01 & 1.83 & 0.00 \\
\hline & Med Medicare \& State & 9.09 & 0.01 & 1.82 & 0.00 \\
\hline & Med Medicare \& County-level Vars & 2.98 & 0.24 & 1.24 & 0.17 \\
\hline & County-Level Controls \& State & 9.46 & 0.02 & 2.00 & 0.00 \\
\hline & County-Level Controls & 0.14 & 0.19 & 1.07 & 0.08 \\
\hline
\end{tabular}


Figures 
Figure 2.1. Difference in percent of establishments from firms with less than 10 employees and 1000 or more employees offering health insurance: 2000

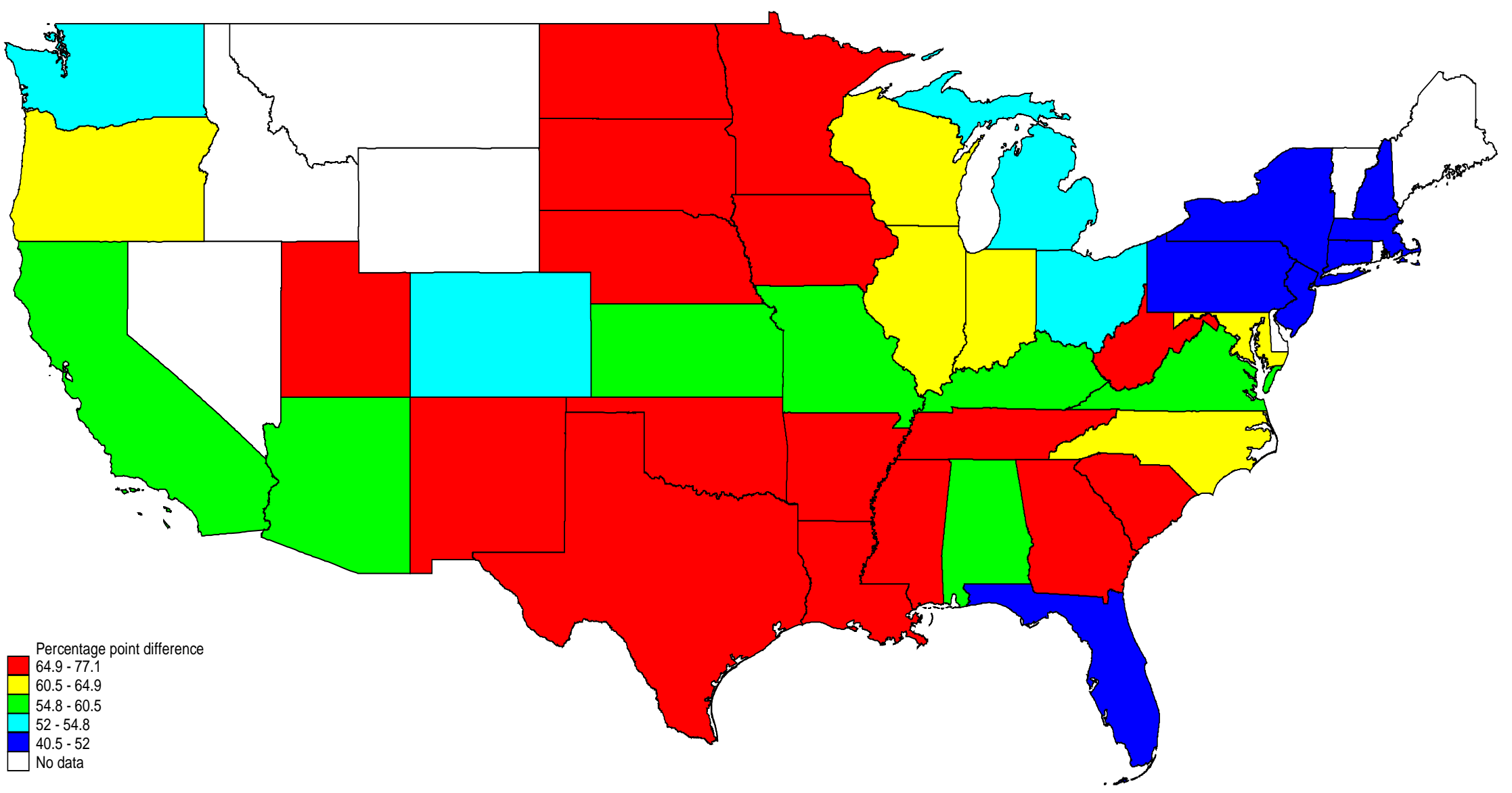

Source: Agency for Healthcare Research and Quality, Center for Cost and Financing Studies. 2000 Medical Expenditure Panel Survey-Insurance Component. 
Figure 2.2. Difference in percent of establishments from firms with less than 10 employees and 1000 or more employees offering health insurance: 2005

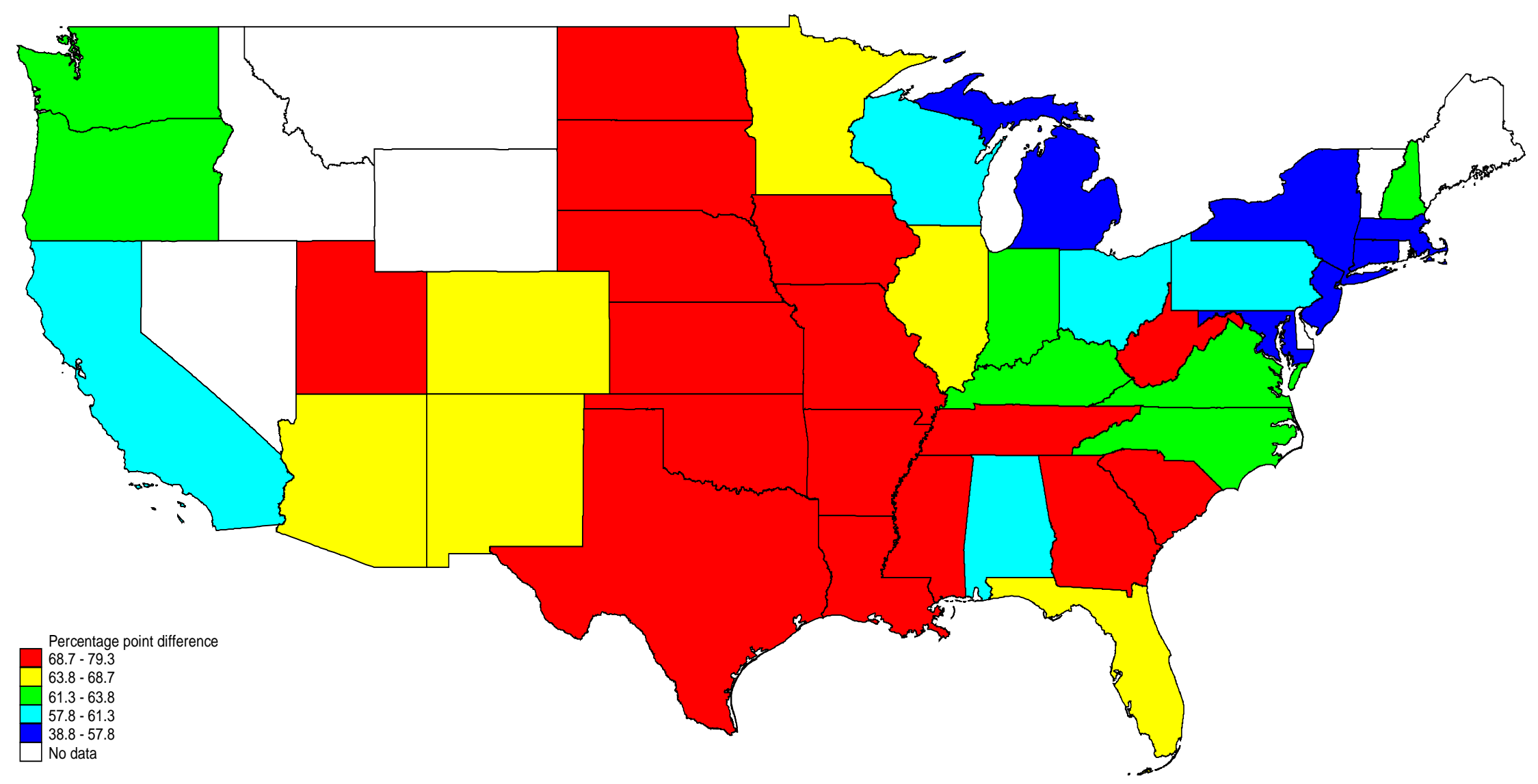

Source: Agency for Healthcare Research and Quality, Center for Cost and Financing Studies. 2005 Medical Expenditure Panel Survey-Insurance Component. 
Figure 2.3. Change in average total single premium (in dollars) per enrolled employee at private-sector establishments that offer health insurance by firm size: U.S., 2000 and 2005

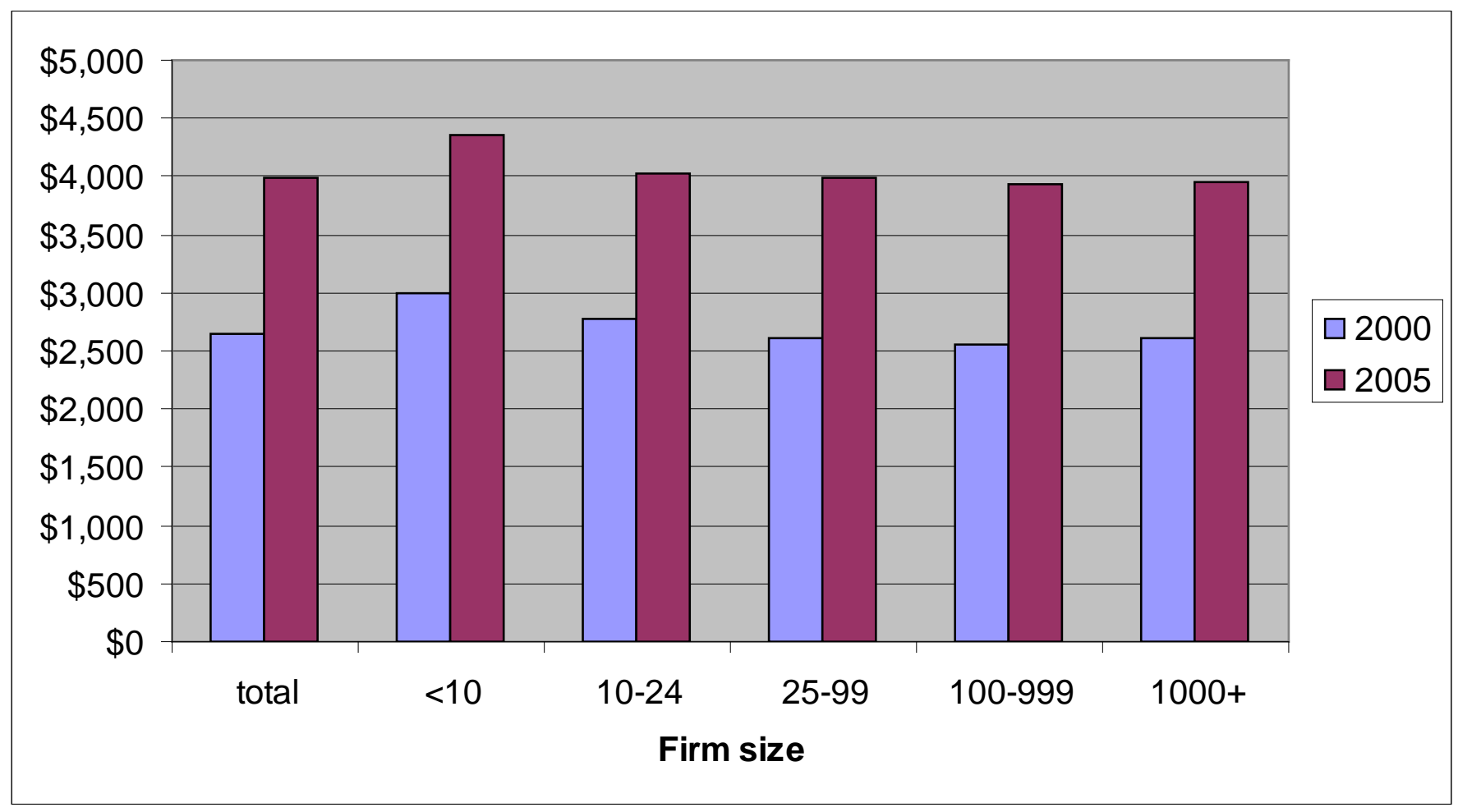

Source: Agency for Healthcare Research and Quality, Center for Cost and Financing Studies. 2000 and 2005 Medical Expenditure Panel Survey-Insurance Component. 
Figure 2.4. Percent increase in Premiums for Single Coverage from 2000 to 2005:

Private Sector Establishments Belonging to Firms with Less Than 10 Employees

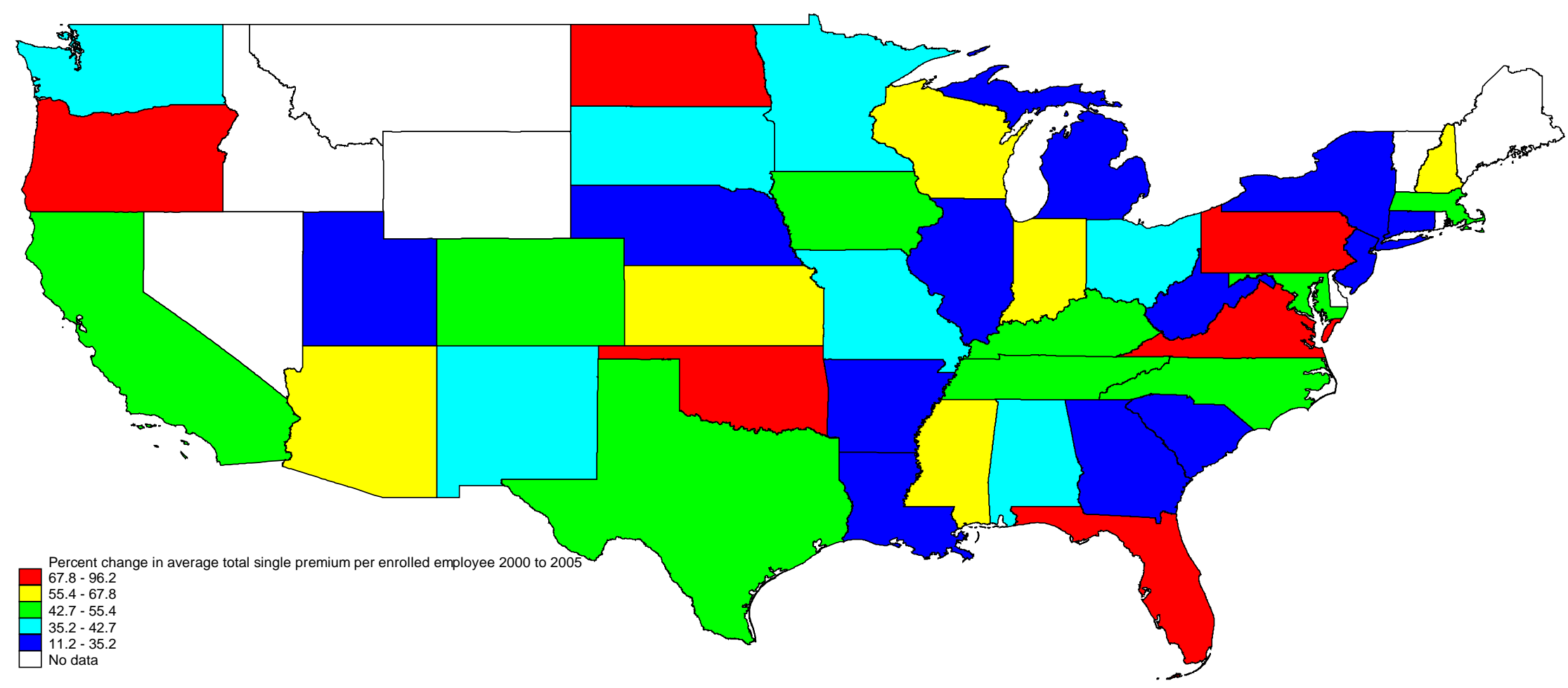

Source: Agency for Healthcare Research and Quality, Center for Cost and Financing Studies. 2000 and 2005 Medical Expenditure Panel Survey-Insurance Component. 
Figure 2.5. Percent increase in Premiums for Family Coverage from 2000 to 2005:

Private Sector Establishments Belonging to Firms with less than 10 Employees

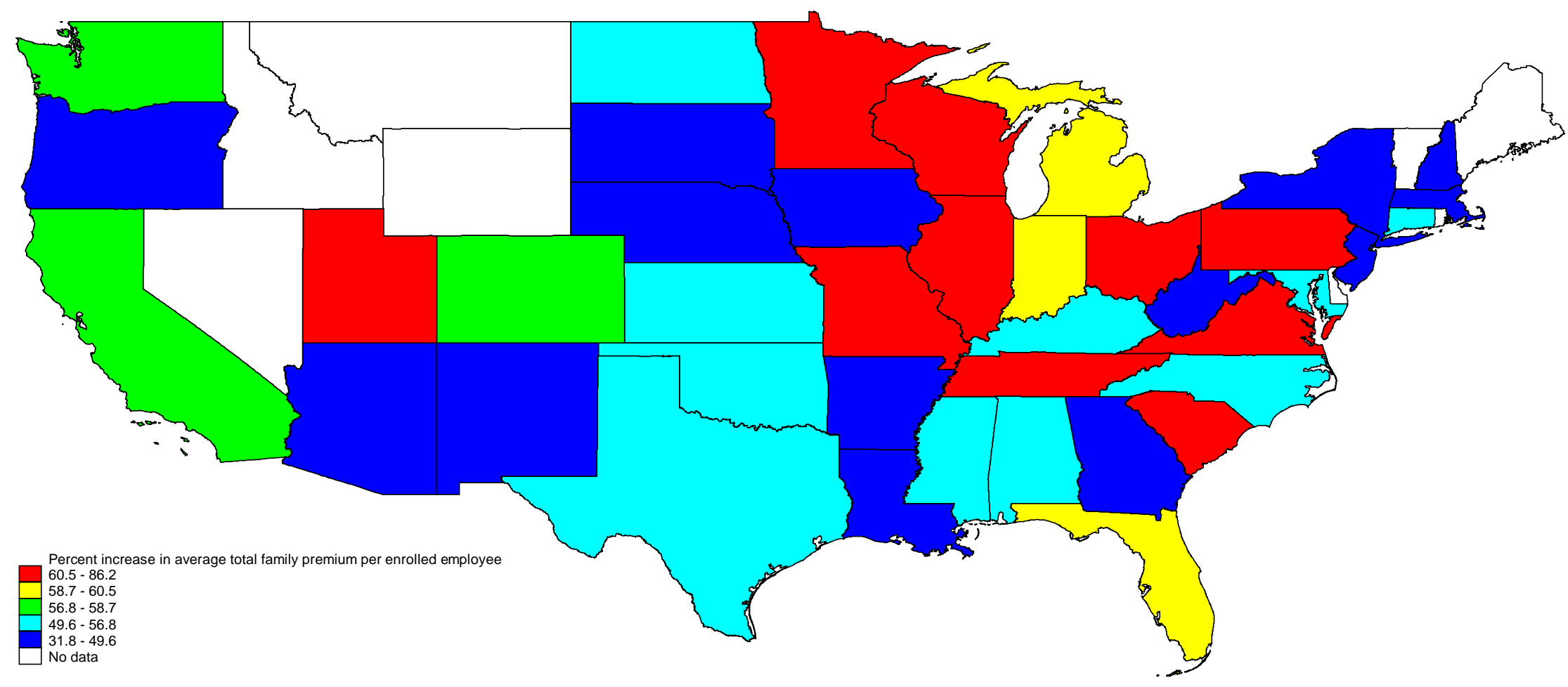

Source: Agency for Healthcare Research and Quality, Center for Cost and Financing Studies. 2000 and 2005 Medical Expenditure Panel Survey-Insurance Component. 
Figure 2.6. State Health Insurance Index from Council for Affordable Health Insurance

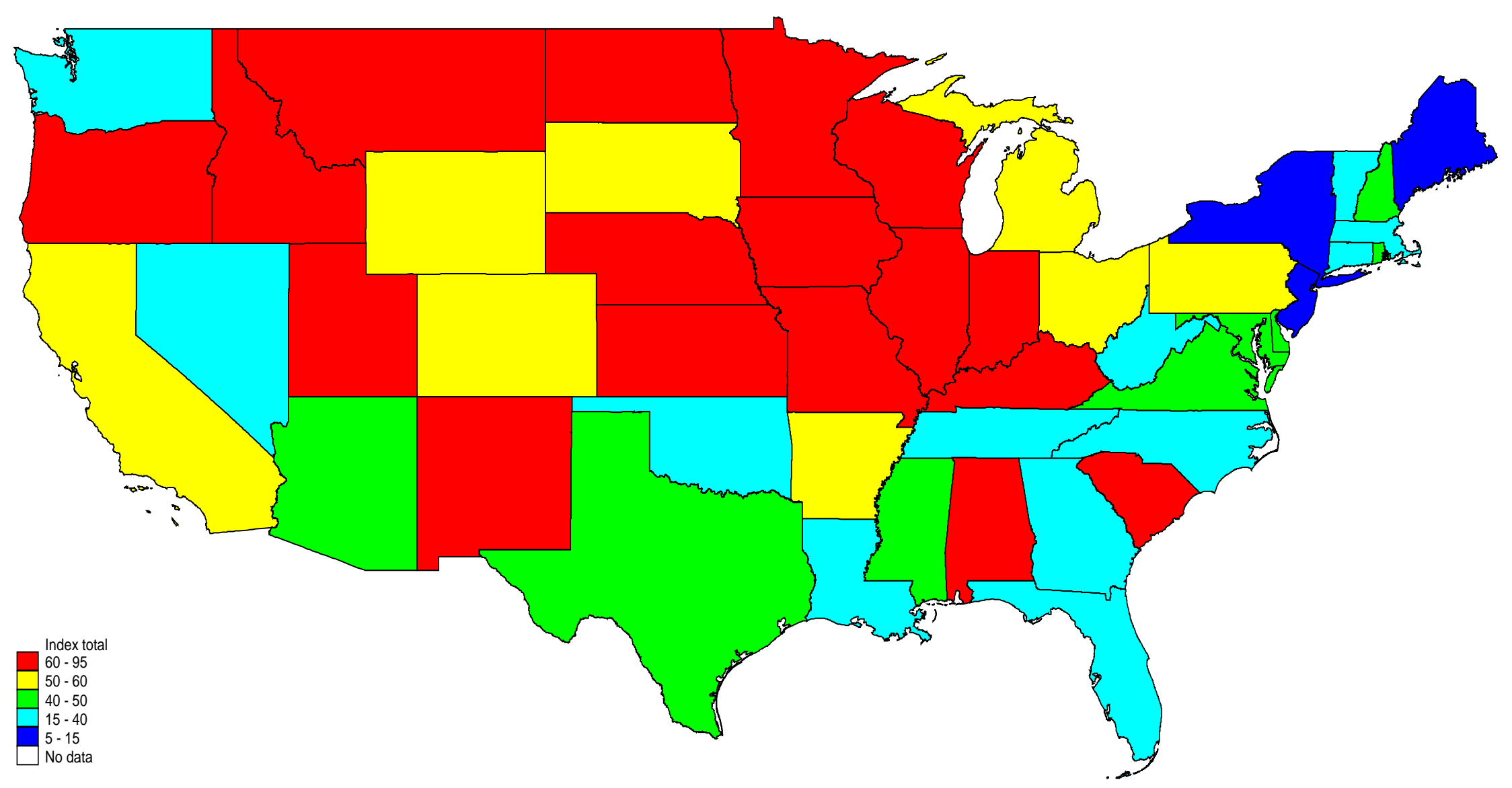

Note: Index for Alaska and Hawaii is 55 and 40, respectively.

Source: Matthews, Merrill, J.P. Wieske, and Victoria Craig Bunce. 2006. "State Health Insurance Index 2006: A 50-State

Comparison of the Nation's Health Insurance Market. Report from the Council for Affordable Health Insurance. Alexandria, VA. 
Figure 2.7. Mandated benefits by state and contribution towards premium costs: 2005

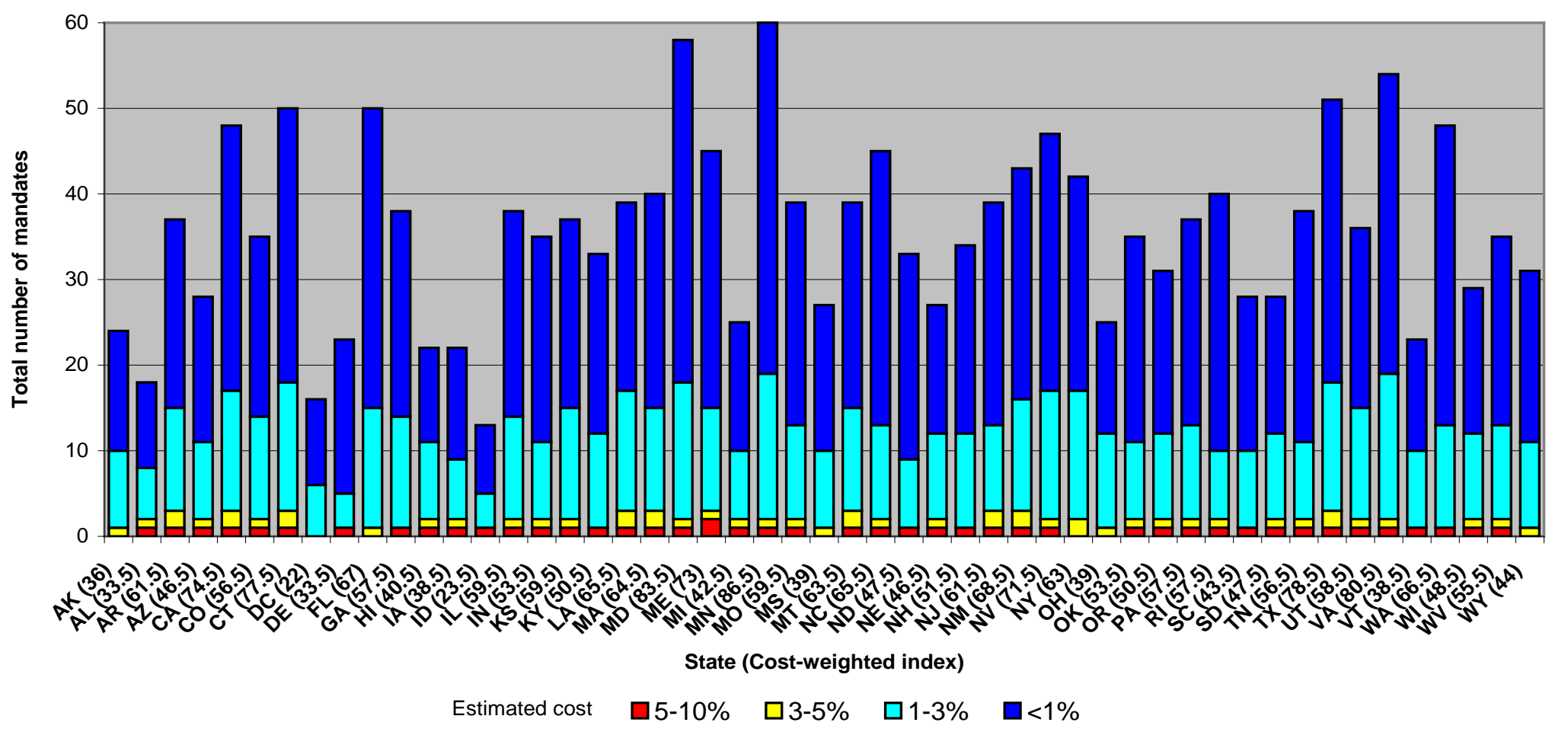

Notes: The cost-weighted index is calculated for each state by summing across the number of mandated benefits contributing 5 to 10 percent multiplied by a weight of 7.5, the number contributing 3 to 5 percent multiplied by a weight of 4 , the number contributing 1 to 3 percent by a weight of 2 , and those contributing less than 1 percent by a weight of 1 . The cost-range estimates are calculated as if the mandate were added to a comprehensive family policy that did not include the coverage (Bunce and Wieske, 2005).

Source: Victoria Craig Bunce and J.P. Wieske. 2005. “Health Insurance Mandates in the States: 2005.” Report prepared for the Council for Affordable Health Insurance, Alexandria, VA. 
Figure 3.1. Average total employee contribution (in dollars) per enrolled employee at private-sector establishments that offer health insurance by firm size: U.S.

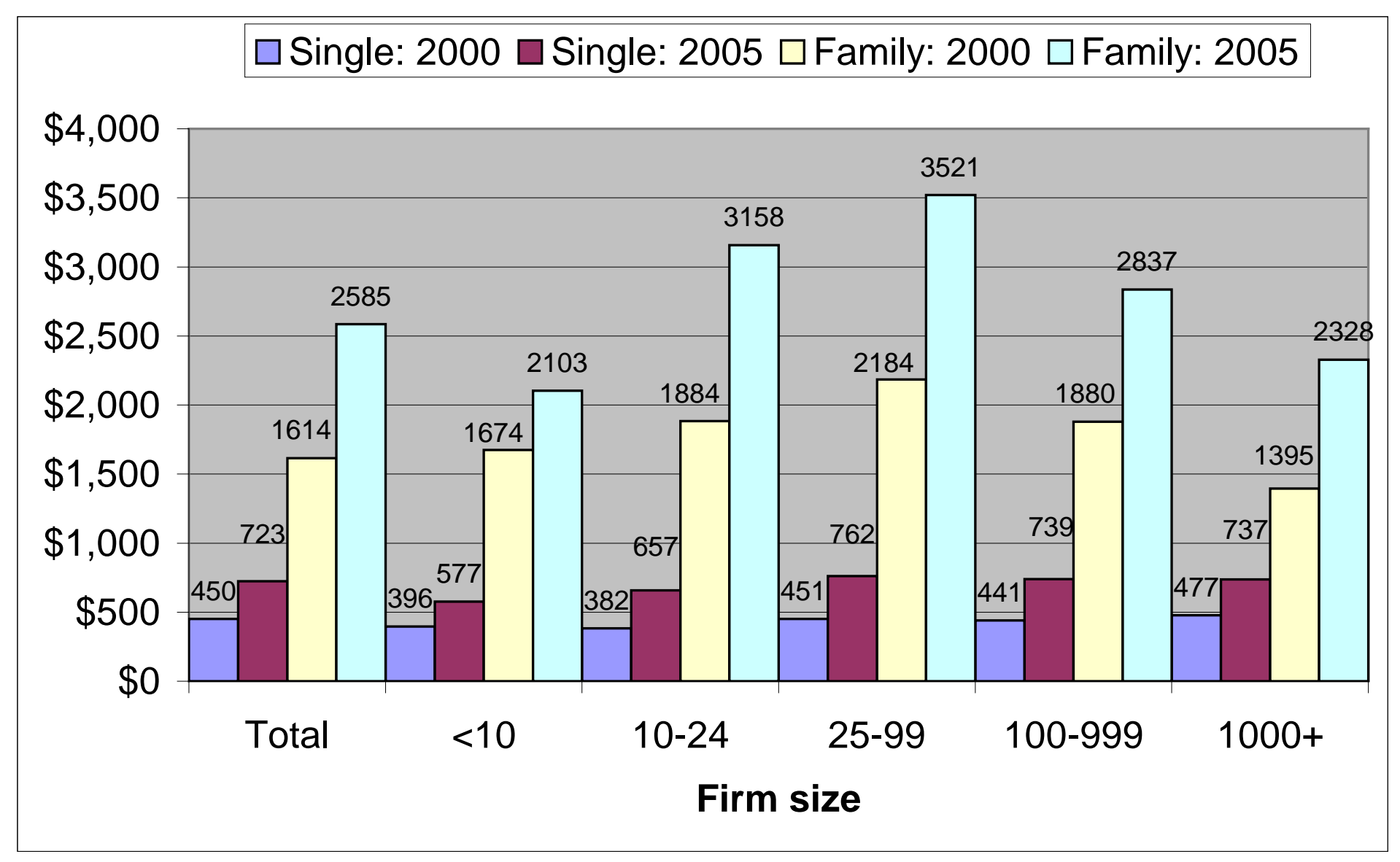

Source: Agency for Healthcare Research and Quality, Center for Cost and Financing Studies. 2000 and 2005 Medical Expenditure Panel Survey-Insurance Component. 
Figure 3.2. Percent of total premiums contributed by enrolled employees at private-sector establishments that offer health insurance by firm size: U.S.

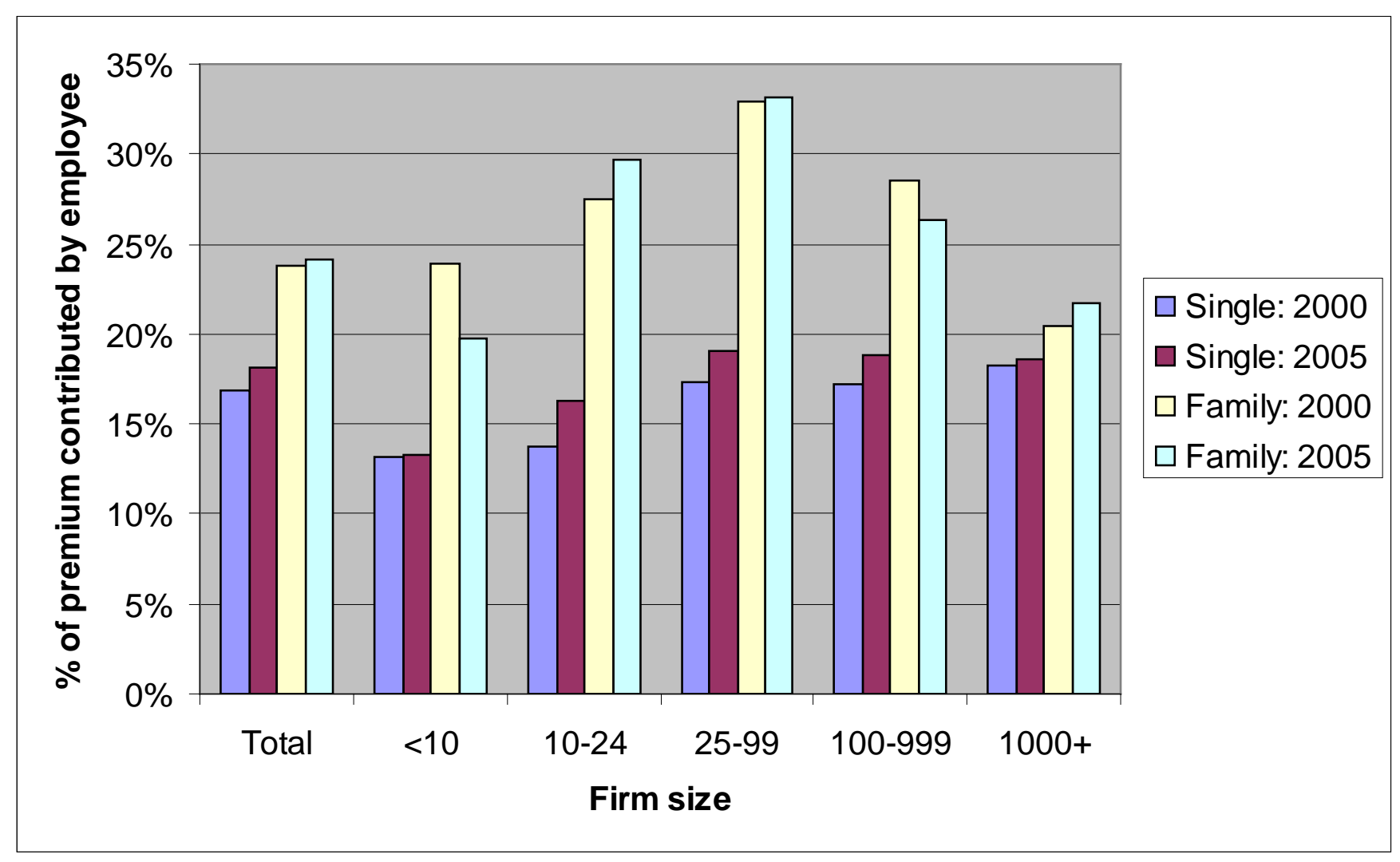

Source: Agency for Healthcare Research and Quality, Center for Cost and Financing Studies. 2000 and 2005 Medical Expenditure Panel Survey-Insurance Component. 
Figure 3.3. Percent of total premiums contributed for single coverage by employees enrolled at private-sector establishments that offer health insurance by firm size and percent low-wage employees*: U.S.

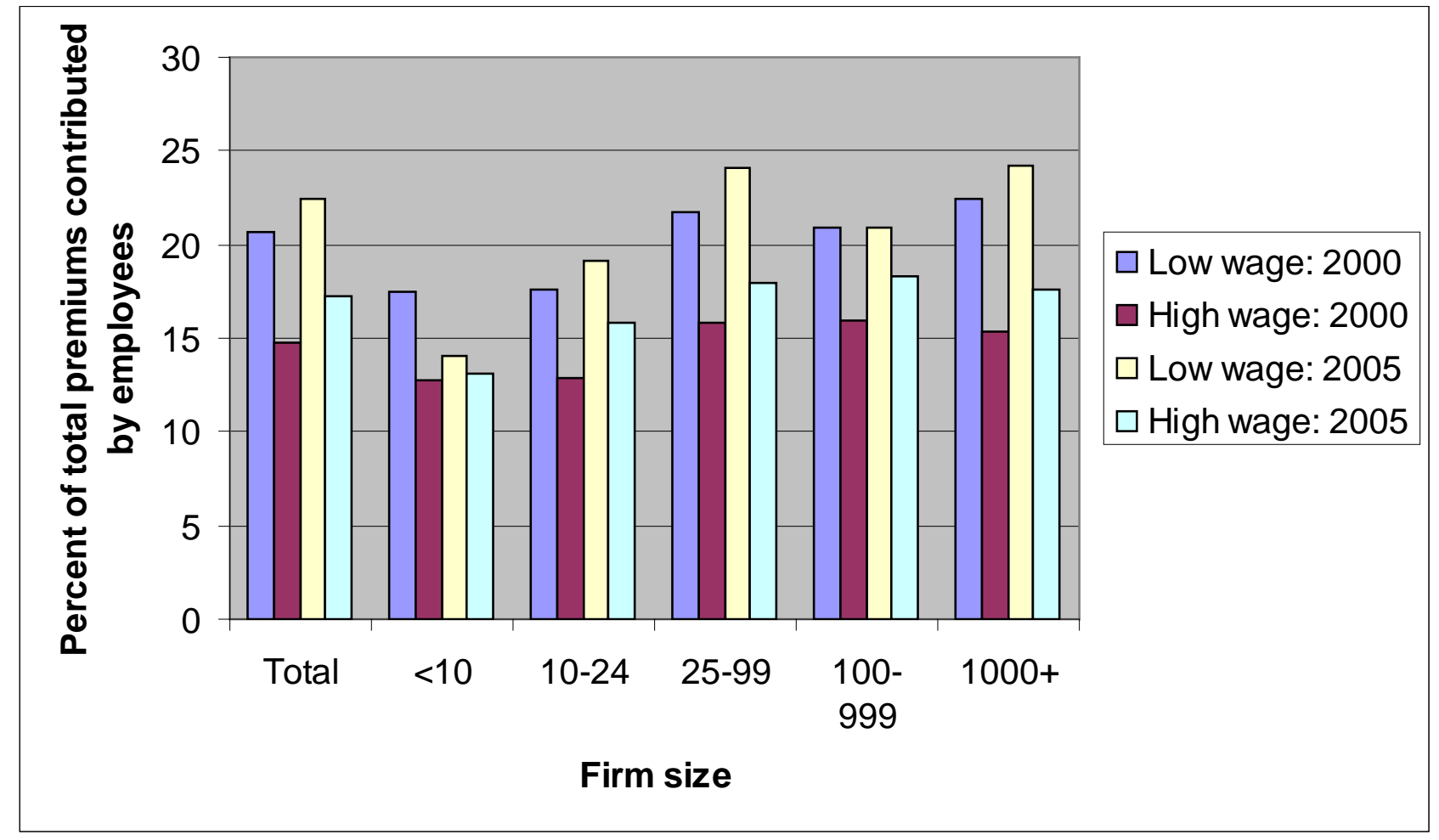

* Low wage: 50 percent or more of the establishment's workers earn low wages High wage: less than 50 percent of the establishment's workers earn low wages

Note: In 2000, the MEPS-IC defined low wage as less than $\$ 9.50$ per hour and in 2005 defined low wage as less than $\$ 10$ per hour.

Source: Agency for Healthcare Research and Quality, Center for Cost and Financing Studies. 2000 and 2005 Medical Expenditure Panel Survey-Insurance Component. 
Figure 3.4. Percent of private-sector establishments that offer health insurance that offer at least one health insurance plan that required no employee contribution by firm size: U.S.

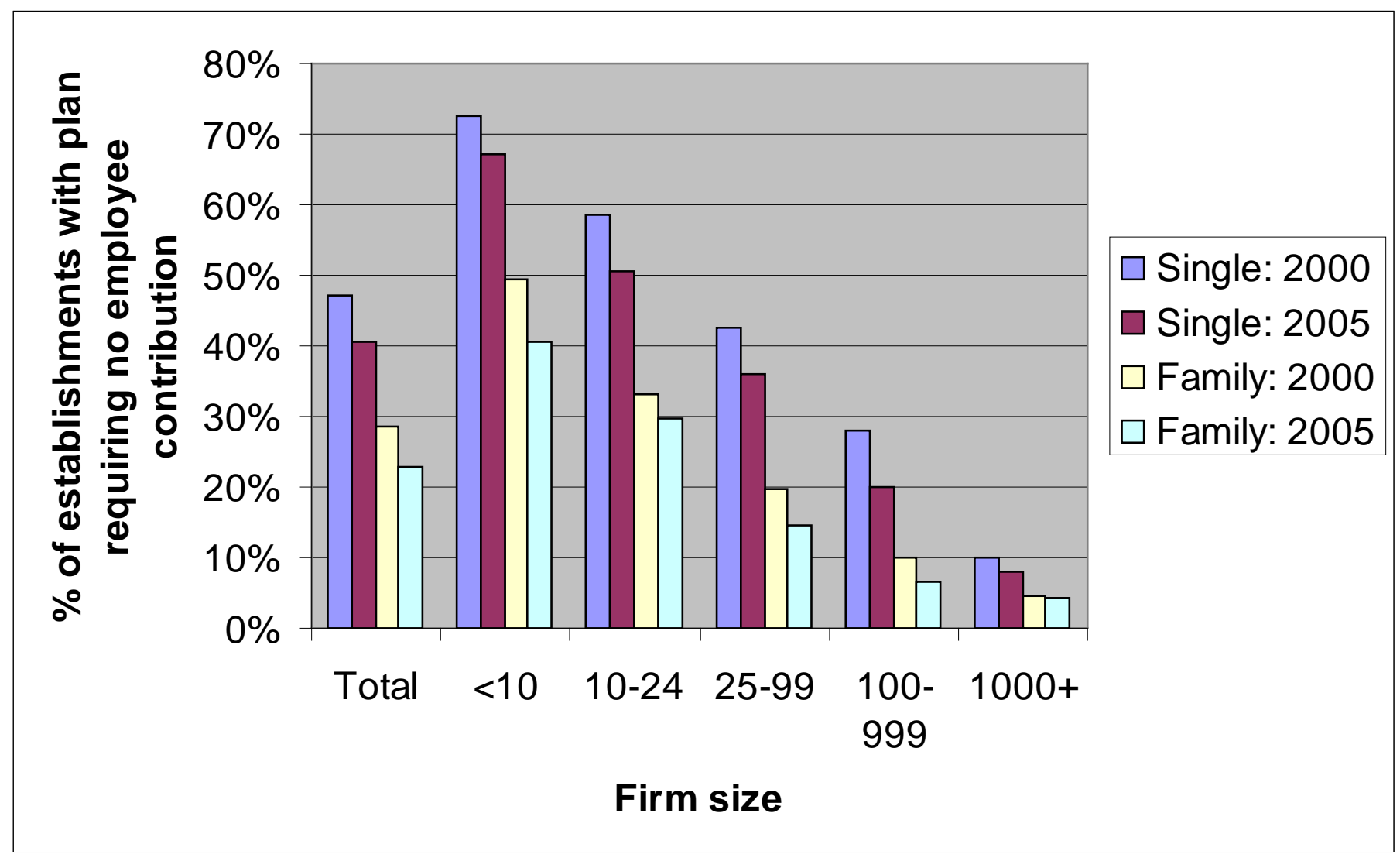

Source: Agency for Healthcare Research and Quality, Center for Cost and Financing Studies. 2000 and 2005 Medical Expenditure Panel Survey-Insurance Component. 
Figure 4.1 Unemployment Rate Comparison: Detroit MI vs. Bethesda-Rockville MD

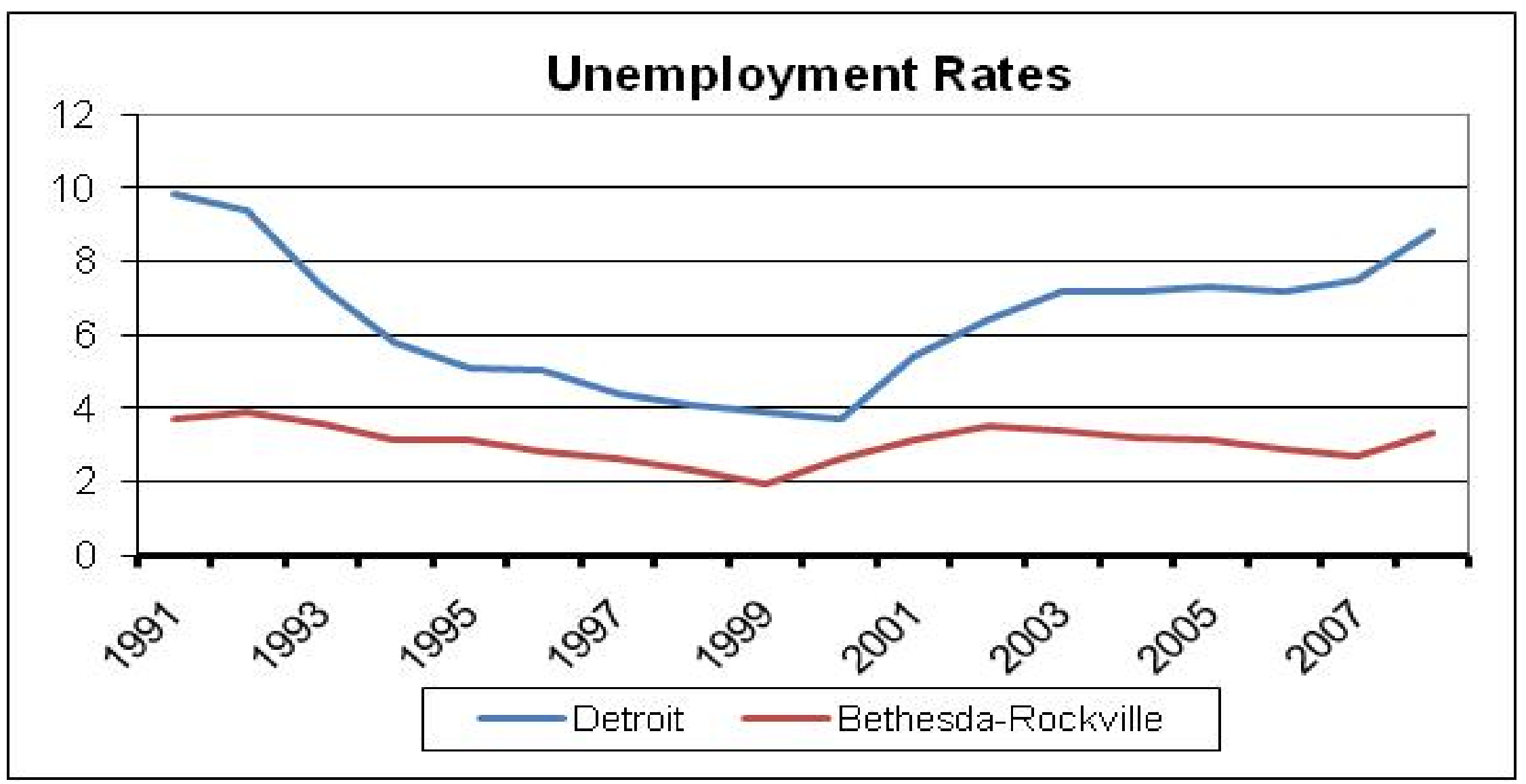

Source: Bureau of Labor Statistics Local Area Unemployment Statistics (LAUS) program. 